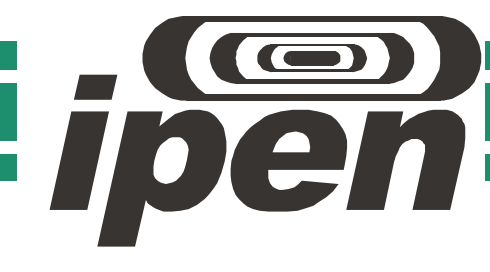

AUTARQUIA ASSOCIADA À UNIVERSIDADE DE SÃO PAULO

\title{
APLICAÇÃO DA QUIMIOMETRIA PARA A CARACTERIZAÇÃO QUÍMICA DE COMBUSTÍVEIS TIPO MTR POR FLUORESCÊNCIA DE RAIOS X
}

\section{CLAYTON PEREIRA DA SILVA}

\author{
Dissertação apresentada como parte \\ dos requisitos para obtenção do Grau \\ de Mestre em Ciências na Área \\ de Tecnologia Nuclear - Materiais \\ Orientador: \\ Prof. Dr. Marcos Antonio Scapin
}


INSTITUTO DE PESQUISAS ENERGÉTICAS E NUCLEARES-

Autarquia Associada à Universidade de São Paulo

\section{APLICAÇÃO DA QUIMIOMETRIA PARA CARACTERIZAÇÃ̃O QUÍMICA DE COMBUSTÍVEIS TIPO MTR POR FLUORESCÊNCIA DE RAIOS X}

CLAYTON PEREIRA DA SILVA

Dissertação apresentada como parte dos requisitos para a obtenção do Grau de Mestre em Ciências na área de Tecnologia Nuclear - Materiais.

Orientador:

Prof. Dr. Marcos Antonio Scapin 
"Aos meus familiares que me proporcionaram liberdade e tranquilidade para que eu pudesse desenvolver meu trabalho". 


\section{AGRADECIMENTOS}

Ao Prof. Dr. Marcos Antonio Scapin, por acreditar em meu potencial, pelo incentivo, orientações e contribuições durante o desenvolvimento de todo o trabalho.

Ao Instituto de Pesquisar Energéticas e Nucleares (IPEN-CNEN/SP), por fornecer a infraestrutura necessária para o meu aprendizado e desenvolvimento deste trabalho.

Ao Conselho Nacional de Desenvolvimento Científico e Tecnológico (CNPq-Edital Universal) n. 479106/2010-0, Brasil, CAPES - PNPD n. 02889/2009-9 e Comissão Nacional de Energia Nuclear (CNEN), Brasil (PCI n. 680.020/2008-0), pelo apoio financeiro.

Ao Eng. Ary Pereira Junior, do Centro de Combustível Nuclear (CCN) do IPENCNEN/SP, por fornecer os relatórios de análises do $\mathrm{U}_{3} \mathrm{Si}_{2}$.

Aos meus colegas e amigos que me ajudaram a descarregar a pressão e o stress durante este trabalho.

Aos meus familiares que me proporcionaram liberdade e tranquilidade para que eu pudesse desenvolver meu trabalho em plenitude.

À minha irmã Eliane que, por vezes, arrumou tempo para realizar as correções deste texto, que não foram poucas.

À Denise por me aturar em momentos em que nem eu mesmo o faria.

Por tudo, a Deus! 


\title{
APLICAÇÃO DA QUIMIOMETRIA PARA CARACTERIZAÇÃO QUÍMICA DE COMBUSTÍVEIS TIPO MTR POR FLUORESCÊNCIA DE RAIOS X
}

\author{
Clayton Pereira da Silva
}

\begin{abstract}
RESUMO
No Brasil e no mundo a tecnologia nuclear vem ocupando posição de destaque com diversas aplicações na indústria, geração de energia, meio ambiente e na medicina, melhorando a qualidade de exames e tratamentos, consequentemente, a vida das pessoas. $\mathrm{O}$ urânio é o principal elemento utilizado em instalações nucleares, servindo como material base desde a geração de eletricidade à fabricação de radiofármacos. Nos anos 50, em meio à guerra fria, a então recém-criada Agência Internacional de Energia Atômica se propôs a supervisionar instalações nucleares e incentivar a fabricação de combustíveis nucleares com baixo teor de urânio, conhecidos como combustíveis do tipo Material Test Reactor (MTR), fabricados inicialmente na forma de $\mathrm{U}_{3} \mathrm{O}_{8}$ e mais tarde o $\mathrm{U}_{3} \mathrm{Si}_{2}$, ambos dispersos em alumínio. A utilização desta tecnologia requer uma constante melhoria de todos os processos que envolvem a fabricação do MTR sujeita a diversos protocolos internacionais, os quais procuram garantir a confiabilidade desse combustível do ponto de vista prático e ambiental. Dentro desse contexto, o controle de impurezas, do ponto de vista da economia de nêutrons, afeta diretamente a qualidade de qualquer combustível nuclear, fazendo-se necessário um controle rigoroso. A literatura reporta procedimentos que, além de gerar resíduos, são demorados e dispendiosos, pois necessitam de curva de calibração univariada e materiais de referência. Assim, o objetivo deste trabalho é estabelecer e validar uma metodologia de análise química quantitativa não destrutiva, de baixo custo e tempo de análise, tal como, minimizar a geração de resíduo para a determinação multielementar dos maiores constituintes $\left(\mathrm{U}_{\text {total }}\right.$ e $\mathrm{Si}$ ) e as impurezas $(\mathrm{B}, \mathrm{Mg}, \mathrm{Al}, \mathrm{Cr}, \mathrm{Mn}, \mathrm{Fe}, \mathrm{Co}, \mathrm{Ni}, \mathrm{Cu}, \mathrm{Zn}$, Mo, Cd e outros) presentes em $\mathrm{U}_{3} \mathrm{O}_{8}$ e $\mathrm{U}_{3} \mathrm{Si}_{2}$, atendendo as necessidades de reatores nucleares na qualificação de combustíveis nucleares do tipo MTR. Para tanto, foi aplicada a técnica de fluorescência de raios $X$ que permite análises químicas rápidas e não destrutivas, além de não necessitar de tratamentos químicos prévios (dissolução, digestão e
\end{abstract}


outros) na fase de preparação de amostras. Para as correções de efeitos espectrais e de matriz foram aplicados e avaliados os métodos de parâmetros fundamentais, de curva de calibração univariada e de calibração multivariada. Os resultados foram comparados por meios de testes estatísticos em conformidade com a norma ISO 17025 com os MRCs (123(1-7) e 124(1-7)) de $\mathrm{U}_{3} \mathrm{O}_{8}$ da New Brunswick Laboratory (NBL) e 16 amostras de $\mathrm{U}_{3} \mathrm{Si}_{2}$ cedidas pelo $\mathrm{CCN}$ do IPEN-CNEN-SP. A quimiometria demonstrou-se um método promissor para a determinação de maiores e menores constituintes em combustíveis nuclear a base de $\mathrm{U}_{3} \mathrm{O}_{8}$ e $\mathrm{U}_{3} \mathrm{Si}_{2}$, uma vez que a precisão e exatidão são estatisticamente iguais aos métodos de análises volumétrica, gravimétrica e ICP-OES. 


\title{
CHEMOMETRICS APPLICATION IN FUEL'S MTR TYPE CHEMICAL CHARACTERIZATION BY X-RAY FLUORESCENCE
}

\section{Clayton Pereira da Silva}

\begin{abstract}
In Brazil and worldwide the nuclear power has occupied a prominent position with many applications in industry, power generation, environment and medicine, improving the quality of tests and treatments, therefore people's lives. Uranium is the main element used in nuclear facilities and it's employed as base material to generation of electricity in the manufacture of radiopharmaceuticals. In the '50s, during the Cold War, the then newly created International Atomic Energy Agency proposed to oversee nuclear facilities and encourage the manufacture of nuclear fuels with low-enriched uranium (LEU) fuel came then type Material Test Reactor (MTR), manufactured initially in $\mathrm{U}_{3} \mathrm{O}_{8}$ and $\mathrm{U}_{3} \mathrm{Si}_{2}$ later, both dispersed in aluminum. The use of this technology requires a constant improvement of all processes involving the manufacture of MTR subject to several international protocols, which seek to ensure the reliability of the fuel from the standpoint of practical and environmental. In this context, the control of impurities, from the point of view of neutron economy, directly affects the quality of any nuclear fuel, so strict control is necessary. The literature has reported procedures which, beyond generating residues, are lengthy and costly, they need calibration curve and consequently reference materials. The aim of this work is to establish and validate a methodology for nondestructive quantitative chemical analysis, low cost and analysis time, as well as minimize the generation of waste, for multielement determination of major constituents $\left(\mathrm{U}_{\text {total }}\right.$ and $\left.\mathrm{Si}\right)$ and impurities $(\mathrm{B}, \mathrm{Mg}$, $\mathrm{Al}, \mathrm{Cr}, \mathrm{Mn}, \mathrm{Fe}, \mathrm{Co}, \mathrm{Ni}, \mathrm{Cu}, \mathrm{Zn}, \mathrm{Mo}, \mathrm{Cd}$ and others) present in $\mathrm{U}_{3} \mathrm{O}_{8}$ and $\mathrm{U}_{3} \mathrm{Si}_{2}$, meeting the needs of nuclear reactors in the nuclear fuel qualification type MTR. For that purposes, will be applied the X-ray fluorescence technique which allows fast chemical and nondestructive analysis, aside from sample preparation procedures that do not require previous chemical treatments (dissolving, digesting, and others). To corrections like effects of spectral and matrix were applied and evaluated the fundamental parameter method, univariate calibration curve and multivariate calibration. The results were compared by
\end{abstract}


means of statistical tests in accordance with ISO 17025 in MRCs (123 (1-7) and 124 (1-7)) MCRs of $\mathrm{U}_{3} \mathrm{O}_{8}$ from New Brunswick Laboratory (NBL) and $16 \mathrm{U}_{3} \mathrm{Si}_{2}$ samples provided by CC of IPEN/CNEN-SP. The chemometrics is a promising method to determination of minor and major constituents on the $\mathrm{U}_{3} \mathrm{Si}_{2}$ and $\mathrm{U}_{3} \mathrm{O}_{8}$ basis nuclear fuel, because the precision and accuracy are statistically equal volumetric analysis, gravimetric and ICPOES methods. 


\section{SUMÁRIO}

Página

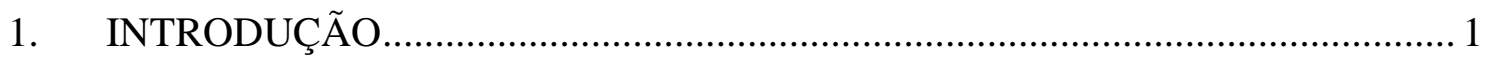

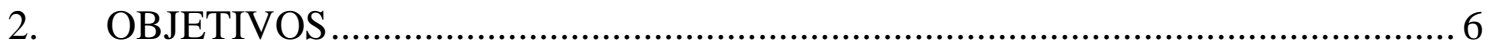

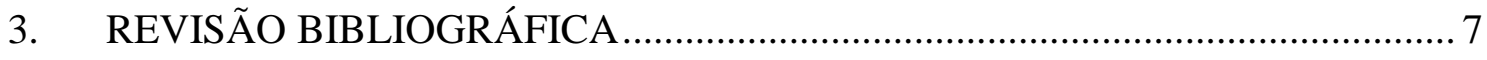

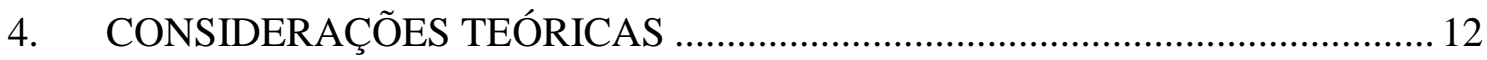

4.1. Curva de Calibração Univariada (CC) ............................................................ 15

4.2. Método de Parâmetros Fundamentais .............................................................. 17

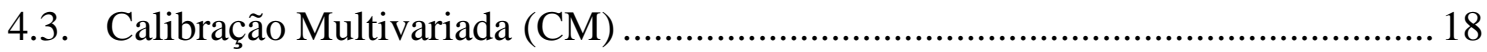

4.3.1. Análise de Componentes Principais ........................................................................... 19

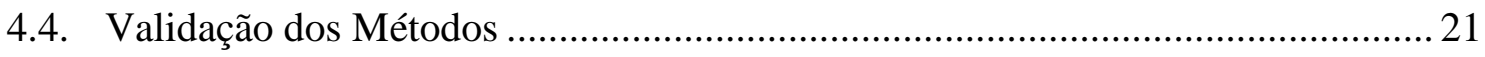

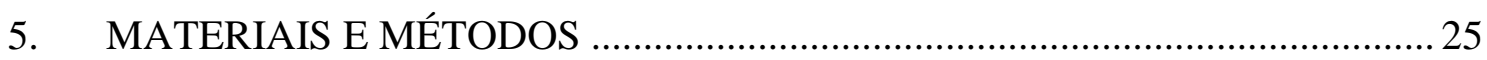

5.1. Equipamentos, acessórios e materiais de referência............................................2 25

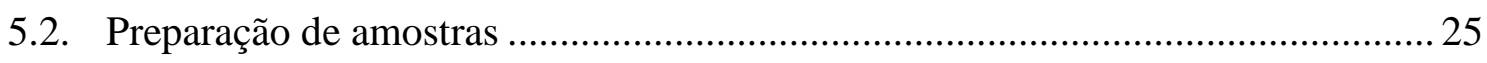

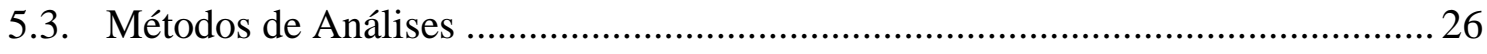

5.3.1. Método de curva de calibração univariada ............................................................ 26

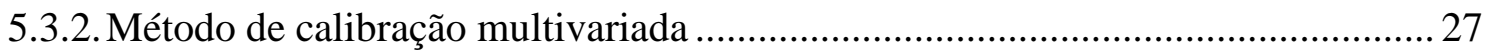

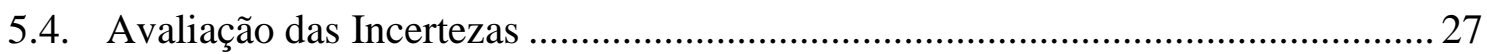

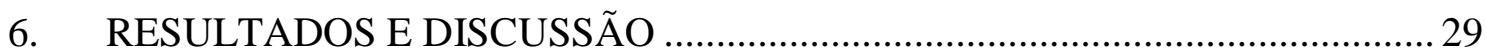

6.1. Curva de Calibração univariada (CU) ............................................................. 31

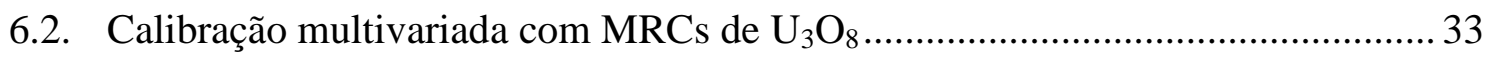

6.3. Comparação entre curva de calibração univariada e multivariada ......................... 37

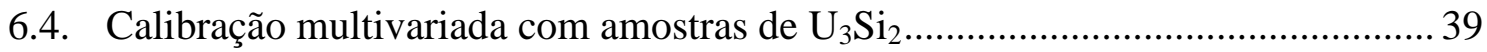

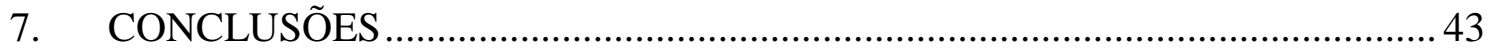

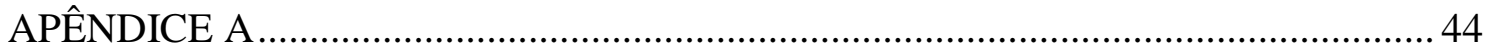

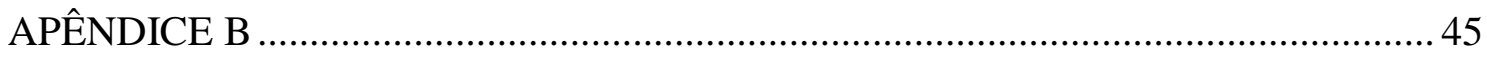

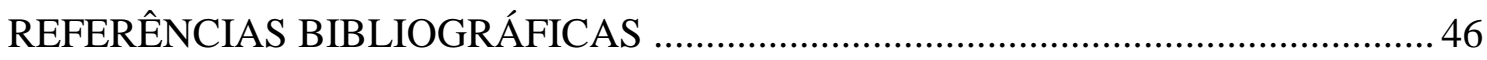




\section{LISTA DE TABELAS}

TABELA 1 - Limites de impurezas aceitáveis em $\mathrm{U}_{3} \mathrm{Si}_{2}$ (Laucht et al., 1998) .................9

TABELA 2 - Condições Instrumentais de medida: elemento (E), linha de emissão (LE), colimador $(\mathrm{C})$, cristal de difração $(\mathrm{CD})$, detector (D), tempo de contagem

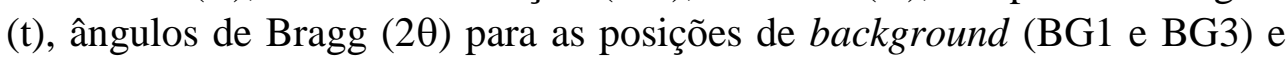
pico.

TABELA 3 - Valores certificados (Xcert \pm s) e determinados (Xdet \pm s), desvios padrão relativo percentual (DPR\%), erros relativo percentual (ER\%), limites de quantificação (LQ) e Z-score calculados para o MRC 124 (1) - NBL, e os coeficientes de correlação $\left(\mathrm{r}^{2}\right)$ das curvas de calibração.

TABELA 4 - Valores certificados $(X \operatorname{cert} \pm \sigma)$ e determinados $(X \operatorname{det} \pm \sigma)$, desvios padrão relativo percentual (DPR\%), erros relativo percentual (ER\%), limites de quantificação (LQ) e Z-score calculados para o MRC 124 (1) - NBL

TABELA 5 - Teores médios $(X)$ e variância $\left(\sigma^{2}\right)$ calculados para $U$ - análise volumétrica $\left(\mathrm{X}_{\mathrm{AV}}\right), \mathrm{Si}$-análise gravimétrica $\left(\mathrm{X}_{\mathrm{AG}}\right), \mathrm{B}, \mathrm{Mg}, \mathrm{Al}, \mathrm{Si}, \mathrm{Ca}, \mathrm{V}, \mathrm{Cr}, \mathrm{Mn}, \mathrm{Fe}, \mathrm{Co}$, $\mathrm{Ni}, \mathrm{Cu}, \mathrm{Zn}, \mathrm{Mo}, \mathrm{Cd}, \mathrm{Ba}, \mathrm{Sn}$ e Pb-ICP-OES (XICP-OES) e calibração multivariada-WDXRF ( $X_{C M-F R X}$ ), limites de quantificação (LQ) e valores calculados para a distribuição Fisher-Snedecor $(\mathrm{F})$ na análise da variância (ANOVA) e de $t$-Student para a comparação das médias. 


\section{LISTA DE FIGURAS}

Página

FIGURA 1- Esquema de montagem da placa combustível (Ferrufino, 2011-adaptado) ..8

FIGURA 2 - Esquema de montagem do elemento combustível (Ferrufino, 2011) ............8

FIGURA 3 - Modelo esquemático demonstrando o efeito fotoelétrico e a ocorrência de raios $\mathrm{X}$

FIGURA 4 - Esquema de funcionamento de um espectrômetro de fluorescência de raios $\mathrm{X}$ do tipo EDXRF (OceanKingIndian, 2012)

FIGURA 5 - Esquema de funcionamento de um espectrômetro de fluorescência de raios $\mathrm{X}$ do tipo WDXRF

FIGURA 6 - Diferenças na resolução espectral entre os espectrômetros de EDXRF (azul) e WDXRF (vermelho). (HORIBGA SCIENTIFIC, 2012 - adaptada) ........ 14

FIGURA 7 - Diagrama de causa e efeito das fontes de incerteza associadas ao método.. 27

FIGURA 8 - Espectro WDXRF do MRC 124 (1) - NBL de $\mathrm{U}_{3} \mathrm{O}_{8}$

FIGURA 9 - Valores de Z-score calculados para o MRC 124 (1) NBL por curva de calibração univariada

Figura 10 - Gráfico intensidade versus energia para obtenção da matriz X com MRCs de $\mathrm{U}_{3} \mathrm{O}_{8}$

Figura 11- Gráfico de loading versus energia para a $\mathrm{PC} 1 \mathrm{em} \mathrm{U}_{3} \mathrm{O}_{8}$ 34

Figura 12 - Valores de Z-score calculado para o MRC 124 (1) por calibração multivariada

FIGURA 13 - Comparação da precisão em termos de DPR\% entre os métodos CC e CM calculados para os elementos certificados pelo MRC 124 (1) - NBL.

FIGURA 14 - Comparação da exatidão entre os métodos CC e CM, em termos de valores de Z-score, calculados para o MRC 124 (1) - NBL

FIGURA 15 - Comparação do LQ entre os métodos CC e CM 38

FIGURA 16 - Gráfico intensidade versus energia para obtenção da matriz X com amostras de $\mathrm{U}_{3} \mathrm{Si}_{2}$

FIGURA 17 - Gráfico dos loadings versus energia, para a PC1 e PC2 em $\mathrm{U}_{3} \mathrm{Si}_{2}$ 40 


\section{INTRODUÇÃO}

Com a finalidade de atender à demanda nacional e diminuir a dependência externa no que diz respeito a insumos utilizados nos procedimentos de pesquisa com radiofármacos, o Governo brasileiro lançou o projeto do Reator Multipropósito Brasileiro (RMB) que, além da produção e desenvolvimento de radiofármacos, irá proporcionar um aumento nas pesquisas sobre a seleção e desenvolvimento de novas concepções e materiais para os elementos combustíveis.

A produção do elemento combustível tipo MTR (Material Testing Reactor) sumariamente se inicia com a mistura entre pó de alumínio metálico (Al) e pó de siliceto de urânio, óxido de urânio ou ainda urânio molibdênio $\left(\mathrm{U}_{3} \mathrm{Si}_{2}, \mathrm{U}_{3} \mathrm{O}_{8}\right.$ ou U-Mo) enriquecido

a $20 \%$ em peso de urânio-235 $\left({ }^{235} \mathrm{U}\right)$, em proporções pré-determinadas. Posteriormente, essa mistura é compactada na forma de briquetes, e estes, desgaseificados a vácuo. Em seguida, é montado um conjunto para laminação, composto por um núcleo (briquete da dispersão $\mathrm{U}_{3} \mathrm{Si}_{2}-\mathrm{Al}$ ), envolto em uma placa de moldura, com dois revestimentos (superior e inferior), em Al. Para garantir a qualidade desse material, rigorosos ensaios são aplicados em todas as fases do processo (Souza, 2011).

O urânio é reconhecido como o material mais utilizado no desenvolvimento da tecnologia nuclear, entretanto, a sua aplicabilidade envolve melhorias constantes em todos os processos, desde a mineração ao descarte. No que tange a fiabilidade do combustível, a caracterização química combinada com proteção ambiental é muito importante no ciclo de produção de urânio ou do ciclo do combustível nuclear, sujeito a um número crescente de convenções e protocolos internacionais (Souza et al., 2012).

O desempenho de um combustível nuclear está intrinsecamente ligado à sua composição química, no qual a ausência de impurezas (B, Cd, Co, Cu, Fe, Mn, Zn, e outros) é extremamente importante do ponto de vista da economia de nêutrons, já que a presença compromete a densidade energética do combustível. Tal importância tem promovido o uso de várias técnicas analíticas instrumentais para a determinação de impurezas em compostos de urânio como: LIBS (Espectrometria de Emissão Óptica com Plasma Induzido por Laser), FAAS (Espectrometria de Absorção Atômica em Chama), GF AAS (Espectrometria de Absorção Atômica com Forno de Grafite), ICP-OES (Espectrometria de emissão Óptica com Plasma Indutivamente Acoplado) e ICP-MS (Espectrometria de Massa com Plasma Indutivamente Acoplado) (IAEA, 1999, Reis et al., 2009; Satyanarayana et al., 2010, Souza et al., 2012). 
Contudo, para a aplicação das técnicas mencionadas, tratamentos químicos prévios como dissolução, digestão, calcinação, e outros são necessários. Esses procedimentos são relativamente demorados e dispendiosos, além disso, produzem resíduos e efluentes, os quais necessitam de atenção especial, por se tratar de material nuclear (Satyanarayana et al., 2010).

A literatura reporta que a FRX (espectrometria de fluorescência de raios X) permite análises químicas não destrutivas, rápidas e multielementares, demonstrando viabilidade para a determinação de maiores e menores constituintes e traços em $\mathrm{U}_{3} \mathrm{O}_{8}$ e $\mathrm{U}_{3} \mathrm{Si}_{2}$ (Scapin et al., 2011a; Silva; C. et al., 2011).

A FRX está fundamentada no efeito fotoelétrico, quando um átomo é excitado por raios $\mathrm{X}$, existe uma probabilidade de elétrons das camadas mais internas serem ejetados, para se estabilizar, elétrons das camadas externas ocupam esse vazio, nesse processo, ocorre liberação de energia a qual é característica para cada elemento químico. Essa energia pode ser medida por meio das técnicas EDXRF (espectrometria de fluorescência de raios $\mathrm{X}$ por dispersão de energia) ou WDXRF (espectrometria de fluorescência de raios $\mathrm{X}$ por dispersão de comprimento de onda). Na EDXRF, as energias características são detectadas simultaneamente por um detector semicondutor de $\mathrm{Si} / \mathrm{Li}$ e separadas por meio de um software multicanal. Na WRXRF, são difratadas em cristais de difração, de acordo com a Lei de Bragg e detectadas por detectores de cintilação ou proporcional de fluxo (Müller, 1972; Tertian et al., 1982).

Uma diferença a ser destacada entre as técnicas EDXRF e WDXRF está relacionada à resolução espectral, ou seja, sistemas WDXRF apresentam maior resolução, proporcionando a vantagem de se reduzir à sobreposição de linhas espectrais e se obter menores limites de detecção, consequentemente, análise mais sensíveis. No entanto, os componentes ópticos adicionais (por exemplo, cristais de difração, colimadores e outros) aumentam significativamente o seu custo, tornando a WDXRF muito mais cara.

A técnica WDXRF apresenta, dentro de um contexto metrológico, sensibilidade, repetibilidade e reprodutibilidade satisfatórias para quantificar os elementos do Boro $(Z=5)$ ao $U(Z=92)$. Contudo, efeitos físicos de matriz, como homogeneidade e granulometria e os espectrais, como sobreposição de linhas e absorção e/ou intensificação (efeitos interelementos) ocorrem, dependendo do material analisado. Esses efeitos interferem nos resultados de análises, mas, podem ser normalizados, minimizados ou corrigidos (Silva, C. et al., 2011). No caso dos efeitos físicos, normalmente realiza-se a diminuição da granulometria por meio de moagem. Nos espectrais, aplica-se a quimiometria, ou seja, 
métodos matemáticos ou estatísticos como o de deconvolução, para a separação de linhas espectrais sobrepostas e calibração univariada (CC), por parâmetros fundamentais (FP) ou multivariada (CM), para as correções dos efeitos interelementos (Scapin et al, 2011b).

No método de curva de calibração univariada, os raios $\mathrm{X}$ característicos de um determinado elemento, expressos em contagem por segundos (cps) são correlacionados com a sua concentração. Por meio de regressão linear se obtém uma curva de intensidade (cps) versus concentração. Se os parâmetros instrumentais de medidas estão bem definidos, o coeficiente de correlação dessa curva será próximo de 1, demonstrando alta correlação. Assim, interpolando-se nessa curva a cps do elemento de uma amostra desconhecida, determina-se a sua concentração (Pimentel et al., 1996; Souza 2007). O procedimento é simples, entretanto, a curva de calibração univariada deverá ser construída com MRCs (materiais de referências certificados) semelhantes à amostra analisada. Essa condição é uma desvantagem, visto que MRCs são caros e, dependendo do tipo de amostras, não estão comercialmente disponíveis. Além disso, para alguns elementos, os efeitos espectrais (absorção/intensificação) não podem ser normalizados, impedindo análise direta. Nesse caso são aplicados procedimentos de preparação de amostra, como o método de adição, dupla diluição, fusão, dissolução entre outros.

O método de parâmetros fundamentais (FP) utiliza algoritmos que permitem corrigir os efeitos espectrais a partir da medida da intensidade da linha de emissão do elemento e dos valores tabelados dos principais parâmetros fundamentais, como distribuição espectral primária (fonte), coeficiente de absorção (fotoelétrico e de massa), rendimento de fluorescência e outros. Nele supõe-se que a amostra é homogênea, apresenta espessura infinita e tem uma superfície razoavelmente plana (Lachance et al., 1995; Scapin, 2003).

No método FP é possível analisar amostras sem a utilização de MRCs, porém, os resultados se tornam mais confiáveis quando os parâmetros que fazem parte da expressão matemática são obtidos com base em padrões semelhantes às amostras. O cálculo envolve duas etapas fundamentais: calibração e previsão.

$\mathrm{Na}$ etapa de calibração, a equação de FP é utilizada para prever a intensidade das linhas características do padrão de calibração. Os cálculos são realizados especificamente para o espectrômetro em que as medidas são executadas, uma vez que a equação de FP considera aspectos de geometria, fonte e condições instrumentais. As intensidades teoricamente calculadas são relacionadas às intensidades medidas, e esta última, corrigida para cada linha característica. Esta correção é obtida por meio do coeficiente angular da 
curva, intensidades líquidas (experimentais) versus intensidades calculadas, que correspondem ao fator proporcional utilizado na correção (Nagata et al., 2001).

$\mathrm{Na}$ etapa da previsão é necessário estimar primeiramente uma composição aproximada da amostra. Normalmente, é considerada a intensidade relativa das linhas de emissão detectadas para cada elemento presente na matriz, assumindo que o total emitido corresponde a uma composição de $100 \%$ (ou outro total se os constituintes menores forem ignorados) (Criss et al., 1968; Nagata et al., 2001).

Valendo-se desta equação, calculam-se quais intensidades deveriam ser observadas para a suposta composição e a compara com os valores medidos, ajusta-se a composição assumida e calcula o novo conjunto de intensidades esperadas. Esse processo de interação é repetido automaticamente até que a composição suposta forneça uma intensidade de raios $\mathrm{X}$ correspondente ao valor medido para um nível de significância de 0,05. A composição que atender a essa relação é o resultado da análise (Bertin, 1970; Nagata et al., 2001; Scapin, 2008).

A calibração multivariada tem como conceito básico relacionar dois blocos de dados (X e Y), onde $\mathrm{X}(\mathrm{n}, \mathrm{m})$ é o bloco dos dados experimentais, contendo as variáveis independentes, representado em suas linhas pelas amostras do conjunto e em suas colunas pelas variáveis medidas e o outro bloco (Y), formado pela(s) variável(eis) dependentes(s) (Ferreira et al., 1999; Parreira, 2003).

Dessa forma, na calibração multivariada, ao contrário do que ocorre na univariada, utilizam-se múltiplas respostas (várias linhas características de emissão) para se relacionarem com a(s) propriedade(s) medida(s) das amostras (Beebe et al., 1998; Parreira, 2003).

As principais vantagens da calibração multivariada consistem em permitir determinações simultâneas de mais de um elemento de interesse, mesmo na presença de interferentes, e apresentar uma diminuição do erro estimado no modelo, por ser um método que utiliza múltiplas variáveis.

A calibração multivariada, de modo geral, pode ser dividida em duas etapas consecutivas:

- Modelagem: estabelece-se uma relação entre o sinal medido e a propriedade que se deseja quantificar da amostra;

- Validação: assegura que o modelo reflete o comportamento do elemento. 
Os métodos de regressão multivariada são classificados em dois tipos principais: Direto - Quadrados Mínimos Clássico (CLS - Classical Least Squares) e Inverso - (ILS Inverse Least Squares).

A construção do modelo de calibração pode ser feita por vários métodos e a escolha entre cada um deles está relacionada ao perfil do conjunto de dados (Ribeiro, 2001). Depois de construído, o modelo deve ser validado, ou seja, testado para garantir que os valores obtidos para a variável dependente sejam iguais ou muito próximos dos experimentais (Parreira, 2003).

Dentro desse contexto, nesse trabalho foi proposto um estudo para se verificar a possibilidade de aplicar a calibração multivariada para a determinação simultânea de impurezas e $\mathrm{U}_{\text {total }}$ em $\mathrm{U}_{3} \mathrm{O}_{8}$ e impurezas, $\mathrm{Si}$ e $\mathrm{U}_{\text {total }}$ em $\mathrm{U}_{3} \mathrm{Si}_{2}$, por meio de análise direta e não destrutiva, ou seja, sem tratamentos químicos prévios na preparação de amostra, utilizando-se a espectrometria de fluorescência de raios X por dispersão de comprimento de onda. 


\section{OBJETIVOS}

Avaliar o potencial da técnica de fluorescência de raios $\mathrm{X}$ por dispersão de comprimento de onda para a caracterização química de materiais nucleares em conformidade com as especificações técnicas estabelecidas para combustível nuclear à base de $\mathrm{U}_{3} \mathrm{O}_{8}$ e $\mathrm{U}_{3} \mathrm{Si}_{2}$.

Estabelecer e validar uma metodologia de análise química quantitativa, não destrutiva, de baixo custo e tempo de análise, assim como minimizar a geração de resíduo para a determinação simultânea dos maiores constituintes $\left(\mathrm{U}_{\text {total }}\right.$ e $\left.\mathrm{Si}\right)$ e impurezas $(\mathrm{B}, \mathrm{Mg}$, $\mathrm{Al}, \mathrm{Cr}, \mathrm{Mn}, \mathrm{Fe}, \mathrm{Co}, \mathrm{Ni}, \mathrm{Cu}, \mathrm{Zn}, \mathrm{Mo}, \mathrm{Cd}$ e outros) presentes em $\mathrm{U}_{3} \mathrm{O}_{8}$ e $\mathrm{U}_{3} \mathrm{Si}_{2}$, em conformidade com a ISO/IEC 17025. 


\section{REVISÃO BIBLIOGRÁFICA}

O projeto do primeiro reator nuclear multipropósito brasileiro de grande porte (RMB), deverá entrar em funcionamento em 2017. Como o próprio nome diz, o equipamento, orçado em $\mathrm{R} \$ 850$ milhões, tem múltiplas finalidades. Entre as principais está a produção de radioisótopos para uso na medicina nuclear, como exames e tratamento do câncer, além de pesquisas em campos tão diversos como tecnologia nuclear, energia, agricultura, indústria, ciência de materiais e meio ambiente (Baima, 2012).

No Brasil, são realizados cerca de 1,5 milhão de procedimentos por ano com radiofármacos. Mais de $80 \%$ deles usam o radioisótopo tecnécio-99, derivado do molibdênio-99, insumo totalmente importado atualmente, visto que, não há produção nacional. Somados a outros elementos radioativos também utilizados nos serviços de saúde, cuja demanda não é plenamente suprida pelos pequenos reatores de pesquisa instalados no país, o gasto passa dos $\mathrm{R} \$ 30$ milhões anuais. O reator terá vida útil prevista de 50 anos. Só a produção de radioisótopos será suficiente para pagar o investimento em 20 anos (Baima, 2012).

Com o RMB, o Brasil se tornará autossuficiente no setor, podendo dobrar a quantidade de radiofármacos ofertada à sociedade e exportar eventuais excedentes, ingressando em um mercado mundial restrito, hoje, dominado por instituições do Canadá, África do Sul, Holanda, Bélgica e França, que produzem mais de 95\% do suprimento global de molibdênio-99. Em 2009 e 2010, paradas não programadas nos reatores do Canadá e da Holanda provocaram uma crise no abastecimento e levaram à suspensão de milhões de procedimentos em todo mundo.

Além da produção de radiofármacos para fins medicinais, o RMB terá um fluxo de nêutrons de grande intensidade, suficiente para testar combustíveis e materiais usados nos reatores de geração de energia e de propulsão, fornecendo maior segurança a esses projetos e garantindo a continuidade no desenvolvimento do conhecimento nuclear do país (Baima, 2012).

O RMB já conta com a tecnologia de fabricação de seu combustível, o qual será do tipo placa (MTR) a base de $\mathrm{U}_{3} \mathrm{Si}_{2}$ desenvolvido pelo Centro de Combustível Nuclear (CCN) do Instituto de Pesquisas Energéticas e Nucleares (IPEN-CNEN/SP) (Fonte Nuclear, 2012).

Atualmente, a produção do elemento combustível tipo MTR sumariamente se inicia com a mistura entre pó de alumínio metálico $(\mathrm{Al})$ e pó de siliceto de urânio $\left(\mathrm{U}_{3} \mathrm{Si}_{2}\right)$ 
enriquecido a $20 \%$ em peso de uranio-235 $\left({ }^{235} \mathrm{U}\right)$, em proporções pré-determinadas. Posteriormente, essa mistura é compactada na forma de briquetes, e estes, desgaseificados a vácuo. Em seguida, é montado um conjunto para laminação, composto por um núcleo (briquete da $\mathrm{U}_{3} \mathrm{Si}_{2}-\mathrm{Al}$ ), envolto em uma placa de moldura, com dois revestimentos (superior e inferior), em Al (FIG. 1) (Saliba Silva et al., 2007; Ferrufino, 2011).

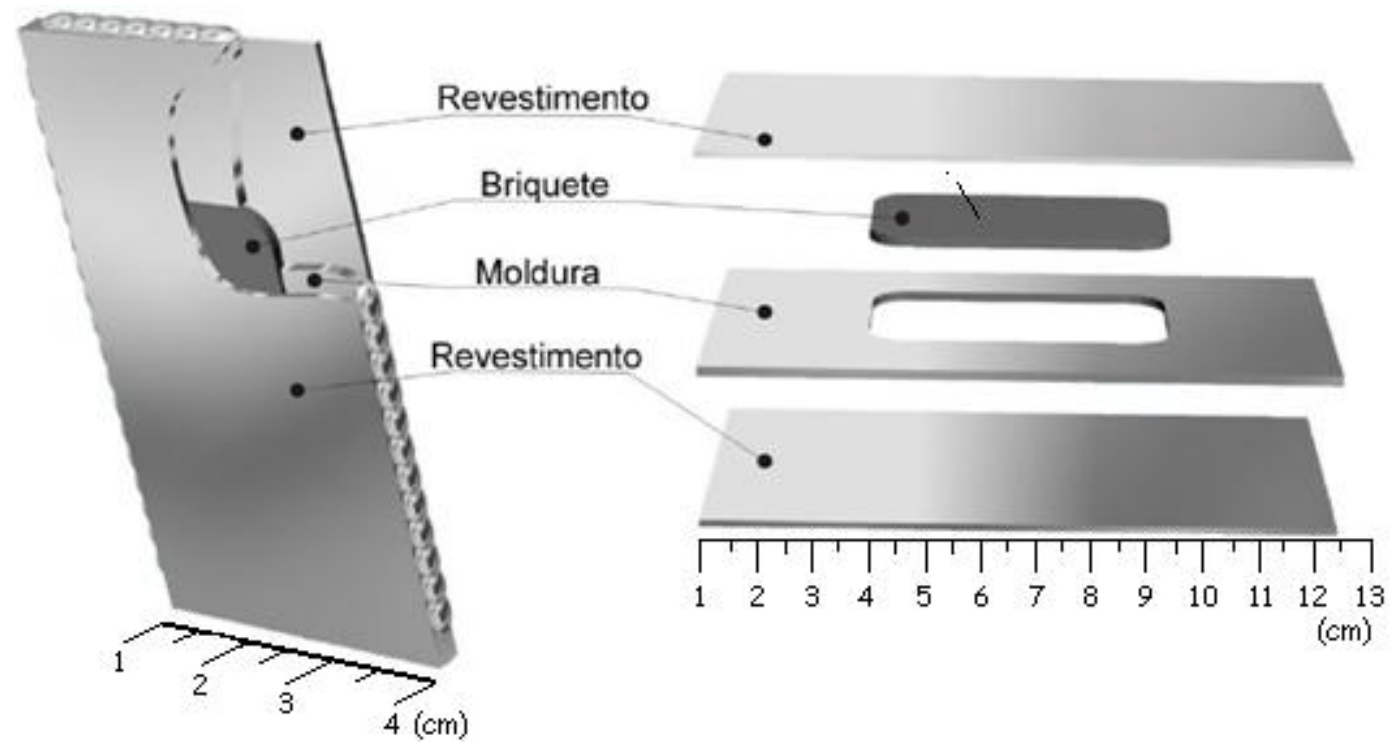

FIGURA 1- Esquema de montagem da placa combustível (Ferrufino, 2011 - adaptado)

Essas placas são cravadas paralelamente entre si em suportes laterais e afixadas por um pino de sustentação e um bocal, conforme mostra a FIG. 2 .

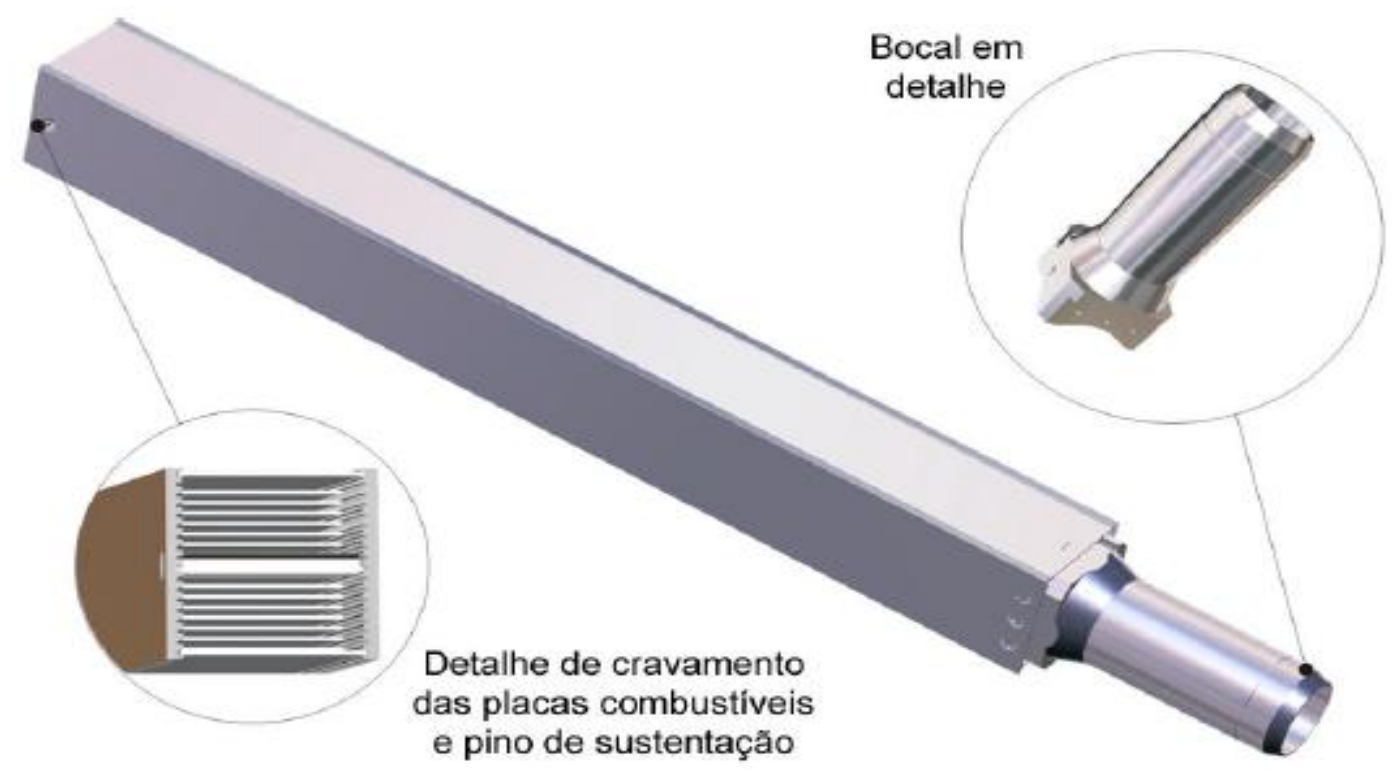

FIGURA 2 - Esquema de montagem do elemento combustível (Ferrufino, 2011) 
Embora não seja uma tecnologia inovadora, o $\mathrm{U}_{3} \mathrm{Si}_{2} \operatorname{com} 4,8 \mathrm{~g} \mathrm{U} \mathrm{cm}^{3}$ é atualmente o combustível comercialmente mais avançado do mundo (Fonte Nuclear, 2012). O seu desempenho nos reatores depende da sua composição química, e a ausência de impurezas é um requisito, no que diz respeito à economia de nêutrons, pois a presença compromete a densidade energética (Gopalkrishnnan et al., 1997; Souza. et al., 2012).

A TAB.1 apresenta os limites de impurezas aceitáveis para o $\mathrm{U}_{3} \mathrm{Si}_{2}$ produzido no Centro de Combustível Nuclear IPEN/CNEN-SP.

TABELA 1 - Limites de impurezas aceitáveis em $\mathrm{U}_{3} \mathrm{Si}_{2}$

\begin{tabular}{cccc}
\hline Elemento & Valor $\left(\mu \mathrm{g} \mathrm{g}^{-1}\right)$ & Elemento & Valor $\left(\mu \mathrm{g} \mathrm{g}^{-1}\right)$ \\
\hline $\mathrm{Al}$ & 150 & $\mathrm{Mn}$ & 25 \\
$\mathrm{~B}$ & 10 & $\mathrm{Mo}$ & 100 \\
$\mathrm{C}$ & 550 & $\mathrm{Ni}$ & 100 \\
$\mathrm{Ca}$ & 100 & $\mathrm{P}$ & 100 \\
$\mathrm{Cr}$ & 50 & $\mathrm{Si}$ & 100 \\
$\mathrm{Co}$ & 5 & $\mathrm{Na}$ & 25 \\
$\mathrm{Cu}$ & 50 & $\mathrm{Sn}$ & 100 \\
$\mathrm{Fe}$ & 250 & $\mathrm{Va}$ & 10 \\
$\mathrm{~Pb}$ & 10 & $\mathrm{~W}$ & 100 \\
$\mathrm{Li}$ & 10 & $\mathrm{Zr}$ & 250 \\
$\mathrm{Mg}$ & 50 & $\mathrm{Total}$ & 1500 \\
\hline Laucht et al., 1998 & \multicolumn{3}{c}{}
\end{tabular}

Os elementos com alta seção de choque como B e Cd, causam a absorção de nêutrons térmicos. Os metais alcalinos, alcalinos terrosos e de transição, tendem a formar óxidos, modificando a razão metal/oxigênio na matriz combustível (ASTM, 1993; IAEA, 1999; IAEA, 2005; Verma et al., 2007; Souza. et al., 2012). Além disso, esses elementos juntamente às terras raras como $\mathrm{Sm}, \mathrm{Eu}, \mathrm{Gd}$ e $\mathrm{Dy}$, mesmo em nível ultra traço diminuem sua densidade energética, visto que, após a irradiação no reator, produzem radionuclídeos (Ramanaiah, 1998; Malhotra et al., 1999; Verma et al., 2007; Souza. et al., 2012).

Várias técnicas têm sido aplicadas para a determinação de impurezas em compostos de urânio e, entre elas, os métodos espectrométricos são os mais utilizados, já que muitos elementos podem ser medidos simultaneamente em curto período de tempo, usando pouca quantidade de amostra. Cada método tem vantagens e desvantagens em relação às interferências espectrais, à acurácia, ao custo, ao tipo de amostra (sólido ou líquido) e ao equipamento utilizado nas análises. Para a aplicabilidade do método, deve-se levar em 
consideração o limite de detecção, os passos da separação da matriz e a pré-concentração (Satyanarayana et al., 2010; Souza. et al., 2012).

Dentre os métodos espectrométricos utilizados para a determinação de impurezas em compostos de urânio, podemos citar a FAAS (Espectrometria de Absorção Atômica em Chama) e ICP-OES (Espectrometria de emissão Óptica com Plasma Indutivamente Acoplado), ambos necessitando da prévia separação do urânio em razão de sua interferência espectral. A separação pode ser realizada por extração com solvente, precipitação, cromatografia de troca iônica, destilação ou eletrólise (Sulcek et al., 1989; Arruda, 2006; Santos et al., 2010).

A literatura reporta que a cromatografia iônica pode ser um método complementar às técnicas espectrométricas, pois apresenta simples automação, separação rápida, seletividade e sensibilidade, além disso, é multielementar e amplamente utilizada para análises de combustível nuclear, tanto no produto final como nas etapas de processamento dos materiais. A separação dos íons metálicos de transição é realizada por meio de complexação, utilizando-se agentes quelantes, como ácidos orgânicos (ácido cítrico, ácido oxálico, PDCA ${ }^{1}$, e outros) e posteriormente as colunas catiônicas ou aniônicas (Knight et al., 1984; Verma et al., 2007; Souza. et al., 2012).

As técnicas e os procedimentos mencionados apresentam, dentro de um contexto metrológico, acurácia e robustez satisfatórias, entretanto, os tratamentos químicos prévios tornam as análises demoradas e dispendiosas, além de produzir resíduos, que necessitam de tratamentos químicos para o descarte ou ambiente adequado para a estocagem.

Scapin et al.(2011a), utilizou as técnicas de WDXRF e EDXRF para a determinação de urânio total e silício na matriz de siliceto de urânio, por meio de análise direta e não destrutiva. Os resultados foram comparados com os métodos de análise gravimétrica (determinação de silício) e volumétrica (determinação de urânio total). Dentre as técnicas aplicadas, a WDXRF apresentou os resultados mais concordantes, demostrando-se satisfatória para a determinação de urânio total e silício em matrizes de siliceto de urânio, entretanto, o artigo não reporta a determinação de impurezas.

Silva, C. et al.(2011) desenvolveu um estudo para o aumento de resolução dos detectores do WDXRF por meio de métodos matemáticos para a determinação de impurezas em óxido de urânio, utilizando análise direta e não destrutiva. Os resultados mostraram que a metodologia permite a determinação de 11 impurezas $(\mathrm{Ca}, \mathrm{Ni}, \mathrm{Zn}, \mathrm{Cr}$,

\footnotetext{
${ }_{1}^{1}$ pyridine-2,6-dicarboxylic acid / acetate buffer
} 
Mo, $\mathrm{Sn}, \mathrm{Zr}, \mathrm{Fe}, \mathrm{Si}, \mathrm{Mg}$ e Cu) com acurácia menor que 10\%, exceção para $\mathrm{Zr}, \mathrm{Fe}, \mathrm{Si}, \mathrm{Mg}$ e $\mathrm{Cu}(30-56 \%)$, no entanto, o artigo não reporta a determinação de urânio.

Assim, existe uma necessidade de se desenvolver métodos simples e rápidos para a caracterização química dos materiais utilizados como combustível nuclear. 


\section{CONSIDERAÇÕES TEÓRICAS}

A fluorescência de raios X é classificada como uma técnica de emissão atômica, fundamentada no efeito fotoelétrico. Quando um átomo é submetido a um processo de irradiação utilizando-se uma fonte de raios $X$ (tubos de raios $X$, indução por partícula, radioisótopos naturais, luz síncrotron e outros), um elétron pode ser ejetado das camadas eletrônicas mais internas do átomo. Para estabilização desse estado de excitação, elétrons das camadas eletrônicas mais externas ocupam rapidamente as vacâncias geradas, liberando a diferença de energia existente entre os dois níveis de energia. A radiação emitida para cada transição é característica para cada elemento presente na amostra, FIG.3. Assim, a energia emitida por determinado elemento pode ser utilizada para identificá-lo. (Jenkis et al., 1972; Skoog et al., 2002; Bortoleto, 2007).

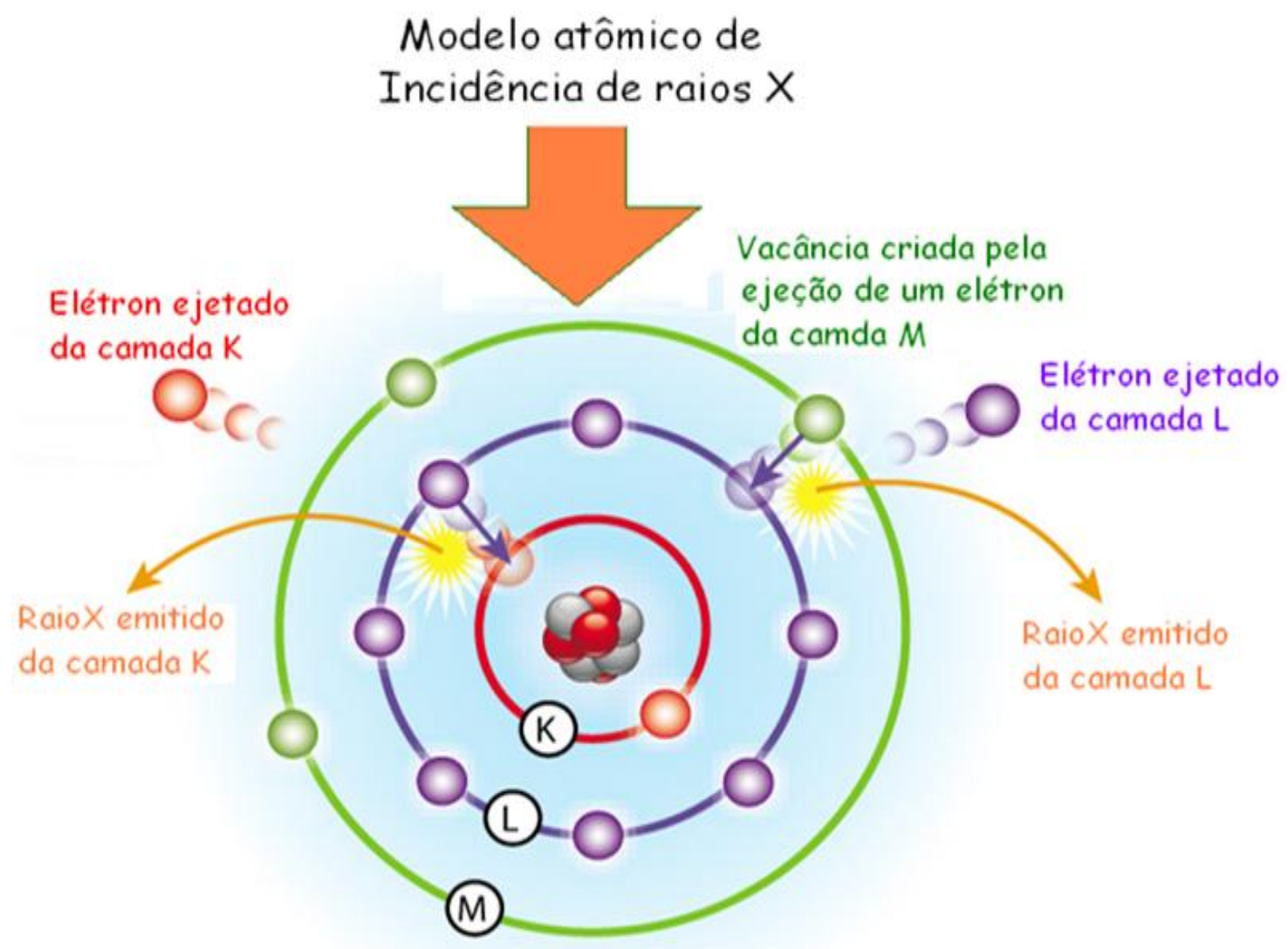

FIGURA 3 - Modelo esquemático demonstrando o efeito fotoelétrico e a ocorrência de raios $\mathrm{X}$ 
$\mathrm{Na}$ EDXRF as energias características são detectadas simultaneamente por um detector semicondutor de $\mathrm{Si} / \mathrm{Li}$ e separadas por meio de um software acoplado a uma placa analisadora multicanal conforme mostrado na FIG. 4 (Müller, 1972; Tertian et al., 1982).

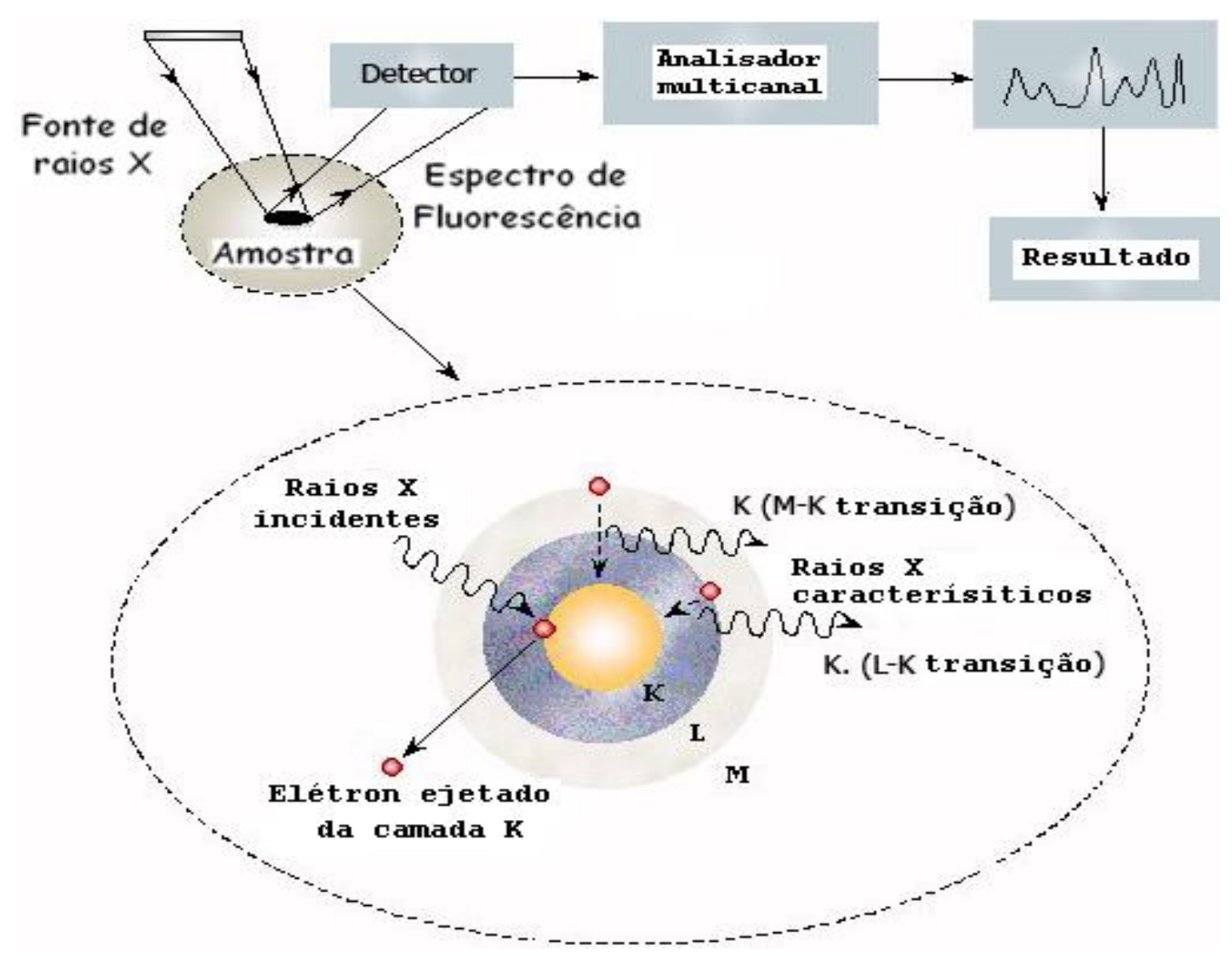

FIGURA 4 - Esquema de funcionamento de um espectrômetro de fluorescência de raios X do tipo EDXRF (OceanKingIndian, 2012)

Os WDXRF são constituídos essencialmente por um cristal e um detector monocanal, utilizados para a medida sequencial de vários comprimentos de onda, ou por um detector multicanal que apresenta um conjunto de cristais e detectores para realização de medidas simultâneas. Nos espectrômetros convencionais, um cristal de espaço interplanar conhecido (cristal analisador), movimentado por um goniômetro, atua como uma rede de difração. Ele dispersa o feixe policromático proveniente da emissão da amostra, difratando cada comprimento de onda característico a um ângulo específico, ou seja, quanto maior o comprimento de onda, maior o ângulo de dispersão segundo a lei de Bragg como mostra a FIG. 5 (Skoog et al., 2002; Bortoleto, 2007). 


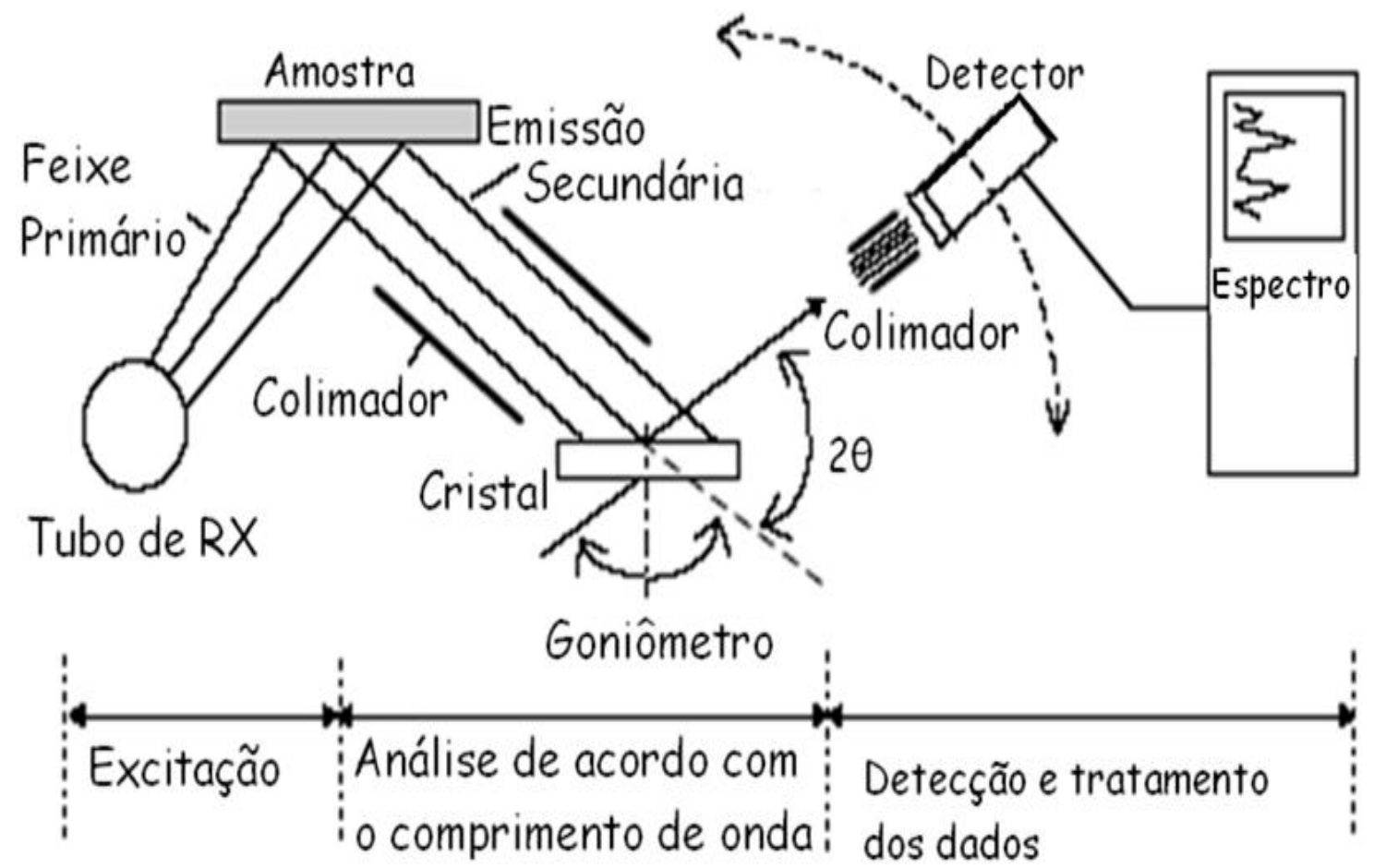

FIGURA 5 - Esquema de funcionamento de um espectrômetro de fluorescência de raios X do tipo WDXRF

Uma diferença a ser destacada entre as técnicas EDXRF e WDXRF se refere à resolução espectral, ou seja, sistemas WDXRF fornecem maior resolução, proporcionando a vantagem de se reduzir à sobreposição de linhas espectrais e menores limites de detecção, permitindo assim análises mais precisas (FIG. 5). No entanto, os componentes ópticos adicionais (por exemplo, cristais de difração, colimadores e outros) aumentam significativamente o seu custo, tornando-a muito mais cara.

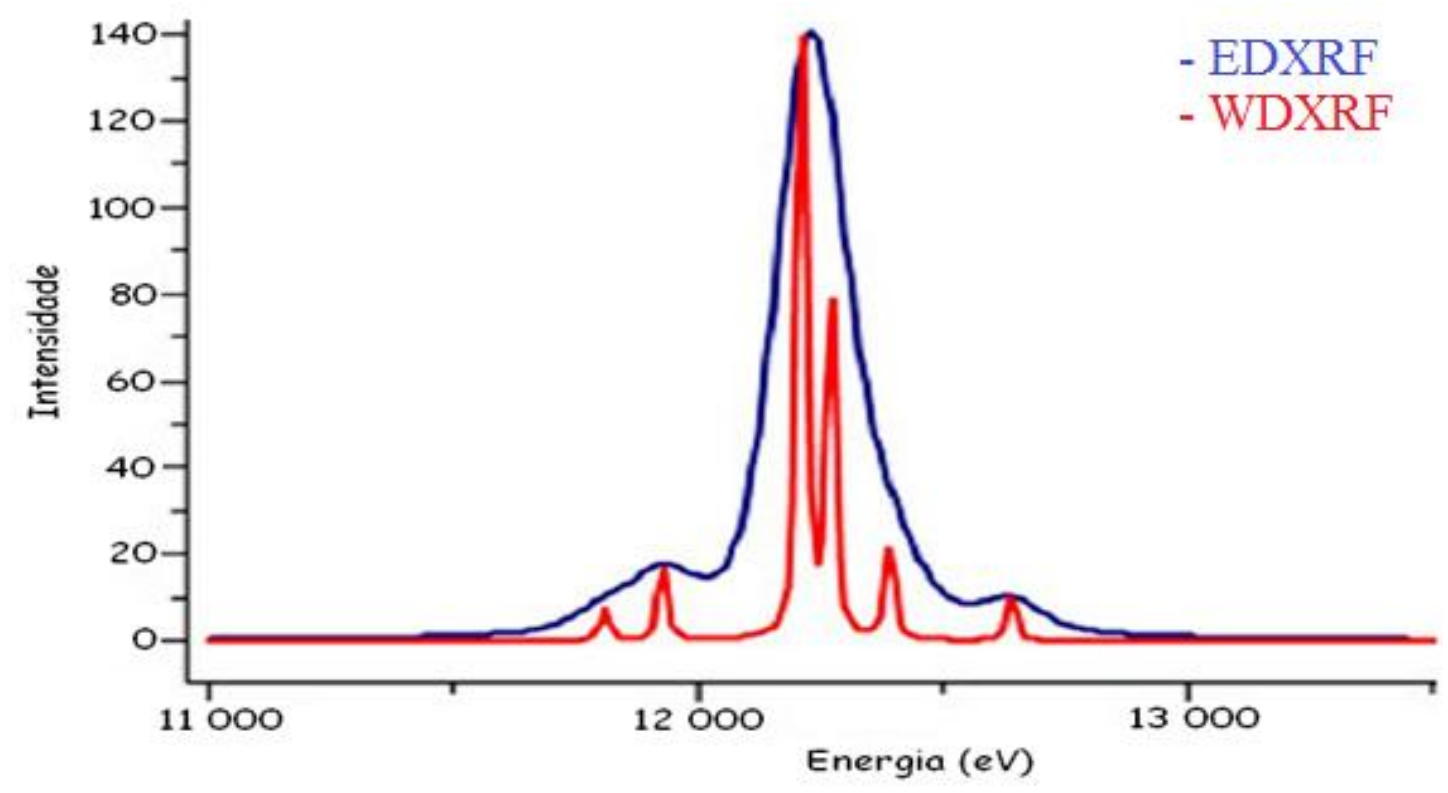

FIGURA 6 - Diferenças na resolução espectral entre os espectrômetros de EDXRF (AZUL) e WDXRF (vermelho). (Horibga Scientific, 2012 - adaptada) 
As vantagens associadas à utilização de WDXRF ressaltam-se no fato das análises serem obtidas quase sem interferências espectrais, dado a alta resolução proporcionada pelo sistema cristal/goniômetro. Este fato permite uma seleção de comprimentos de onda com máxima eficiência na linha de interesse ou eficiência mínima nas linhas interferentes. Além disso, existem filtros que possibilitam eliminar as interferências entre as linhas características da fonte e o sinal de emissão do elemento de interesse, bem como a escolha correta do cristal analisador, possibilitando separar e selecionar uma região específica e muito estreita do espectro de emissão de raios X (Bortoleto, 2007).

A literatura reporta que a técnica tem sido amplamente utilizada para análises químicas de solo, sedimentos, rochas, filmes finos metálicos sobre diversos tipos de substratos, óleo lubrificante e outros (Scapin, 2008; Scapin et. al., 2009), utilizando-se metodologia empírica, isto é, por meio de curvas de calibração ou de algoritmos, sem curva de calibração, como o método de parâmetros fundamentais e mais recentemente, os métodos quimiométricos (Bortoleto, 2007).

\subsection{Curva de Calibração Univariada (CC)}

O método de curva de calibração univariada pode ser considerado um modo de correlacionar o resultado de uma medida com um determinado valor tomado como verdadeiro, estabelecendo um grau de exatidão do sistema (VIM, 2008).

A concentração de um analito não é diretamente observável, visto que, sempre se procura um modo indireto, ou seja, por meio de outras grandezas como absorção ou emissão de luz, condutividade ou ainda pesos e volume, para que se obtenha uma medida de concentração. Assim, para alcançar o objetivo final da análise, é preciso antes encontrar uma função que correlacione às medidas realizadas com a concentração procurada, que significa fazer uma calibração (Draper et al., 1981; Box et al., 1987; Pimentel et al., 1996).

O processo de desenvolvimento de uma curva de calibração univariada consiste em duas etapas. Inicialmente, na etapa de calibração, são realizadas medidas em MRCs, com as mesmas características das amostras que se pretende determinar, para construir um modelo matemático que relacione o valor medido com a concentração desejada. Em seguida, na etapa de previsão, aplica-se o modelo para prever novas concentrações a partir dos sinais obtidos.

Numa curva de calibração univariada bem ajustada, os pontos gerados pela intensidade (cps) versus concentração, obtidos experimentalmente, devem passar o mais 
próximo da curva. O método de mínimos quadrados com regressão linear pode ser aplicado para gerar esta curva, pois fornece resultados não tendenciosos e com variância mínima, dentro de determinadas suposições estatísticas (Draper et al., 1981; Box et al., 1987; Pimentel et. al, 1995; Souza, 2007).

O modelo de regressão linear pressupõe que a variável aleatória x é conhecida (concentração) e a variável dependente y é desconhecida (cps). Por meio dos mínimos quadrados, são calculados o coeficiente angular e ponto de intersecção.

Para uma curva de calibração linear, o sinal observado (x) ou resposta (y) é dado pela Eq. 1.

$$
y=a x+b
$$

Na qual:

$\mathrm{y} \equiv$ contagem (cps);

$\mathrm{a} \equiv$ coeficiente angular do modelo de calibração;

$\mathrm{b} \equiv$ parâmetro de erro do modelo de calibração;

$\mathrm{x}=$ concentração do analito.

Assim, a função preditiva é dada pela inversão da Eq.1 como mostra a Eq. 2 abaixo.

$$
\mathrm{F}(\mathrm{x})=\frac{\mathrm{y}-\mathrm{b}}{\mathrm{a}}
$$

Se os parâmetros instrumentais de medidas estão bem definidos, o coeficiente de correlação dessa curva será próximo de 1, ou seja, o sinal observado estará diretamente relacionado com sua respectiva concentração (Pimentel, 1996). Valores abaixo de 0,90 indicam uma relação deficiente. (ASTM, 2003; Silva, J., 2011).

O procedimento é simples, entretanto, para garantir um bom ajuste, a curva de calibração univariada deverá ser construída com MRCs (materiais de referências certificados) semelhantes à amostra analisada para minimizar os efeitos interelementos (absorção/intensificação) (Thompson et al., 2002). Essa condição é uma desvantagem, visto que, dependendo do tipo de amostras, não estão comercialmente disponíveis. Além disso, em amostras complexas como geológicas e mineralógicas, os efeitos espectrais impossibilitam a análise direta. Por esse motivo, são aplicados procedimentos de preparação de amostra, como o método de adição, dupla diluição, fusão, dissolução entre outros. 


\subsection{Método de Parâmetros Fundamentais}

O método de parâmetros fundamentais (FP) utiliza algoritmos que permitem calcular a composição química de uma amostra, sem a utilização de padrões similares, a partir da medida da intensidade da linha de emissão do analito e dos valores tabelados dos principais parâmetros fundamentais, como distribuição espectral primária (fonte), coeficiente de absorção (fotoelétrico e de massa), rendimento de fluorescência e outros (Bertin, 1970; Lachance et al., 1995; Nagata et al., 2001; Scapin, 2003; Scapin, 2008).

O coeficiente de absorção $(\mu \mathrm{m})$ é uma constante que relaciona a perda de intensidade de fluorescência quando a radiação atravessa uma amostra dividida pela densidade do material (Criss et al., 1968; Bertin, 1970; Nagata et al., 2001).

A Eq. 3 apresenta a expressão matemática necessária para aplicação do método de FP, considerando-se a excitação da amostra por meio de radiação monocromática. Utilizando-se fonte policromática na análise de amostras multicomponentes, a expressão torna-se mais complexa, o que leva à utilização de recursos computacionais (Nagata et al., 2001).

$$
W_{i}=\left(a I_{i} * b I_{i}+c\right)\left(1+k+\sum A i j F j+\sum Q i j F j F k+\sum \frac{R i j F j}{1+W_{i}}\right)+\sum B i j F j+\sum D i j k F j F k+c
$$

Na qual:

$\mathrm{Wi} \equiv$ termo de quantificação;

a, b,c $\equiv$ coeficientes das curvas de calibração;

$\mathrm{Ii} \equiv$ intensidade dos raios-X;

$\mathrm{K} \equiv$ termo constante;

Aij $\equiv$ coeficiente de absorção/excitação;

$\mathrm{Fj} \equiv$ valor de análises ou correção de intensidade dos raios-X;

Qij $\equiv$ coeficiente de absorção/excitação (correção secundária);

Rij $\equiv$ correção do coeficiente de excitação;

Bij $\equiv$ correção de sobreposição de linhas (overlap);

Dij $\equiv$ correção do coeficiente de absorção/excitação;

O método de parâmetros fundamentais admite que a amostra seja homogênea, apresente a espessura infinita e tenha uma superfície razoavelmente plana. Apesar da possibilidade de analisar amostras sem a utilização de padrões, o método ganha maior confiabilidade se os diversos parâmetros que fazem parte da expressão matemática são obtidos com base em padrões adequados. O cálculo envolve duas etapas fundamentais: a 
calibração e a previsão. Na primeira etapa, a equação de FP é utilizada para prever a intensidade das linhas características do padrão de calibração.

Os cálculos são realizados especificamente para o espectrômetro em que as medidas são executadas, pelo fato de a equação de FP considerar aspectos de geometria, fonte e condições instrumentais. As intensidades teoricamente calculadas são relacionadas com as intensidades medidas, e esta última, corrigida para cada linha característica. Esta correção é obtida por meio do coeficiente angular da curva, intensidades líquidas (experimentais) vs intensidades calculadas, que corresponde ao fator proporcional utilizado na correção (De Vries et al., 1993; Nagata et al., 2001).

$\mathrm{Na}$ etapa da previsão é necessário estimar primeiramente uma composição aproximada da amostra. Normalmente, é considerada a intensidade relativa das linhas de emissão detectadas para cada elemento presente na matriz, supondo que o total emitido corresponde a uma composição de 100\% (ou outro total se os constituintes menores forem ignorados) (Criss, 1968, Nagata et al., 2001).

Assim, por meio desta equação, são executados cálculos para se determinar quais intensidades devem ser observadas para a suposta composição, e por meio de comparação com os valores medidos, ajusta-se a composição assumida em que o novo conjunto de intensidades esperadas é calculado. Esse processo é repetido automaticamente até que a composição suposta forneça uma intensidade de raios-X correspondente ao valor medido para um nível de significância de 0,05. A composição que atender a esta relação é o resultado da análise (Bertin,1970; Nagata et al., 2001; Scapin, 2008).

\subsection{Calibração Multivariada (CM)}

A denominação "Análise Multivariada" corresponde a um grande número de métodos e técnicas que utilizam, simultaneamente, todas as variáveis na interpretação teórica do conjunto de dados obtidos (Neto, 2004).

Há uma família de métodos quimiométricos, chamados de métodos de calibração multivariados, os quais permitem a descrição de fenômenos muito diversos e complexos através da combinação de um pequeno número de contribuições básicas e facilmente interpretáveis (Juan et. al, 2011). A versatilidade e simplicidade da resolução multivariada explica sua aplicação bem-sucedida na modelagem de processos bioquímicos e químicos e na interpretação de dados ambientais associados à fluorescência de raios X (Sena et al, 2000; Shimamoto et al, 2011; Leme, 2012; Schwab et al, 2012). 
A aplicação de métodos matemáticos a um conjunto de dados naturalmente multivariado permite reduzir o espaço dimensional a que esse está confinado, facilitando assim, a sua interpretação e visualização. Esta redução pode ser realizada por meio de uma Análise de Componentes Principais.

\subsubsection{Análise de Componentes Principais}

O conceito de análise de componentes principais proposto por Pearson em 1901 e posteriormente desenvolvido por Hotelling na década de 70 foi agregado à calibração multivariada, o qual se tornou praticamente indispensável (Barros Neto et al, 2006).

A Análise de Componentes Principais (PCA) é um procedimento matemático que, por meio de uma transformação ortogonal, converte um conjunto de observações de variáveis possivelmente correlacionadas em um conjunto de variáveis não correlacionadas linearmente, chamados de componentes principais, reduzindo a dimensão dos dados originais para facilitar a sua observação (Ferreira et. al., 1999; Matos et al, 2003; Brereton, 2007; Juan et. al., 2011).

Em uma matriz, a alta colinearidade entre os dados é um indicativo de que representações melhores podem ser construídas em novas bases para os dados fornecidos. Assim, por meio da combinação linear das antigas variáveis, são desenvolvidos novos vetores formando uma nova base de dados ortogonal, na qual as variáveis são linearmente independentes. Os novos vetores, também conhecidos como componentes principais, são ortogonais entre si e ordenados em termos da variância dos dados originais de modo que o primeiro vetor aponta na direção de maior variância (Wold et al., 1987; Parreira, 2003).

A decomposição ortogonal pode ser realizada por meio do método SVD (Singular Value Decomposition), em que uma matriz X de " $\mathrm{n}$ " amostras por "m" variáveis é decomposta em matrizes menores T, P e E, que correspondem às matrizes de scores, loadings e resíduos, respectivamente. A matriz de scores possibilita determinar o número de agrupamentos entre variáveis. Já a matriz dos loadings permite determinar os coeficientes da combinação linear (o peso de cada variável), enquanto a matriz E, mostra os erros (Bouroche et al., 1982; Ferreira et al., 1999; Leme, 2012).

A PCA é um método de normalização, portanto amostras anômalas (outliars) influenciam diretamente no processo de SVD. Assim, um processo rigoroso de identificação e eliminação das mesmas deve ser realizado no início dos procedimentos (Wold, 1987). Muitas vezes, os dados devem passar por um pré-processamento como 
centrar na média, escalar pela variância ou ainda autoescalar, para que se possam evidenciar amostras anômalas. (Ferreira et al., 1997; Parreira, 2003).

Centrar na média significa calcular o centroide da matriz de dados, levando-o à origem pela subtração de cada elemento de cada coluna pela sua respectiva média (Eq. 4). É importante ressaltar que os dados devem ser da mesma ordem de grandeza e estarem na mesma unidade, como no caso da espectroscopia (Ribeiro, 2001).

$$
X_{i j(\mathrm{~cm})}=X_{i j}-\bar{X}_{j}
$$

Em que:

$X_{i j(\mathrm{~cm})} \equiv$ valor centrado na média para a variável i na amostra j;

$X_{i j} \equiv$ valor da variável i na amostra j;

$\bar{X}_{j} \equiv$ média dos valores da coluna $\mathrm{j}$.

Escalar pela variância e autoescalar, confere a todos os eixos da coordenada o mesmo comprimento e, consequentemente, dedica a mesma influência para cada variável no modelo, visto que a PCA, é um método de mínimos quadrados. Estes procedimentos são aplicados conforme as Eqs. 5 e 6.

$$
X_{i j(v a r)}=\frac{X_{i j}}{S_{j}}
$$

Na qual:

$X_{i j(v a r)} \equiv$ valor escalado pela variância para a variável j na amostra i;

$X_{i j} \equiv$ valor da variável j na amostra i;

$S_{j} \equiv$ desvio padrão dos valores da variável $\mathrm{j}$.

$$
X_{i j(a s)}=\frac{\overline{X_{j}}}{s_{j}}
$$

Em que:

$S_{j} \equiv$ desvio padrão dos valores da variável j.

$X_{i j(a s)} \equiv$ valor autoescalado da variável j da amostra i;

$\bar{X}_{\mathrm{J}} \equiv$ valor médio das amostras da coluna j.

O objetivo da PCA não é explicar as correlações existentes entre as variáveis, mas encontrar funções matemáticas, entre as variáveis iniciais, que expliquem o máximo 
possível da variação existente nos dados e permita descrever e reduzir essas variáveis (Reis, 1997).

\subsection{Validação dos Métodos}

Validar um método é obter a confirmação por exame de evidência objetiva de que os requisitos específicos para um determinado uso são cumpridos (EURACHEM, 1998). Validar um método analítico consiste em realizar uma série de testes para obter dados que caracterizem e permitam avaliar a metodologia empregada de modo que ela possa ou não gerar resultados satisfatórios de acordo com a incerteza pretendida (Oliveira Junior, 2002).

Quando uma medição é realizada, esse resultado é somente uma aproximação ou uma estimativa do valor do mensurando. Assim, a expressão completa que representará o valor de tal mensurando deverá incluir a incerteza de medição (INMETRO, 2010).

O documento Orientações Sobre Técnicas Analíticas (INMETRO, 2010, DOQCGCRE-008) tem como objetivo orientar laboratórios na tarefa de demonstrar que um método analítico, nas condições em que é praticado, tem as características necessárias para a obtenção de resultados com a qualidade exigida.

Durante um processo de validação, os métodos podem variar de acordo com as características do ensaio empregado, assim, são fornecidas orientações quanto aos parâmetros relevantes (especificidade, linearidade, sensibilidade, exatidão, precisão, limite de detecção, repetitividade, reprodutividade e robustez) para se realizar uma validação.

Seletividade ou especificidade é a garantia de que a matriz da amostra não contém componentes que possam interferir no desempenho da medição. Os interferentes podem aumentar ou reduzir o sinal, e a magnitude do efeito também pode depender da concentração. A literatura dispõe de diversos experimentos para avaliação da seletividade sobre validação de métodos analíticos que envolvem ensaios com padrões ou materiais de referência, amostras com e sem o analito, além da avaliação da capacidade de identificação do analito de interesse na presença de interferentes.

A linearidade é a proporcionalidade que determinado método apresenta entre as concentrações do analito e suas respectivas intensidades em um resultado de análise (Matsubara, 2011). Essa proporcionalidade pode ser calculada pela padronização interna ou externa como apresentado na seção 4.1.

A sensibilidade é definida como a intensidade líquida obtida por unidade de concentração. Para calcular a sensibilidade, a medida intensidade não deve ser corrigida 
para efeitos de matriz e deve-se assumir uma relação linear entre a intensidade e concentração, conforme Eq. 1.

Repetitividade é o grau de concordância de um conjunto de medições, realizadas inúmeras vezes, utilizando-se o mesmo operador, o mesmo sistema de medição, o mesmo local e as mesmas condições de medida por um curto espaço de tempo (VIM, 2008). A repetitividade pode ser expressa em termos da dispersão dos resultados e pode ser determinada por meio de materiais de referência (INMETRO, 2010).

Reprodutividade é a comparação do desempenho de resultados obtidos em diferentes laboratórios, procurando analisar o grau de concordância entre eles. (VIM, 2008; INMETRO, 2010).

A robustez pode ser avaliada no desenvolvimento da pesquisa e varia de acordo com o processo em análise. Alterações em diferentes variáveis do método indicam os principais fatores que podem influenciar, de modo mais significativo, a resposta do método (Brito et al., 2003).

A exatidão é avaliada numericamente por meio da tendência, observando-se o grau do erro relativo percentual (ER\%), como mostra a Eq. 7 (Rousseal, 2001; VIM, 2008).

$$
E R \%=\frac{\left(X_{l a b}-X_{v}\right)}{X_{v}} * 100
$$

Na qual:

$$
\begin{aligned}
& \mathrm{X}_{\mathrm{lab}} \equiv \text { valor obtido experimentalmente; } \\
& \mathrm{X}_{\mathrm{v}} \equiv \text { valor aceito como verdadeiro (valor MRC); }
\end{aligned}
$$

Entretanto, na avaliação da exatidão quando utilizado um MRC, os valores como média e desvio padrão obtidos por meio de réplicas de medidas devem ser comparados com seus respectivos valores certificados. Para tal comparação, além do ER\%, pode-se aplicar o índice Z (Z-score) mostrado na Eq. 8.

$$
Z=\frac{\left(X_{l a b}-X_{v}\right)}{\sqrt{U_{l a b}^{2}-U_{v}^{2}}}
$$

Em que:

$$
\begin{aligned}
& \mathrm{X}_{\mathrm{lab}} \equiv \text { valor obtido experimentalmente; } \\
& \mathrm{Xv} \equiv \text { valor aceito como verdadeiro (valor MRC); } \\
& \mathrm{U}_{\mathrm{lab}} \equiv \text { incerteza calculada pelo laboratório; }
\end{aligned}
$$




\section{$\mathrm{U}_{\mathrm{v}} \equiv$ incerteza certificada pelo MRC.}

No cálculo da exatidão, quando não há MRC disponível, pode-se realizar a comparação entre as médias de dois métodos distintos, aplicando-se o teste $t$-student (Eq. 9), num determinado intervalo de confiança.

$$
t_{\text {calculado }}=\frac{\left(d-d_{0}\right)}{\frac{s_{d}}{\sqrt{n}}}
$$

Na qual,

$\mathrm{d} \equiv$ média da amostra da diferença;

$d_{0} \equiv$ valor testado da média das diferenças nas populações;

$s_{d} \equiv$ desvio padrão da amostra das diferenças;

$\mathrm{d} \equiv$ tamanho da amostra das diferenças.

A precisão pode ser avaliada pelo coeficiente de variação (CV\%), também chamado de desvio padrão relativo percentual (DPR\%), calculado pela Eq. 10:

$$
D P R \%=\frac{s}{\bar{X}} \cdot 100
$$

Na qual:

$\mathrm{s} \equiv$ desvio padrão;

$\bar{X} \equiv$ média dos valores obtidos.

A precisão de dois métodos distintos pode ser comparada pela variância, aplicando-se o teste de Fisher-Snedecor, (Eq. 11) por meio da tabela ANOVA.

$$
F=\frac{s_{1}^{2} \sigma_{2}^{2}}{s_{2}^{2} \sigma_{1}^{2}}
$$

Em que:

$$
\mathrm{F} \equiv \text { teste } \mathrm{F} \text {; }
$$


$\mathrm{s}_{1} \equiv$ desvio padrão amostral do conjunto $1 ;$

$\mathrm{s}_{2} \equiv$ desvio padrão amostral do conjunto 2 ;

$\sigma_{1} \equiv$ variância amostral do conjunto 1 ;

$\sigma_{2} \equiv$ variância amostral do conjunto 1 ;

Para eliminar interferências causadas por valores outliers, pode-se aplicar o teste de Chauvenet, Eq. 12 , in Scapin, 2003.

$$
\left|X_{i}-\bar{X}\right|>k_{n} * s
$$

Na qual:

$$
\begin{array}{lll}
X_{i} & \equiv & \text { valor medido; } \\
\bar{X} & \equiv & \text { valor médio; } \\
K_{n} \equiv & \text { coeficiente de Chauvenet; } \\
s & \equiv & \text { desvio padrão. }
\end{array}
$$

O limite de quantificação (LQ) deve ser calculado para testar, de forma independente, se os resultados de amostras fornecem resultados satisfatórios em termos de tendência e precisão. Este limite pode ser calculado para um nível de significância de 95\%, de acordo com a Eq. 13 (Rousseal, 2001). Em nível de elementos traços, pode-se considerar o LQ a menor concentração da curva analítica.

$$
L Q=2 * \sqrt{\frac{\sum_{m=1}^{n}\left(C_{m}-\bar{C}\right)^{2}}{n-1}}
$$

Na qual:

$$
\begin{array}{lll}
C m & \equiv & \text { valor medido; } \\
\overline{\mathrm{C}} & \equiv & \text { valor médio; } \\
\mathrm{n} & \equiv & \text { número de repetições. }
\end{array}
$$




\section{MATERIAIS E MÉTODOS}

Os materiais e métodos são apresentados a seguir em três itens: equipamentos, acessórios e materiais de referência; preparação de amostras e métodos de análises.

\subsection{Equipamentos, acessórios e materiais de referência}

Nesse trabalho foi utilizado um WDXRF, Rigaku Co, modelo RIX 3000, com tubo de raios-X de $\mathrm{Rh}(3 \mathrm{~kW}), 6$ posições de amostras, 3 posições para filtros (Al, Ti e Ni ), 3 colimadores $(160,460$ e $560 \mu \mathrm{m}), 8$ cristais de difração e 2 detectores (cintilação - SC e proporcional de fluxo - FPC).

Um microcomputador com os aplicativos Microsoft Windows7, MATLAB (V7.0.1), ORIGIN Pro8 e STATISTICA V7 e a infraestrutura laboratorial necessária na preparação de amostras, como prensa hidráulica, balança analítica e homogeneizador mecânico.

Dois conjuntos com sete materiais de referência de pó de $\mathrm{U}_{3} \mathrm{O}_{8}$ ambos certificados para as impurezas B, Mg, Al, Si, Ca, V, Cr, Mn, Fe, Ni, Cu, Zn, Mo, Cd, Sn e Pb (MRC 123 (1-7) - anexo A, e MRC 124 (1-7) - anexo B) da New Brunswick Laboratory - NBL.

Um conjunto de dezesseis amostras de pó de $\mathrm{U}_{3} \mathrm{Si}_{2}$ enriquecido $20 \%$ em ${ }^{235} \mathrm{U}$, fabricados pelo CCN localizado no IPEN-CNEN/SP (SE 002/99 (A1), SE 003/07 (A2), SE 005/04 (A3), SE 006/04 (A4), SE 007/04 (A\%), SE 010/08 (A6), SE 016/09 (A7), SE0 13/09 (A8), SE 014/09 (A9), SE 018/09 (A10), SE 011/09 (A11), SE 019B/10 (A12), SE 020/10 (A13), SE 024/11 (A14), SE 023/11 (A15), SE 028/12 (A16)), com seus respectivos resultados de análises para $\mathrm{U}_{\text {total }}$ e $\mathrm{Si}$ e para as impurezas $\mathrm{B}, \mathrm{Mg}, \mathrm{Al}, \mathrm{Si}, \mathrm{Ca}, \mathrm{V}$, Cr, Mn, Fe, Co, Ni, Cu, Zn, Mo, Cd, Ba, Sn e Pb.

\subsection{Preparação de amostras}

Uma massa de 1,8 g de cada material acima mencionado foi pesada e, em cada um foram adicionados 0,2 $\mathrm{g}$ de cera em pó (Hoechst wax $\mathrm{C}$ Micropowder). Em seguida, foram transferidos para um frasco de polietileno $\left(5 \mathrm{~cm}^{3}\right)$ e homogeneizados em um misturador mecânico (Spex Mixer / Mill) por 5 min. A mistura foi compactada em uma prensa hidráulica utilizando-se uma pressão de $20 \mathrm{MPa}$, por um segundo sobre uma base de ácido bórico (cerca de 1,5 g de $\mathrm{H}_{3} \mathrm{BO}_{3}$ ), previamente prensado com $100 \mathrm{MPa}$ por 10 segundos. No final desse processo, obtiveram-se pastilhas prensadas de dupla camada com 25,01 \pm $0,01 \mathrm{~mm}$ de diâmetro e $5 \pm 1 \mathrm{~mm}$ de espessura total. 


\subsection{Métodos de Análises}

A seguir são apresentados os métodos de análise para a determinação de impurezas em $\mathrm{U}_{3} \mathrm{O}_{8}$ e $\mathrm{U}_{\text {total }}$, Si e impurezas em $\mathrm{U}_{3} \mathrm{Si}_{2}$.

\subsubsection{Método de curva de calibração univariada}

Uma análise qualitativa foi realizada inicialmente no MRC 124 (1) para se verificar as possíveis interferências e se estabelecer as condições instrumentais de medidas. As de sobreposição de linha foram corrigidas por meio de filtros (acessórios disponíveis no espectrômetro) e deconvolução (algoritmo matemático disponível no software, acoplado no espectrômetro). Os coeficientes de correção de sobreposição foram calculados por meio da Eq. 13.

$$
I_{i c}=I_{i}-\sum L i j I i j
$$

Na qual,

$I_{i c} \equiv \quad$ intensidade após a correção de sobreposição;

$I_{i} \equiv \quad$ intensidade antes da correção de sobreposição;

$L i j \equiv \quad$ coeficiente de correção de sobreposição para o elemento $j$;

Iij $\equiv \quad$ intensidade do elemento $j$.

As interferências interelementos (absorção/excitação) foram corrigidas por meio do método de parâmetros fundamentais (FP), como mostrado na Eq. 3 item 4.2. Após o estabelecimento das condições instrumentais, MRCs 123 (1 a 7) foram submetidos ao WDXRF e réplicas de sete medidas para os elementos $\mathrm{B}, \mathrm{Mg}, \mathrm{Al}, \mathrm{Si}, \mathrm{Ca}, \mathrm{V}, \mathrm{Cr}, \mathrm{Mn}, \mathrm{Fe}$, $\mathrm{Ni}, \mathrm{Cu}, \mathrm{Zn}, \mathrm{Mo}, \mathrm{Cd}, \mathrm{Sn}$ e $\mathrm{Pb}$ foram realizadas.

A intensidade líquida de cada elemento foi relacionada com a sua respectiva concentração e por meio de regressão linear foram calculados os coeficientes angular (a), linear (b) e correlação $\left(r^{2}\right)$, assim, as curvas de calibração foram estabelecidas. A validação da metodologia foi realizada utilizando o MRC 124(1), aplicando-se os testes estatísticos descritos no item 4.4. 


\subsubsection{Método de calibração multivariada}

Os MRCs 123 (1 a 7), sob as condições instrumentais estabelecidas, foram medidas no modo $2 \theta$ scan. Os espectros obtidos foram organizados em uma matriz (X) e suas respectivas concentrações na matriz (Y). Calculou-se, então, os seguintes parâmetros:

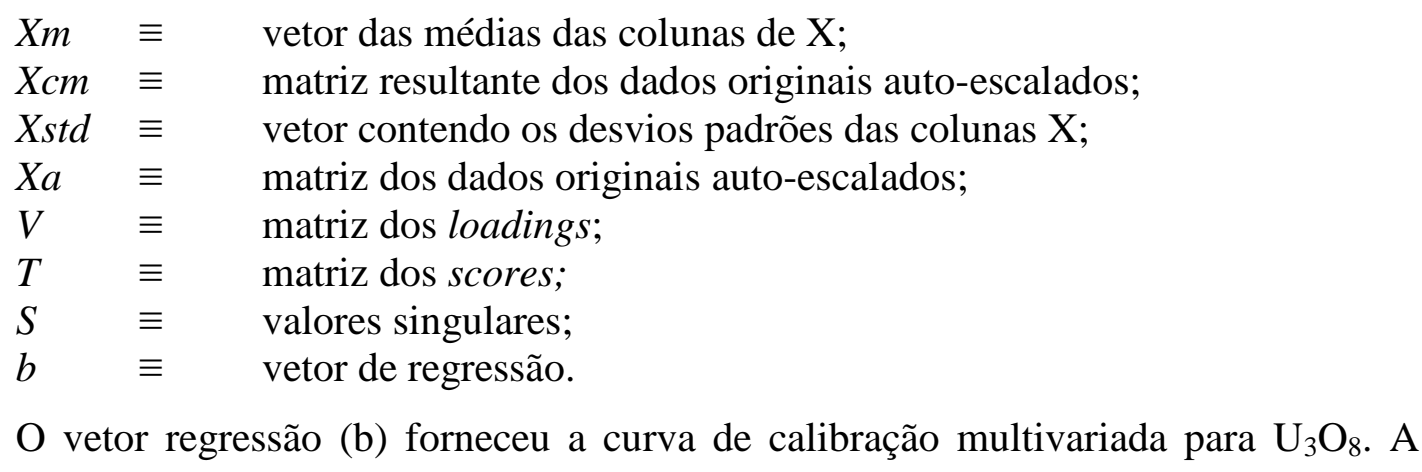
validação da metodologia foi realizada com o MRC 124 (1), aplicando-se os testes estatísticos descritos no item 4.4 .

$\mathrm{O}$ mesmo processo foi aplicado para as amostras de $\mathrm{U}_{3} \mathrm{Si}_{2}$, obtendo-se a curva de calibração multivariada. O limite de quantificação foi calculado de acordo com a Eq. 4 e os resultados comparados com os reportados nos relatórios de análises utilizando-se a análise de variância (ANOVA), para a precisão e teste $t$-Student, para a exatidão.

\subsection{Avaliação das Incertezas}

As fontes de incerteza associadas aos procedimentos de análises que podem influenciar os resultados analíticos são representadas no diagrama de causa e efeito (FIG. 7). $\mathrm{O}$ vetor central representa o mensurando e as suas ramificações as contribuições dos diferentes fatores que podem afetar o resultado das análises.

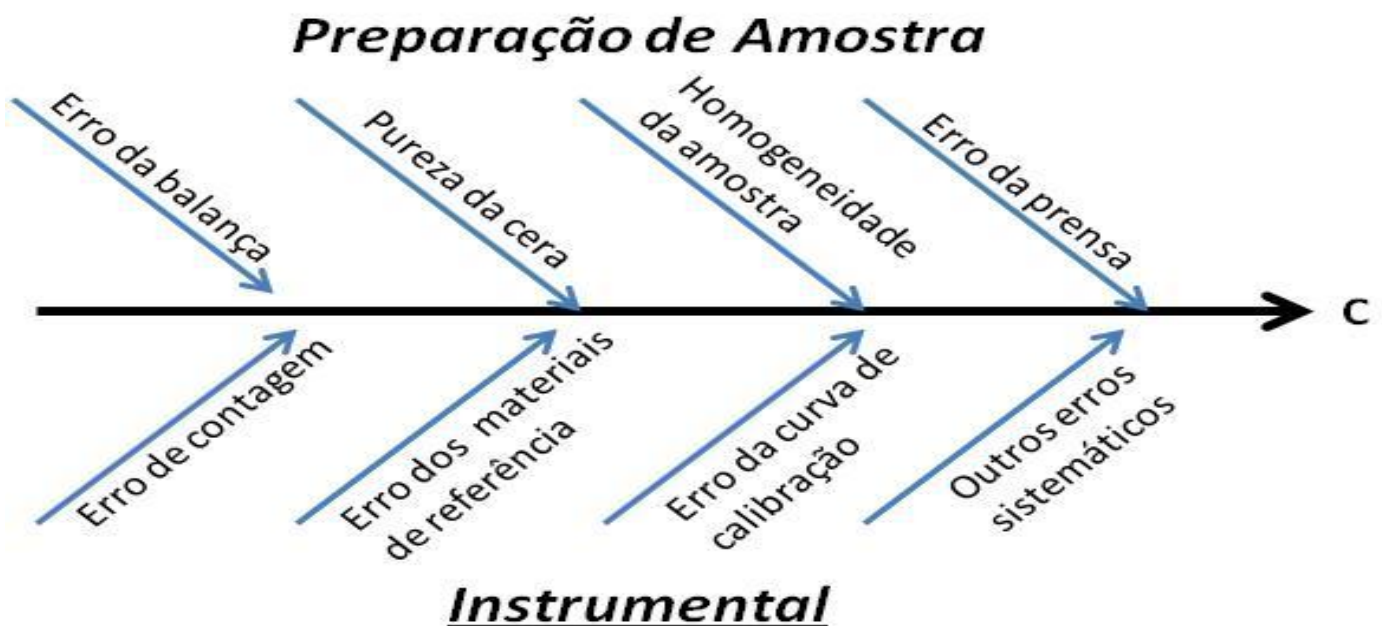

FIGURA 7 - Diagrama de causa e efeito das fontes de incerteza associadas ao método 
O diagrama mostra que as fontes de incerteza associadas estão relacionadas com a preparação de amostra e os parâmetros instrumentais e são independentes. Assim, a incerteza da metodologia foi calculada em termos de incerteza combinada $\left(\mathrm{u}_{\mathrm{c}}\right)$ de acordo com a Eq. 14 (Barca, 2008).

Em que:

$$
u_{c}=\sqrt{u_{1}^{2}+u_{2}^{2}+u_{3}^{2}+\ldots u_{n}^{2}}
$$

$u_{c} \equiv$ incerteza combinada;

$u_{1} \equiv$ incerteza da fonte 1 ;

$u_{2} \equiv$ incerteza da fonte 2 ;

$u_{3} \equiv$ incerteza da fonte 3 ;

Para atingir $95 \%$ de confiança, o valor da incerteza combinada $\left(u_{c}\right)$ foi multiplicado pelo fator de abrangência (k), de acordo com a Eq. 15 (Barca, 2008) e calculado a incerteza expandida.

$$
\mathrm{U}_{95}=\mathrm{k}_{95} * \mathrm{u}_{\mathrm{c}}
$$

Na qual:

$\mathrm{U}_{95} \equiv$ incerteza expandida para $95 \%$ de abrangência;

$\mathrm{K}_{95} \equiv$ fator de abrangência para 95\% (tabelas - distribuição $t$-student);

$\mathrm{u}_{\mathrm{c}} \equiv$ incerteza combinada;

A incerteza referente à balança foi obtida por meio do certificado $(0,001 \%)$. Com relação à prensa, utilizando-se um paquímetro digital, mediu-se três vezes o diâmetro de cada uma das dezesseis amostras de $\mathrm{U}_{3} \mathrm{Si}_{2}$ mencionadas no item 5.1. Posteriormente, calculou-se a área, a razão massa/área, a média, o desvio padrão e o desvio padrão relativo percentual.

Com relação à incerteza instrumental e à pureza da cera, realizaram-se sete medidas das intensidades dos elementos de interesse presentes nos MRCs e no conjunto das amostras de $\mathrm{U}_{3} \mathrm{Si}_{2}$ sob as condições instrumentais estabelecidas para o WDXRF. Posteriormente, para cada elemento calculou-se a média, o desvio padrão e o desvio padrão relativo percentual.

Os resultados para as fontes de incerteza associadas à metodologia mostraram que as de preparação de amostra $(<0,02 \%)$ são desprezíveis quando comparadas às instrumentais (1-5\%), ou seja, para o cálculo da incerteza combinada, os valores do desvio padrão relativo percentual são suficientes para garantir a confiabilidade do resultado reportado. 


\section{RESULTADOS E DISCUSSÃO}

Os resultados da análise qualitativa realizada para o MRC de $\mathrm{U}_{3} \mathrm{O}_{8}-124$ (1) - NBL (FIG. 1) mostraram as seguintes interferências de sobreposição de linhas: U-LB1-2nd sobre Zn-KA; ULB1 sobre Mo-KA; Rh-KB1 sobre Cd-KA. Além disso, baixa intensidade para as linhas B-KA, Mg-KA, Al-KA, Si-KA, V-KA, Cr-KA, Mn-KA, Cu-KA, Zn-KA, Cd-KB1 e Sn-KA.

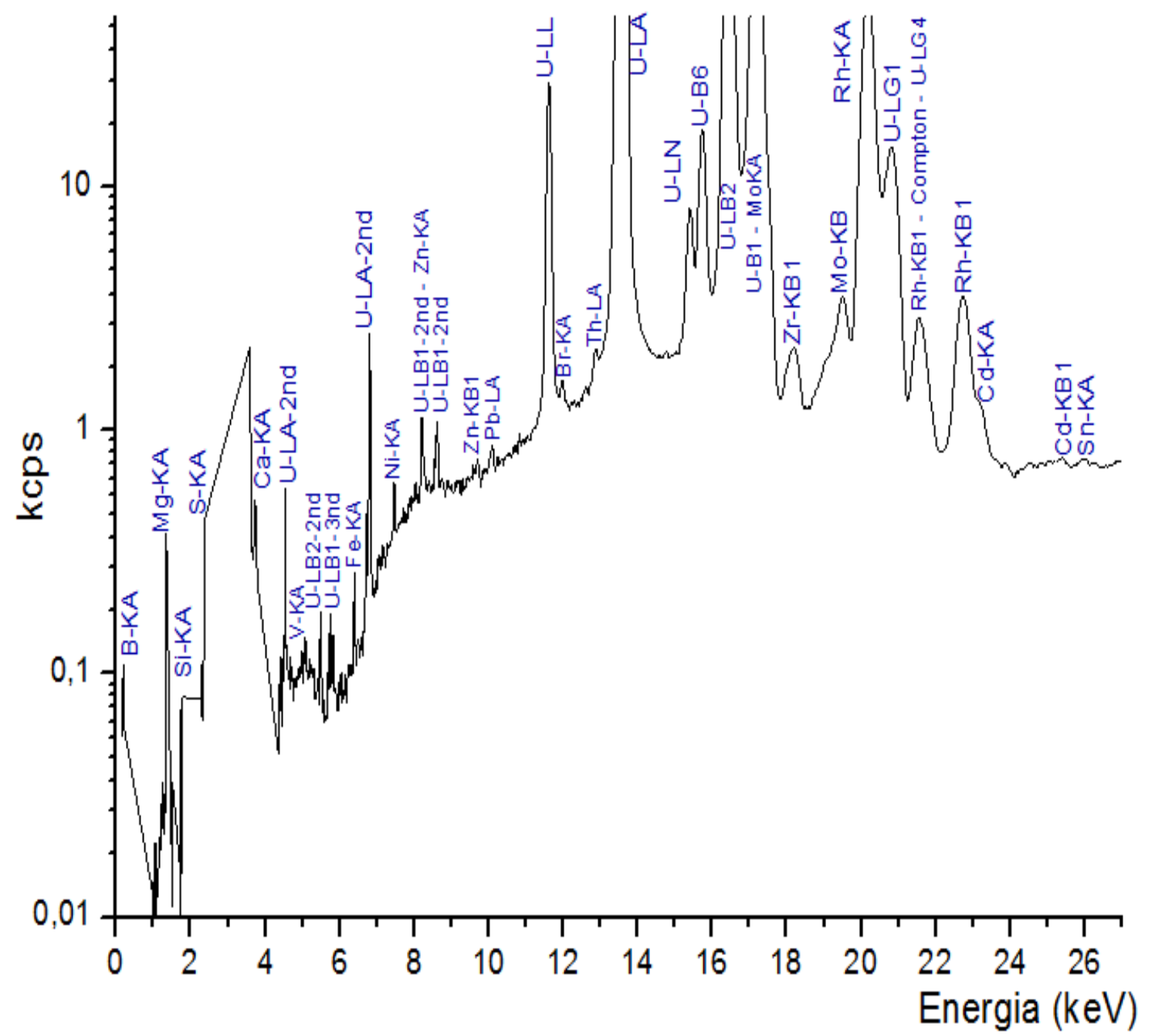

FIGURA 8 - Espectro WDXRF do MRC 124 (1) - NBL de $\mathrm{U}_{3} \mathrm{O}_{8}$

Pelos resultados obtidos, aplicou-se o método de deconvolução para a separação das linhas sobrepostas, exceção para o Cd-KA, para o qual utilizou-se o filtro de zircônio. Posteriormente, programou-se o software acoplado ao espectrômetro para corrigir por meio do método de parâmetros fundamentais as interferências de absorção e intensificação.

As condições instrumentais de medidas estabelecidas para os elementos mencionados acima são apresentadas na TAB. 2. 
TABELA 2 - Condições Instrumentais de medida: elemento (E), linha de emissão (LE), colimador $(\mathrm{C})$, cristal de difração (CD), detector (D), tempo de contagem

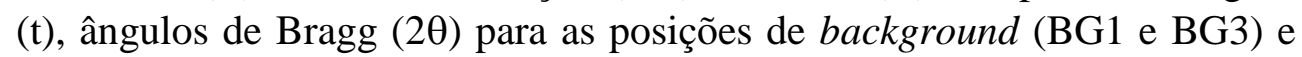
pico.

\begin{tabular}{|c|c|c|c|c|c|c|c|c|}
\hline \multicolumn{6}{|c|}{ Excitação: 50kV x 50mA - tubo de Rh } & \multicolumn{3}{|c|}{$2 \theta$ (graus) } \\
\hline $\mathbf{E}$ & $\mathbf{L E}$ & $\mathbf{C}(\boldsymbol{\mu m})$ & CD & D & $\mathbf{t}(\mathbf{s})$ & BG1 & Pico & BG3 \\
\hline B & B-KA & 560 & RX70 & FPC & 200 & 44,000 & 49,280 & 56,000 \\
\hline $\mathrm{Mg}$ & $\mathrm{Mg}-\mathrm{KA}$ & 560 & TAP & SFP & 200 & 44,850 & 45,190 & 45,650 \\
\hline $\mathrm{Al}$ & $\mathrm{Al}-\mathrm{KA}$ & 560 & PET & SFP & 40 & 144,440 & 145,220 & 145,240 \\
\hline $\mathrm{Si}$ & Si-KA & 560 & PET & SFP & 40 & 108,30 & 109,235 & 109,630 \\
\hline $\mathrm{Ca}$ & Ca-KA & 560 & $\mathrm{Ge}$ & SFP & 40 & 60,860 & 61,260 & 61,660 \\
\hline V & V-KA & 560 & $\mathrm{LiF}$ & $\mathrm{SC}$ & 40 & 76,710 & 76,910 & 77,110 \\
\hline $\mathrm{Cr}$ & $\mathrm{Cr}-\mathrm{KA}$ & 560 & $\mathrm{LiF}$ & $\mathrm{SC}$ & 20 & 69,130 & 69,330 & 69,530 \\
\hline $\mathrm{Mn}$ & $\mathrm{Mn}-\mathrm{KA}$ & 560 & $\mathrm{LiF}$ & $\mathrm{SC}$ & 20 & 62,750 & 62,950 & 63,150 \\
\hline $\mathrm{Fe}$ & Fe-KA & 160 & $\mathrm{LiF}$ & $\mathrm{SC}$ & 20 & 57,300 & 57,505 & 57,700 \\
\hline Co & Co-KA & 560 & $\mathrm{LiF}$ & $\mathrm{SC}$ & 20 & 52,570 & 52,770 & 52,970 \\
\hline $\mathrm{Ni}$ & $\mathrm{Ni}-\mathrm{KA}$ & 160 & $\mathrm{LiF}$ & $\mathrm{SC}$ & 20 & 48,450 & 48,650 & 48,850 \\
\hline $\mathrm{Cu}$ & $\mathrm{Cu}-\mathrm{KA}$ & 560 & $\mathrm{LiF}$ & $\mathrm{SC}$ & 20 & 44,810 & 45,010 & 45,210 \\
\hline $\mathrm{Zn}$ & $\mathrm{Zn}-\mathrm{KA}$ & 160 & $\mathrm{LiF}$ & $\mathrm{SC}$ & 20 & 41,580 & 41,780 & 41,980 \\
\hline Mo & Mo-KA & 560 & $\mathrm{LiF}$ & $\mathrm{SC}$ & 20 & 20,120 & 20,320 & 20,250 \\
\hline $\mathrm{Cd}(\mathrm{F}-\mathrm{Zr})$ & $\mathrm{Cd}-\mathrm{KA}$ & 560 & $\mathrm{LiF}$ & $\mathrm{SC}$ & 20 & 15,110 & 15,300 & 15,500 \\
\hline $\mathrm{Sn}$ & Sn-KA & 160 & $\mathrm{LiF}$ & $\mathrm{SC}$ & 20 & 13,830 & 14,030 & 14,230 \\
\hline $\mathrm{Ba}$ & Ba-LA & 560 & $\mathrm{LiF}$ & $\mathrm{SC}$ & 20 & 86,930 & 87,130 & 87,330 \\
\hline $\mathrm{Pb}$ & $\mathrm{Pb}-\mathrm{LA}$ & 560 & $\mathrm{LiF}$ & $\mathrm{SC}$ & 20 & 33,710 & 33,915 & 34,111 \\
\hline $\mathrm{U}$ & U-LA1-2 $2^{\text {nd }}$ & 560 & $\mathrm{LiF}$ & $\mathrm{SC}$ & 20 & 53,560 & 53,765 & 53,960 \\
\hline
\end{tabular}

TAP: fosfato de tálio - LiF: fluoreto de lítio - Ge: germânio

SC: detector de cintilação - NaI/Tl - FPC: detector proporcional de fluxo

F-Zr: Zr filtro. 


\subsection{Curva de Calibração univariada (CU)}

Sobre as condições instrumentais de medidas os MRCs de $\mathrm{U}_{3} \mathrm{O}_{8} 123$ (1 a 7) - NBL foram submetidos ao espectrômetro, suas intensidades líquidas calculadas para cada elemento e correlacionada com as suas respectivas concentrações, por meio de regressão linear, obtendo-se as curvas de calibração. Para a avaliação da metodologia, analisou-se o MRC 124 (1) - NBL.

$\mathrm{Na}$ TAB. 3 são apresentados os valores certificados $\left(\mathrm{X}_{\text {cert }} \pm \sigma\right)$ e determinados $\left(\mathrm{X}_{\text {det }} \pm \sigma\right)$, os desvios padrão relativo percentual (DPR\%), erros relativo percentual (ER\%), limites de quantificação (LQ) e Z-score, calculados para os elementos certificados no MRC 124 (1) - NBL, e os coeficientes de correlação $\left(\mathrm{r}^{2}\right)$ calculados por meio de regressão linear para cada curva de calibração univariada.

TABELA 3 - Valores certificados (Xcert \pm s) e determinados (Xdet \pm s), desvios padrão relativo percentual (DPR\%), erros relativo percentual (ER\%), limites de quantificação (LQ) e Z-score calculados para o MRC 124 (1) - NBL, e os coeficientes de correlação $\left(\mathrm{r}^{2}\right)$ das curvas de calibração.

\begin{tabular}{lccccccc}
\hline \multirow{2}{*}{ Elementos } & $\begin{array}{c}\mathrm{X}_{\text {cert }} \pm \mathrm{s} \\
\left(\mu \mathrm{g} \mathrm{g}^{-1}\right)\end{array}$ & $\begin{array}{c}\mathrm{X}_{\mathrm{det}} \pm \mathrm{s} \\
\left(\mu \mathrm{g} \mathrm{g}^{-1}\right)\end{array}$ & $\begin{array}{c}\mathrm{DPR} \\
(\%)\end{array}$ & $\begin{array}{c}\text { ER } \\
(\%)\end{array}$ & $\begin{array}{c}\text { LQ } \\
\left(\mu \mathrm{g} \cdot \mathrm{g}^{-1}\right)\end{array}$ & Z-score & $\mathrm{r}^{2}$ \\
\hline $\mathrm{B}$ & $5,1 \pm 1,0$ & $\mathrm{ND}$ & $\mathrm{NC}$ & $\mathrm{NC}$ & $\mathrm{NC}$ & $\mathrm{NC}$ & 0,01 \\
$\mathrm{Mg}$ & $101 \pm 13$ & $105 \pm 22$ & 21,0 & 4,0 & 36 & 0,3 & 0,98 \\
$\mathrm{Al}$ & $205 \pm 37$ & $\mathrm{ND}$ & $\mathrm{NC}$ & $\mathrm{NC}$ & $\mathrm{NC}$ & $\mathrm{NC}$ & 0,81 \\
$\mathrm{Si}$ & $202 \pm 58$ & $89 \pm 4$ & 4,5 & 55,7 & 9 & 1,9 & 0,96 \\
$\mathrm{Ca}$ & $200 \pm 36$ & $194 \pm 11$ & 5,7 & 3,3 & 13 & 0,2 & 1,00 \\
$\mathrm{~V}$ & $50,0 \pm 7,2$ & $\mathrm{ND}$ & $\mathrm{NC}$ & $\mathrm{NC}$ & $\mathrm{NC}$ & $\mathrm{NC}$ & 0,06 \\
$\mathrm{Cr}$ & $102 \pm 14$ & $108 \pm 8$ & 7,4 & 5,8 & 13 & 0,4 & 0,98 \\
$\mathrm{Mn}$ & $51,0 \pm 7,6$ & $\mathrm{ND}$ & $\mathrm{NC}$ & $\mathrm{NC}$ & $\mathrm{NC}$ & $\mathrm{NC}$ & 0,75 \\
$\mathrm{Fe}$ & $210 \pm 24$ & $95 \pm 10$ & 10,5 & 54,8 & 21 & 4,8 & 0,91 \\
$\mathrm{Ni}$ & $202 \pm 17$ & $191 \pm 1$ & 0,5 & 5,3 & 2 & 0,6 & 1,00 \\
$\mathrm{Cu}$ & $50,0 \pm 9,4$ & $64 \pm 7$ & 10,9 & 28,8 & 34 & 1,5 & 0,99 \\
$\mathrm{Zn}$ & $202 \pm 57$ & $198 \pm 25$ & 12,6 & 1,9 & 29 & 0,1 & 1,00 \\
$\mathrm{Mo}$ & $100,0 \pm 5,5$ & $92 \pm 5$ & 5,4 & 8,1 & 8 & 1,5 & 0,99 \\
$\mathrm{Cd}$ & $5,20 \pm 0,88$ & $\mathrm{ND}$ & $\mathrm{NC}$ & $\mathrm{NC}$ & $\mathrm{NC}$ & $\mathrm{NC}$ & 0,17 \\
$\mathrm{Sn}$ & $51,0 \pm 6,9$ & $55 \pm 3$ & 5,5 & 7,0 & 6 & 0,5 & 1,00 \\
$\mathrm{~Pb}$ & $51 \pm 15$ & $\mathrm{ND}$ & $\mathrm{NC}$ & $\mathrm{NC}$ & $\mathrm{NC}$ & $\mathrm{NC}$ & 0,81 \\
\hline $\mathrm{ND}=\mathrm{Não} \mathrm{Determinado;} \mathrm{NC}=\mathrm{Não} \mathrm{calculado}$ & & & & &
\end{tabular}


Os resultados avaliados em termos de coeficiente de correlação $\left(\mathrm{r}^{2}\right)$ mostraram que B $(0,01), \mathrm{V}(0,06)$ e $\mathrm{Cd}(0,17)$ são muito inferiores a 1,00 , demonstrando que não há correlação entre as intensidades (taxa de contagem) e suas concentrações. A hipótese mais provável para a discordância é que o método de parâmetros fundamentais, aplicado nas correções de absorção e intensificação, não foi eficaz, assim como o uso do filtro de $\mathrm{Zr}$ para a correção da sobreposição de Rh-KB1 sobre Cd-KA. Com relação a Al $(0,81)$, Mn $(0,75)$ e $\mathrm{Pb}(0,81)$, os valores estão mais próximos a 1,00, indicando correlação, porém, não satisfatória para atender aos testes estatísticos aplicados. Deste modo, a metodologia não permite quantificar $\mathrm{B}, \mathrm{Al}, \mathrm{V}, \mathrm{Mn}, \mathrm{Cd}$ e $\mathrm{Pb}$ em $\mathrm{U}_{3} \mathrm{O}_{8}$.

Para os elementos que apresentaram correlação maior que 0,91 (Mg, Si, Ca, Cr, Fe, $\mathrm{Ni}, \mathrm{Cu}, \mathrm{Zn}, \mathrm{Mo}$ e Sn), pôde-se verificar que a precisão em termos de desvio padrão relativo percentual (DPR\%) é < 7,5\%, para Si, Ca, Cr, Ni, Mo e Sn e < 12,7\% para Fe, Cu e Zn. Dentre os elementos analisados o Mg apresentou o maior DPR\% (21,0\%).

A exatidão, em termos de erro relativo percentual (ER\%), mostrou que $\mathrm{Mg}, \mathrm{Ca}, \mathrm{Cr}$, $\mathrm{Ni}, \mathrm{Zn}$, Mo e $\mathrm{Sn}$ apresentam valores < $10 \%$ e $\mathrm{Si}, \mathrm{Fe}$ e $\mathrm{Cu},>28,8 \%(55,7 ; 54,8 ; 28,8$ e $30,1 \%$ ). Pelos resultados obtidos $\mathrm{Si}$ e $\mathrm{Fe}$ são os elementos que apresentam maiores dispersão com relação ao valor certificado.

Na FIG. 8 são mostrados os valores calculados para o teste índice Z (Z-score), o qual considera a incerteza do MRC para avaliar a exatidão. Nesse teste, se, $|z| \leq 2$ resultado satisfatório; $2<|z|<3$, questionável; $|z| \geq 3$ insatisfatório (INMETRO, 2010).

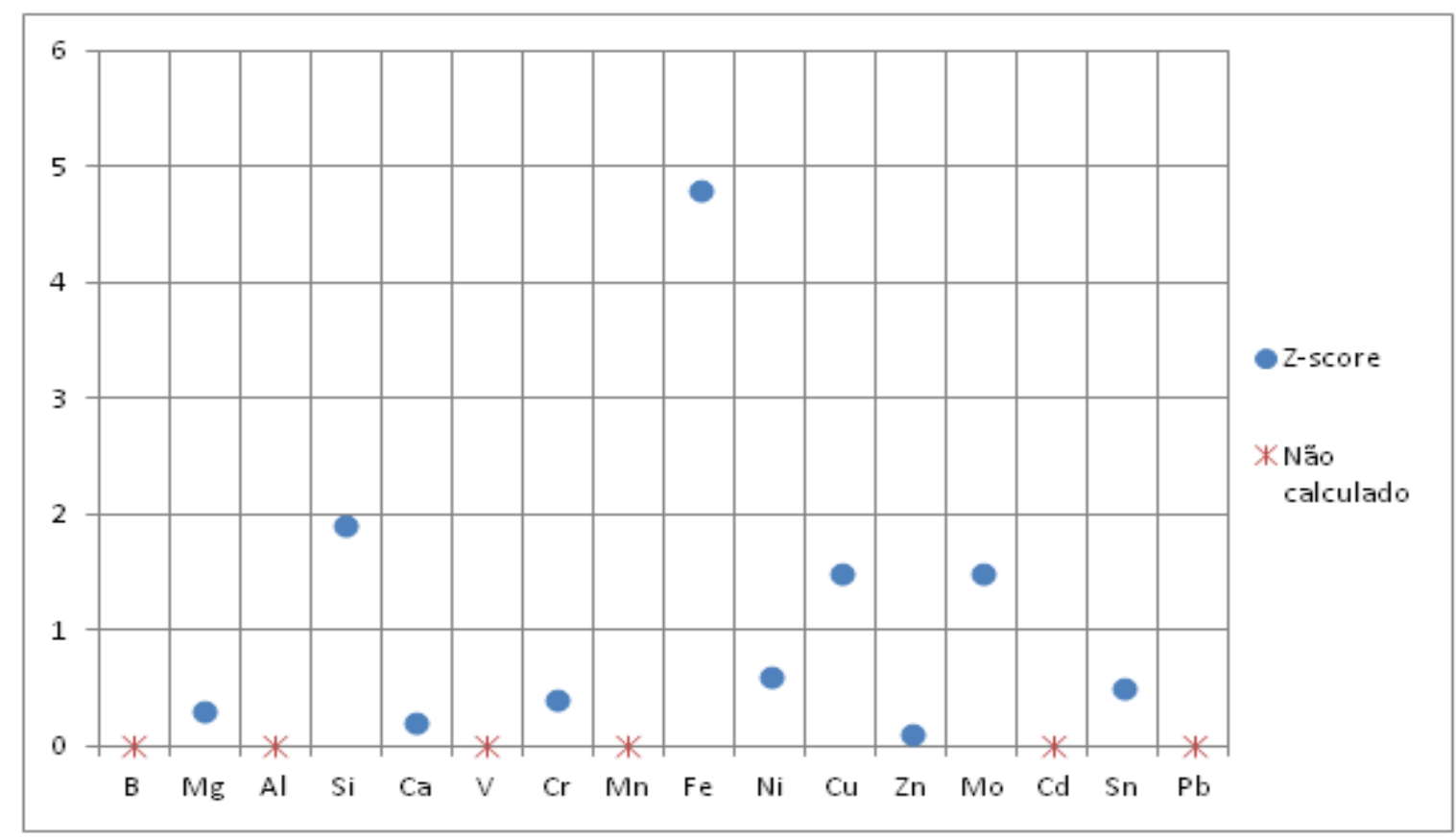

FIGURA 9 - Valores de Z-score calculados para o MRC 124 (1) NBL por curva de calibração univariada 
Os resultados mostraram que para os elementos testados a exatidão é satisfatória, ou seja, estatisticamente não há diferenças significativas entre os valores certificados e os determinados, visto que $\mathrm{Z}<2$. A exceção é observada para $\mathrm{Fe}(4,8)$, insatisfatória.

Com relação aos limites de quantificação (LQ), os resultados mostraram que o método é consideravelmente sensível para a determinação de impurezas, já que Si, Ni, Mo e Sn são quantificados abaixo de $10 \mu \mathrm{g} \mathrm{g}^{-1}, \mathrm{Ca}, \mathrm{Cr}$ e $\mathrm{Fe}<20 \mu \mathrm{g} \mathrm{g}^{-1}, \mathrm{Mg}, \mathrm{Cu}$ e $\mathrm{Zn}<30 \mu \mathrm{g}$ $\mathrm{g}^{-1}$.

Assim, foi possível verificar que o método de curva de calibração univariada por regressão linear permite obter resultados quantitativos confiáveis para a determinação das impurezas $\mathrm{Mg}$, $\mathrm{Si}, \mathrm{Ca}, \mathrm{Cr}, \mathrm{Ni}, \mathrm{Cu}, \mathrm{Zn}, \mathrm{Mo}$ e $\mathrm{Sn}$ em amostras de $\mathrm{U}_{3} \mathrm{O}_{8}$.

\subsection{Calibração multivariada com $M R C s$ de $\mathrm{U}_{3} \mathrm{O}_{8}$}

O modelo de calibração multivariada foi construído utilizando o mesmo conjunto de MRCs (123 (1 a 7) - NBL) sobre as condições instrumentais de medidas apresentadas na TAB. 2, por meio de $2 \theta$ scan. A matriz X (matriz das intensidades) foi obtida por meio da média de réplicas de sete medidas de cada MRC, para cada elemento, de acordo com sua respectiva energia (FIG. 10), resultando uma matriz 7 x 19.

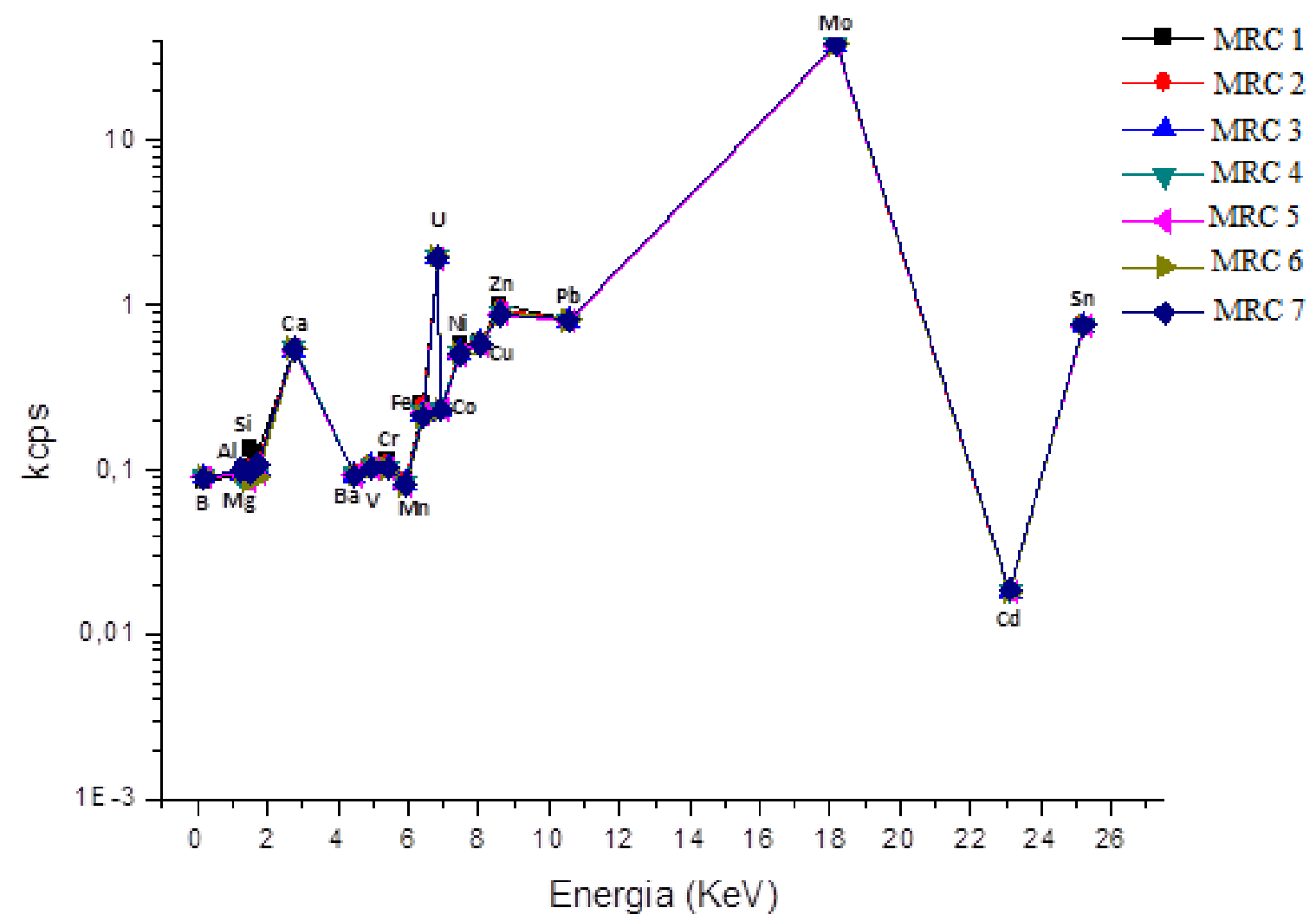

Figura 10 - Gráfico intensidade versus energia para obtenção da matriz X com MRCs de $\mathrm{U}_{3} \mathrm{O}_{8}$ 
Por meio do software MatLab (versão 7.0.1), calculou-se a média e os desvios obtendo-se a matriz dos dados centrados na média. Em seguida, foi feita a análise de componentes principais (PCA) para verificar o número de componentes necessários para descrever o conjunto de dados. Os resultados mostraram que um componente principal é suficiente (PC1=99,9999\%; PC2=0,0001\%) (Ferreira, et al, 1999). A FIG. 11 mostra o gráfico dos loadings versus energia, calculado para PC1.

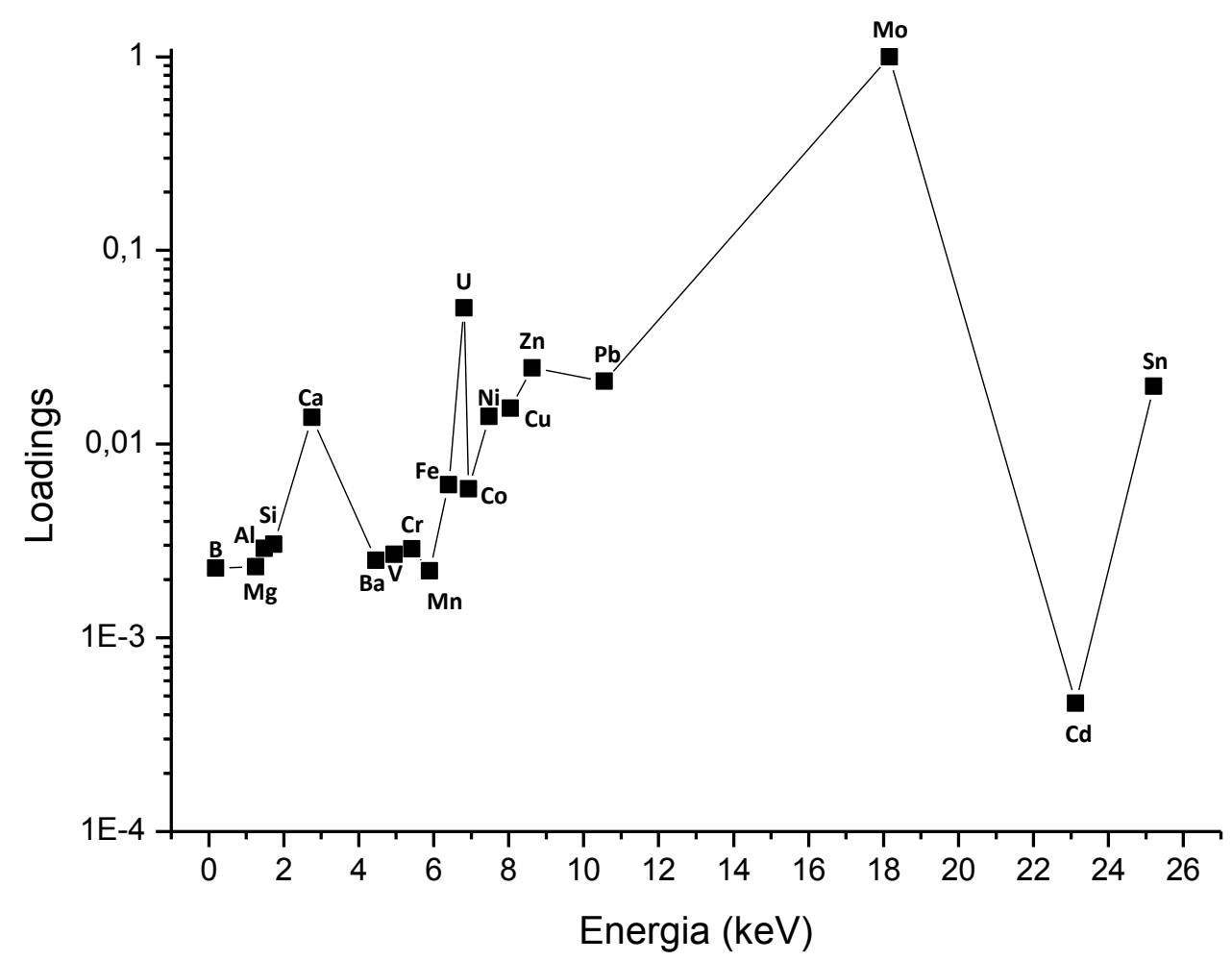

Figura 11- Gráfico dos loadings versus energia para a $\mathrm{PC} 1$ em $\mathrm{U}_{3} \mathrm{O}_{8}$

A comparação entre as FIGs 10 (Gráfico intensidade versus energia para obtenção da matriz X com MRCs de $\mathrm{U}_{3} \mathrm{O}_{8}$ ) e 11 (Gráfico de loading versus energia para a PC1 em $\mathrm{U}_{3} \mathrm{O}_{8}$ ) mostram similaridade, comprovando que um componente é suficiente para descrever todo o conjunto.

O modelo de calibração foi obtido por meio do método dos Quadrados Mínimos Parciais (Partial Least Square - PLS) (Parreira, T. F., 2003), e a validação, por meio de testes estatísticos aplicados ao MRC 124 (1) - NBL. 
Na TAB. 4 são apresentados os valores certificados $\left(X_{\text {cert }} \pm s\right)$ e determinados $\left(\mathrm{X}_{\mathrm{det}} \pm \mathrm{s}\right)$, os desvios padrão relativo percentual (DPR\%), erros relativo percentual (ER\%), limites de quantificação (LQ) e Z-score calculados para os elementos certificados no MRC $124(1)-\mathrm{NBL}$.

TABELA 4 - Valores certificados $(X \operatorname{cer} t \pm \sigma)$ e determinados $(X \operatorname{det} \pm \sigma)$, desvios padrão relativo percentual (DPR\%), erros relativo percentual (ER\%), limites de quantificação (LQ) e Z-score calculados para o MRC 124 (1) - NBL

\begin{tabular}{|c|c|c|c|c|c|c|}
\hline Elemento & $\begin{array}{l}X_{\text {cert }} \pm \sigma \\
\left(\mu g^{-1}\right)\end{array}$ & $\begin{array}{l}X_{\operatorname{det}} \pm \sigma \\
\left(\mu g g^{-1}\right)\end{array}$ & DPR $(\%)$ & $\mathrm{ER}(\%)$ & $\mathrm{LQ}\left(\mu \mathrm{g} \mathrm{g}^{-1}\right)$ & Z-Score \\
\hline B & $5,1 \pm 1,0$ & $4,8 \pm 0,4$ & 8 & 6 & 2,6 & 0,3 \\
\hline $\mathrm{Mg}$ & $101 \pm 13$ & $82 \pm 7$ & 9 & 19 & 43 & 1,5 \\
\hline $\mathrm{Al}$ & $205 \pm 37$ & $166 \pm 14$ & 8 & 19 & 81 & 1,1 \\
\hline $\mathrm{Si}$ & $202 \pm 58$ & $197 \pm 16$ & 8 & 3 & 99 & 0,1 \\
\hline $\mathrm{Ca}$ & $200 \pm 36$ & $176 \pm 14$ & 8 & 12 & 87 & 0,7 \\
\hline V & $50,0 \pm 7,2$ & $40 \pm 4$ & 10 & 20 & 22 & 1,4 \\
\hline $\mathrm{Cr}$ & $102 \pm 14$ & $85 \pm 7$ & 8 & 17 & 43 & 1,2 \\
\hline $\mathrm{Mn}$ & $51,0 \pm 7,6$ & $42 \pm 4$ & 10 & 18 & 21 & 1,2 \\
\hline $\mathrm{Fe}$ & $210 \pm 24$ & $173 \pm 13$ & 8 & 18 & 80 & 1,5 \\
\hline $\mathrm{Ni}$ & $202 \pm 17$ & $169 \pm 12$ & 7 & 16 & 77 & 1,9 \\
\hline $\mathrm{Cu}$ & $50,0 \pm 9,4$ & $42 \pm 4$ & 10 & 16 & 22 & 0,8 \\
\hline $\mathrm{Zn}$ & $202 \pm 57$ & $179 \pm 15$ & 8 & 11 & 88 & 0,4 \\
\hline Mo & $100,0 \pm 7,9$ & $85 \pm 1$ & 1 & 15 & 40 & 1,9 \\
\hline $\mathrm{Cd}$ & $5,20 \pm 0,88$ & $4,2 \pm 0,4$ & 10 & 10 & 2 & 1,1 \\
\hline Sn & $51,0 \pm 6,9$ & $38 \pm 3$ & 8 & 25 & 20 & 1,8 \\
\hline $\mathrm{Pb}$ & $51 \pm 15$ & $35 \pm 3$ & 9 & 31 & 18 & 1,1 \\
\hline
\end{tabular}

Os resultados em termos de DPR\% mostraram que a precisão do método é satisfatória, visto que, para todos os elementos analisados os valores calculados são $\leq 10 \%$, demonstrando que os processos foram reprodutivos.

Avaliando os resultados em termos de ER\%, comparando-se os valores certificados com os determinados, verifica-se que $\mathrm{B}, \mathrm{Si}$ apresentaram valores $<7 \%, \mathrm{Mg}, \mathrm{Al}, \mathrm{Ca}, \mathrm{V}, \mathrm{Cr}$, 
Mn, Fe, Ni, Cu, Zn, Mo e Cd, <20\%. Pelos resultados obtidos constatamos que a dispersão é satisfatória, exceção ao $\mathrm{Sn}(25 \%)$ e $\mathrm{Pb}(31 \%)$, entretanto, considerando as suas concentrações e incertezas certificadas $\left(51,0 \pm 6,9 ; 51 \pm 15 \mu \mathrm{g} \mathrm{g}^{-1}\right)$, esses valores podem ser aceitáveis.

Os limites de quantificação (LQ) são suficientes para a determinação de impurezas em $\mathrm{U}_{3} \mathrm{O}_{8}$, demonstrando que a metodologia apresenta sensibilidade para quantificar $\mathrm{B}$ e $\mathrm{Cd}$ em concentrações inferiores a.3 $\mu \mathrm{g} \mathrm{g}^{-1}$, elementos esses de muito interesse, pois, apresentam alta secção de choque. Além disso, para todos os outros elementos, os LQ são inferiores a $90 \mu \mathrm{g} \mathrm{g}^{-1}$, exceção ao $\mathrm{Si}\left(99 \mu \mathrm{g} \mathrm{g}^{-1}\right)$.

Os valores de Z-score (FIG. 12) são menores que dois (Z-score < 2) para todos os elementos, demonstrando que a exatidão é satisfatória, ou seja, estatisticamente não há diferenças significativas entre os valores certificados e determinados.

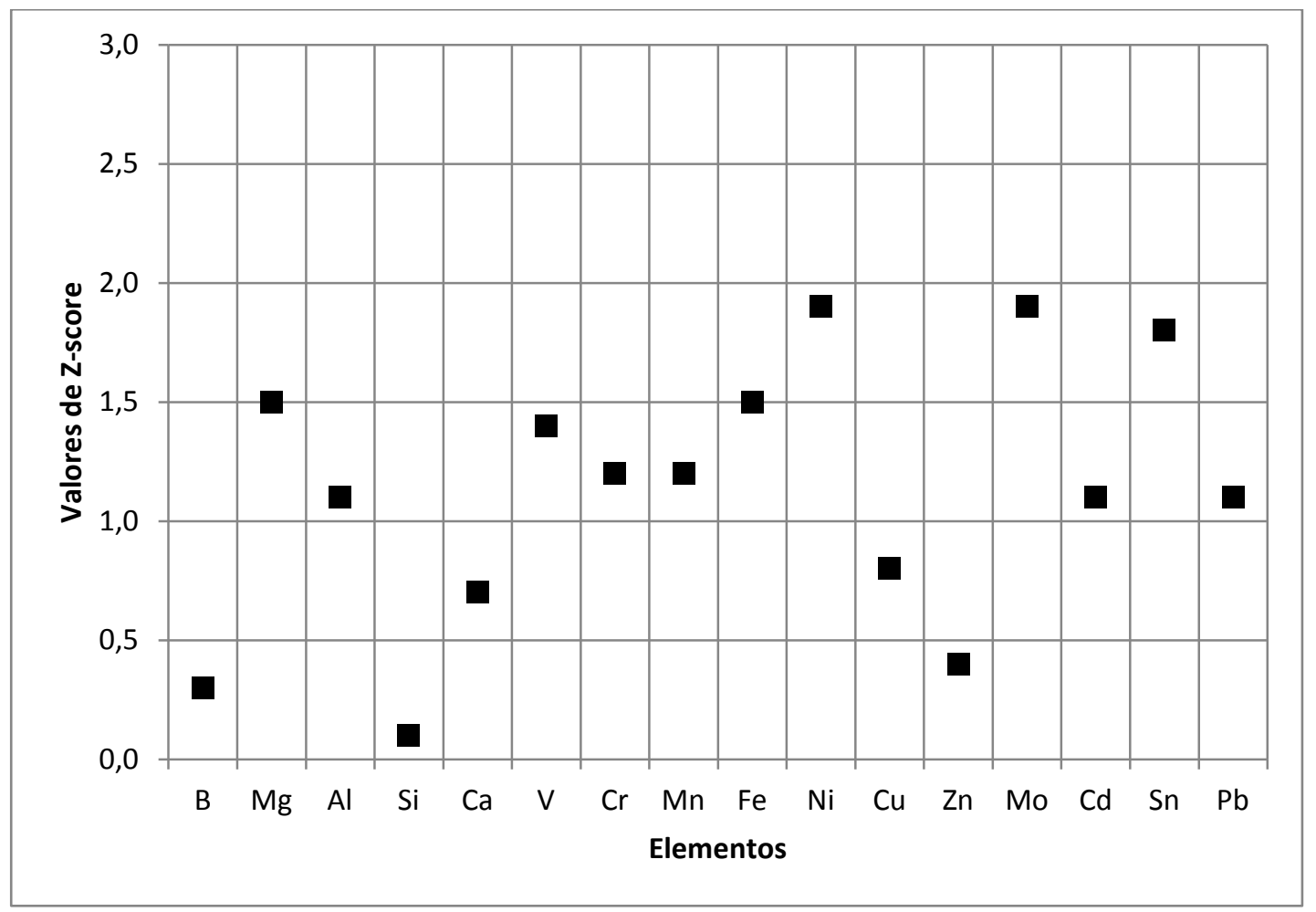

Figura 12 - Valores de Z-score calculado para o MRC 124 (1) por calibração multivariada

Pelos resultados obtidos, comprovou-se a eficácia da metodologia para a análise direta e não destrutiva de impurezas em $\mathrm{U}_{3} \mathrm{O}_{8}$ por meio da calibração multivariada. 


\subsection{Comparação entre curva de calibração univariada e multivariada}

A comparação entre os métodos de curva de calibração univariada (CU) e calibração multivariada (CM) foi feita em termos de precisão (DPR\%), exatidão (Z-score) e limite de quantificação (LQ).

A FIG. 13 mostra a comparação da precisão, em termos de DPR\%, calculados para os elementos certificados no MRC 124 (1) - NBL.

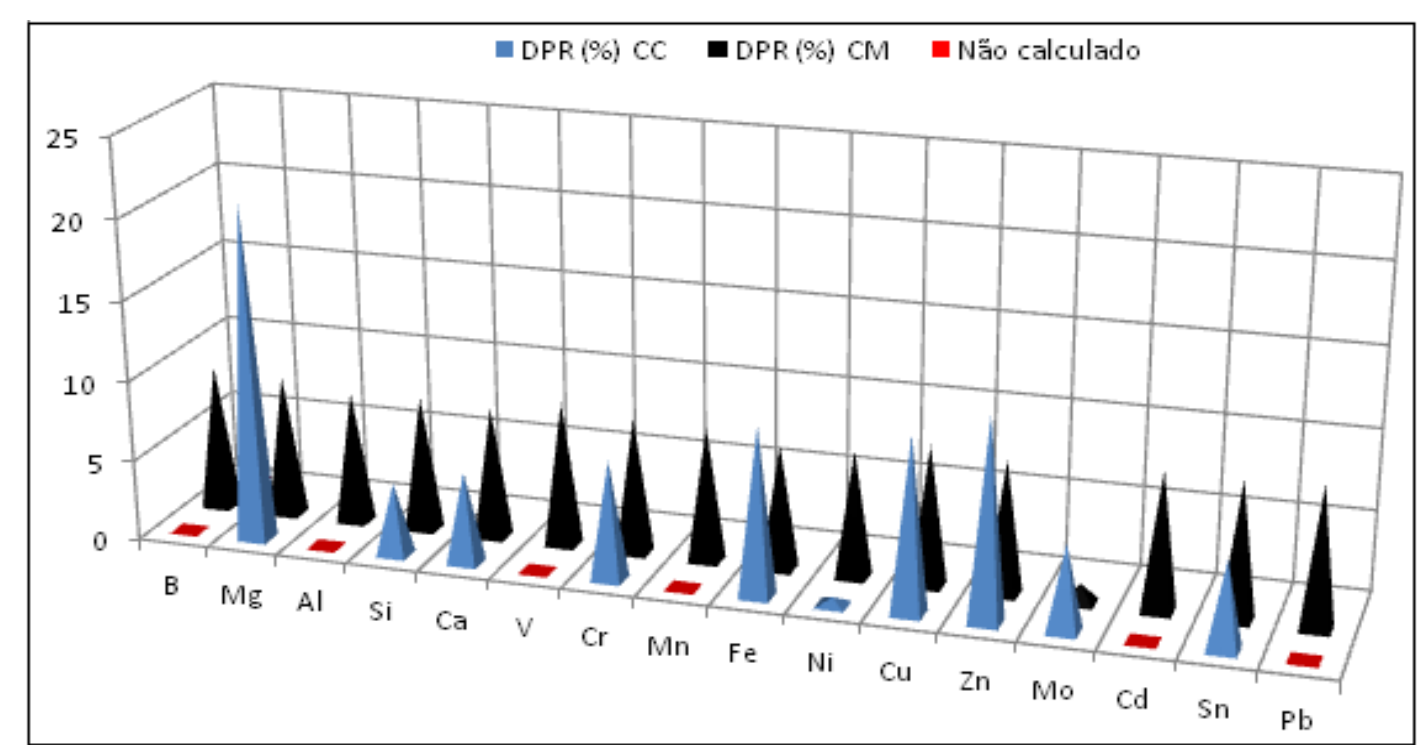

FIGURA 13 - Comparação da precisão em termos de DPR\% entre os métodos CC e CM calculados para os elementos certificados pelo MRC 124 (1) NBL.

Os valores de DPR\% em ambos os métodos são inferiores a 10\%, exceção para o Mg (CC -20,9\%). Assim, pode-se afirmar que para os elementos calculados a precisão entre os métodos são comparáveis, contudo, o método $\mathrm{CM}$ apresenta maior precisão na determinação de $\mathrm{Mg}$.

A FIG. 14 mostra a comparação da exatidão entre os métodos CC e CM, em termos de valores de Z-score, calculados para os elementos certificados no MRC 124 (1) - NBL. 


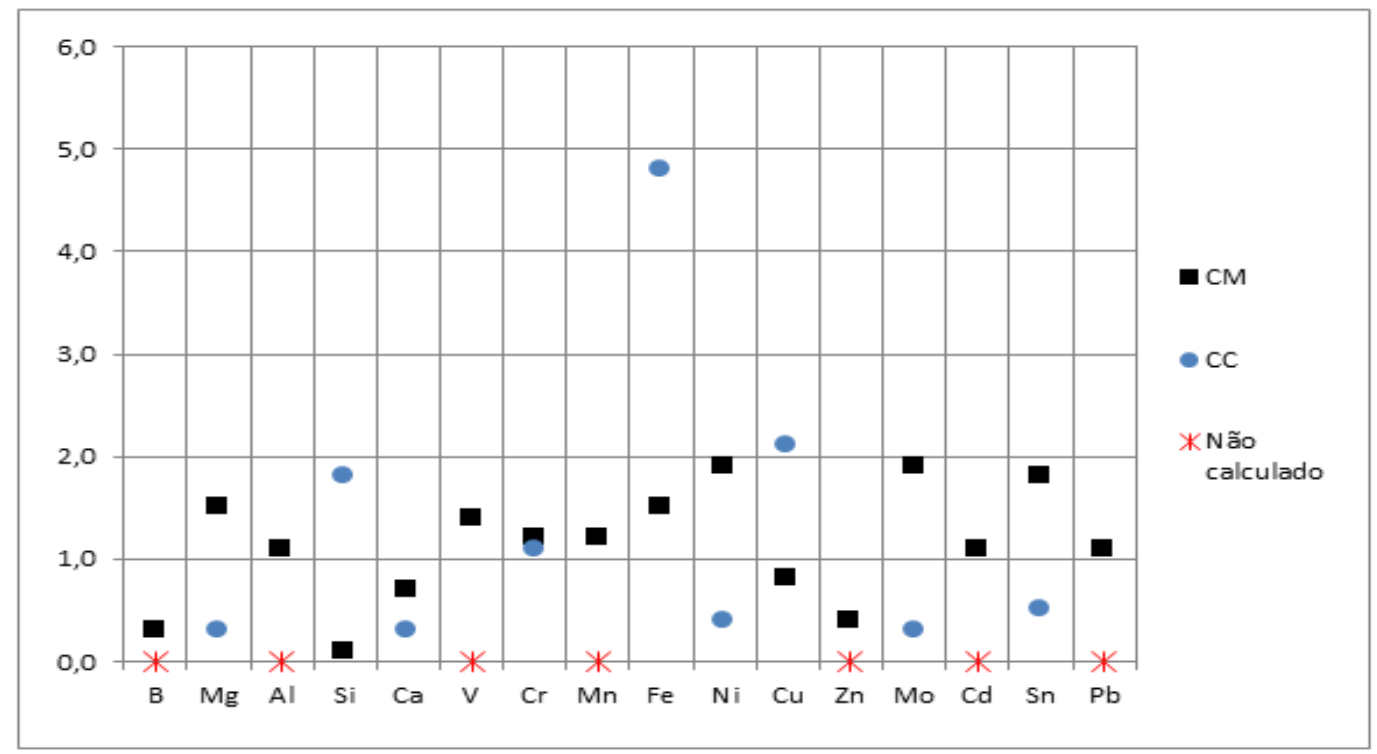

FIGURA 14 - Comparação da exatidão entre os métodos CC e CM, em termos de valores de Z-score, calculados para o MRC 124 (1) - NBL

Os valores de Z-scores para ambos os métodos são <2, exceção para $\mathrm{Cu}(2,1)$ e Fe $(4,8)$ no método CC. Pelos resultados obtidos, pode-se afirmar que a exatidão de ambos os métodos são comparáveis, entretanto, para as determinações de $\mathrm{Cu}$ e $\mathrm{Fe}$, o método $\mathrm{CM}$ apresenta resultados mais confiáveis (exatos). Além disso, o método CM permite determinar $\mathrm{B}, \mathrm{Al}, \mathrm{V}, \mathrm{Mn}, \mathrm{Cd}$ e $\mathrm{Pb}$, com exatidão satisfatória.

Na FIG.15 é mostrada a comparação entre os limites de quantificação (LQ) para os métodos CC e CM.

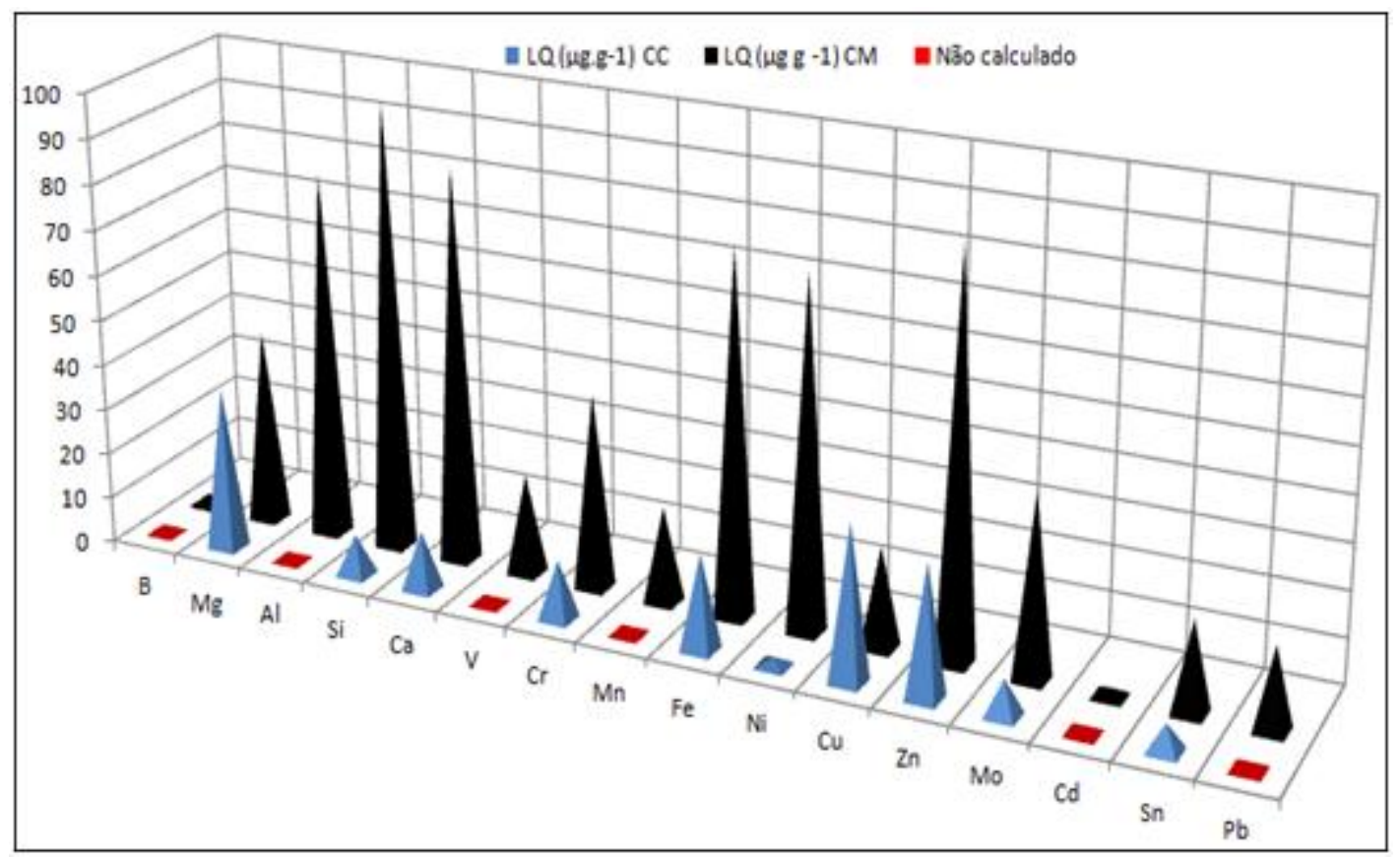

FIGURA 15 - Comparação do LQ entre os métodos CC e CM 
Os limites de quantificação calculados para o método CC são significativamente inferiores ao $\mathrm{CM}$, exceção ao $\mathrm{Cu}$. Contudo, o método $\mathrm{CM}$ apresenta valores que são suficientes para a determinação de impurezas em $\mathrm{U}_{3} \mathrm{O}_{8}$.

Pelos resultados obtidos, verificou-se que o método CM é robusto e confiável, entretanto, o modelo de calibração deve ser constituído com amostras semelhantes às analisadas, pois análises preliminares em $\mathrm{U}_{3} \mathrm{Si}_{2}$, aplicando-se a calibração multivariada feita para $\mathrm{U}_{3} \mathrm{O}_{8}$, apresentaram resultados discordantes. Esse fato dificultou o desenvolvimento do modelo de calibração para análise de $\mathrm{U}_{3} \mathrm{Si}_{2}$, uma vez que, não são comercializados amostras de $\mathrm{U}_{3} \mathrm{Si}_{2}$ certificadas.

\subsection{Calibração multivariada com amostras de $\mathrm{U}_{3} \mathrm{Si}_{2}$}

O modelo de calibração multivariada utilizando as amostras de $\mathrm{U}_{3} \mathrm{Si}_{2}$ foi construído tal qual o de $\mathrm{U}_{3} \mathrm{O}_{8}$, ou seja, sobre as condições instrumentais de medidas apresentadas na TAB. 2, por meio de $2 \theta$ scan. A matriz X (matriz das intensidades) também foi obtida por meio da média da réplica de sete medidas de cada amostra, para cada elemento, de acordo com sua respectiva energia (FIG. 16), resultando uma matriz 16 x 19.

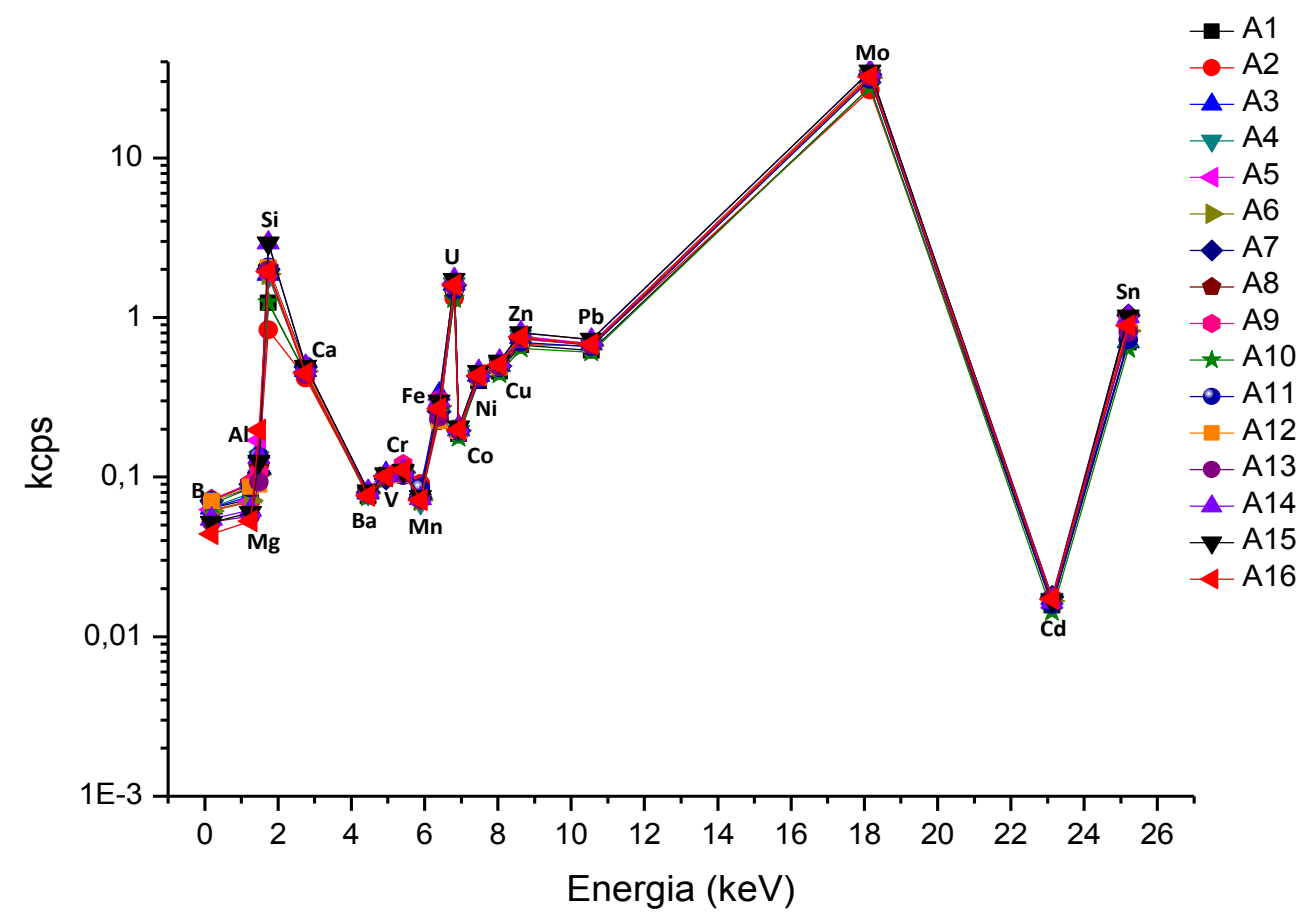

FIGURA 16 - Gráfico intensidade versus energia para obtenção da matriz $\mathrm{X}$ com amostras de $\mathrm{U}_{3} \mathrm{Si}_{2}$ 
A comparação entre as FIGs 10 (intensidade versus energia para obtenção da matriz $\mathrm{X}$ com MRCs de $\mathrm{U}_{3} \mathrm{O}_{8}$ ) com 16 (intensidade versus energia para obtenção da matriz X com amostras de $\mathrm{U}_{3} \mathrm{Si}_{2}$ ), mostram similaridade, entretanto, a intensidade (taxa de contagem kcps) de alguns elementos, especialmente Si (FIG. 16) é consideravelmente maior que a registrada na FIG 10. Esse fato impossibilita o uso da calibração multivariada (matriz X) de $\mathrm{U}_{3} \mathrm{O}_{8}$ para análises de $\mathrm{U}_{3} \mathrm{Si}_{2}$, e vice versa.

A análise de PCA revelou dois componentes principais (PC1=99,982\%; PC2 $=0,016 \%$ ), todavia, a PC1 é suficiente para descrever o modelo de calibração, pois tem o maior peso (cerca de 100\%). A FIG. 17 mostra o gráfico dos loadings versus energia para o componente principal PC1.

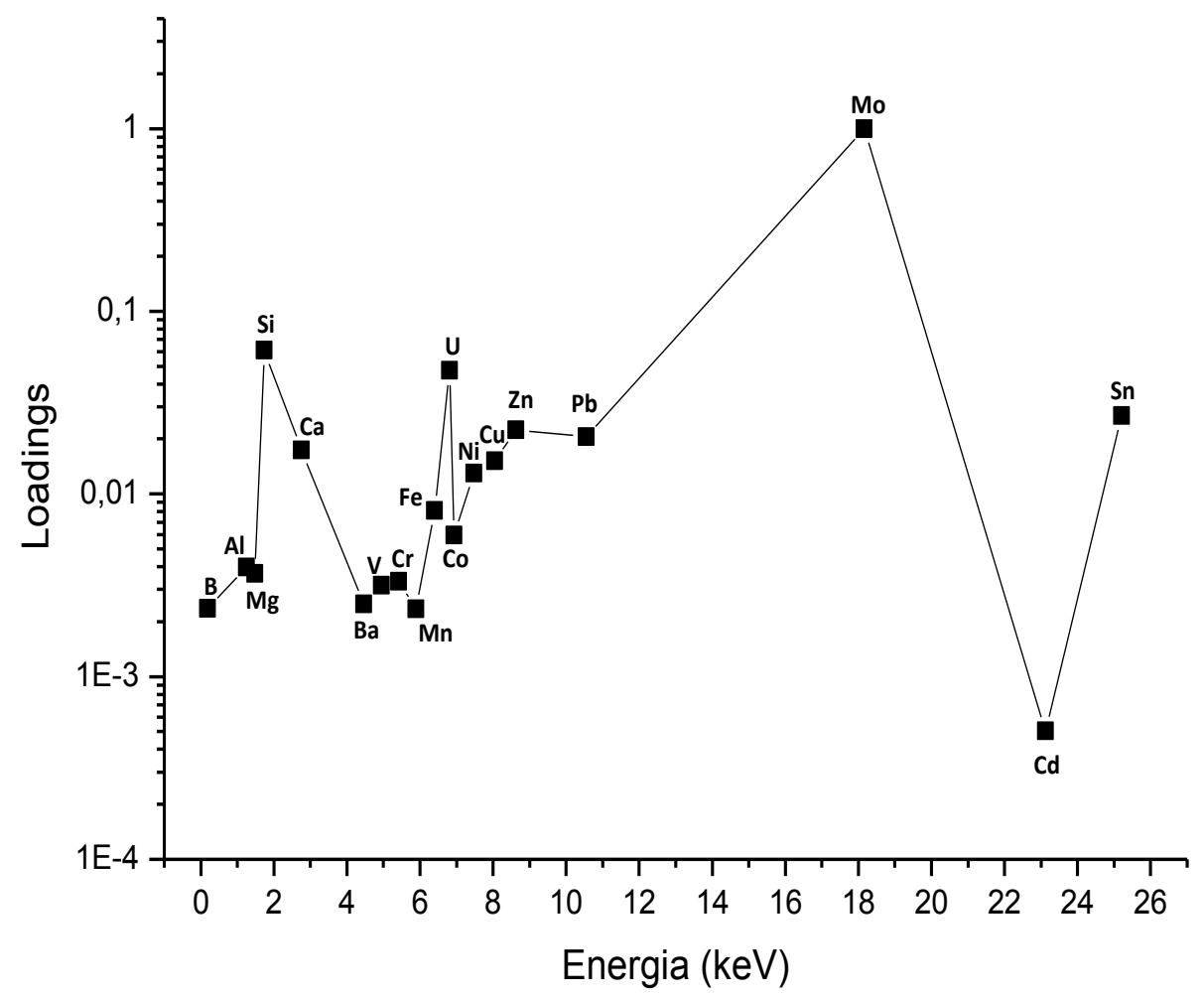

FIGURA 17 - Gráfico dos loadings versus energia, para a PC1 em $\mathrm{U}_{3} \mathrm{Si}_{2}$

A comparação entre as FIGs 16 (Gráfico intensidade versus energia para obtenção da matriz X com amostras de $\mathrm{U}_{3} \mathrm{Si}_{2}$ ) e 17 (Gráfico dos loading versus energia para a PC1 em $\mathrm{U}_{3} \mathrm{Si}_{2}$ ) mostram similaridade, comprovando que um componente é suficiente para descrever todo o conjunto das amostras de $\mathrm{U}_{3} \mathrm{Si}_{2}$, de maneira análoga as de $\mathrm{U}_{3} \mathrm{O}_{8}$.

Na TAB. 5 são apresentados os teores médios $(\bar{X})$ e a variância $\left(\sigma^{2}\right)$ calculados para $\mathrm{U}$, determinado por análise volumétrica $\left(\bar{X}_{\mathrm{AV}}\right), \mathrm{Si}$, por análise gravimétrica $\left(\bar{X}_{\mathrm{AG}}\right), \mathrm{B}, \mathrm{Mg}$, 
Al, Si, Ca, V, Cr, Mn, Fe, Co, Ni, Cu, Zn, Mo, Cd, Ba, Sn e Pb, por ICP-OES ( $\bar{X}_{\text {ICP-OES }}$ ) e calibração multivariada por WDXRF ( $\left.\bar{X}_{\mathrm{CM}-\mathrm{WDXRF}}\right)$. Além disso, os limites de quantificação (LQ) e os valores calculados para a distribuição Fisher-Snedecor (F) na análise de variância (ANOVA) e os de $t$-Student para a comparação das médias.

TABELA 5 - Teores médios $(\overline{\mathbf{X}})$ e variância $\left(\sigma^{2}\right)$ calculados para U - análise volumétrica $\left(\overline{\mathbf{X}}_{\mathrm{AV}}\right)$, Si-análise gravimétrica $\left(\overline{\mathbf{X}}_{\mathrm{AG}}\right), \mathrm{B}, \mathrm{Mg}, \mathrm{Al}, \mathrm{Si}, \mathrm{Ca}, \mathrm{V}, \mathrm{Cr}, \mathrm{Mn}, \mathrm{Fe}, \mathrm{Co}$, $\mathrm{Ni}, \mathrm{Cu}, \mathrm{Zn}, \mathrm{Mo}, \mathrm{Cd}, \mathrm{Ba}, \mathrm{Sn}$ e Pb-ICP-OES (XICP-OES) e calibração multivariada-WDXRF ( $\mathrm{X}_{\mathrm{CM}-\mathrm{FRX}}$ ), limites de quantificação (LQ) e valores calculados para a distribuição Fisher-Snedecor $(\mathrm{F})$ na análise da variância (ANOVA) e de $t$-Student para a comparação das médias.

\begin{tabular}{|c|c|c|c|c|c|c|c|c|c|c|}
\hline Elementos & $\begin{array}{c}\bar{X}_{\mathrm{AV}} \\
(\%)\end{array}$ & $\sigma^{2}$ & $\begin{array}{c}\bar{X}_{\mathrm{CM}-\mathrm{XR}} \\
(\%) \mathrm{F}\end{array}$ & $\boldsymbol{\sigma}^{2}$ & $\begin{array}{c}\text { LQ } \\
(\mu \mathrm{gg}-1)\end{array}$ & $\mathrm{F}$ & $\mathrm{F}_{\text {crític }}$ & $\mathrm{t}$ & $\mathrm{t}_{\text {crítico }}$ & $n$ \\
\hline $\mathrm{U}$ & 91,3 & 0,2 & 91,8 & 5,6 & 1 & 0,6 & 4,5 & 0,8 & 2,1 & 16 \\
\hline & $\begin{array}{c}\bar{X}_{\mathrm{AG}} \\
(\%)\end{array}$ & $\sigma^{2}$ & $\begin{array}{c}\bar{X}_{\text {CM-FRX }} \\
(\%)\end{array}$ & $\sigma^{2}$ & $\begin{array}{c}\text { LQ } \\
(\mu g \mathrm{~g}-1)\end{array}$ & $\mathrm{F}$ & $\mathrm{F}_{\text {crítico }}$ & $\mathrm{t}$ & $\mathrm{t}_{\text {crítico }}$ & $\mathrm{n}$ \\
\hline \multirow[t]{2}{*}{$\mathrm{Si}$} & 7,79 & 0,02 & 7,82 & 0,04 & 1 & 0,2 & 4,2 & 0,5 & 2,1 & 16 \\
\hline & $\begin{array}{c}\bar{X}_{\text {ICP-OES }} \\
(\mu \mathrm{g} g-1)\end{array}$ & $\sigma^{2}$ & $\begin{array}{c}\bar{X}_{\mathrm{CM}-\mathrm{FRX}} \\
(\mu \mathrm{gg}-1)\end{array}$ & $\sigma^{2}$ & $\begin{array}{c}\text { LQ } \\
(\mu \mathrm{g} g-1)\end{array}$ & $\mathrm{F}$ & $\mathrm{F}_{\text {crítico }}$ & $\mathrm{t}$ & $\mathrm{t}_{\text {crítico }}$ & $\mathrm{n}$ \\
\hline B & 1,5 & 1,6 & $<4$ & $\mathrm{NC}$ & 4 & $\mathrm{NC}$ & $\mathrm{NC}$ & $\mathrm{NC}$ & $\mathrm{NC}$ & 10 \\
\hline $\mathrm{Mg}$ & 12,4 & 188,3 & 7,1 & 10,5 & 1 & 2,2 & 4,2 & 1,6 & 2,1 & 16 \\
\hline $\mathrm{Al}$ & 260 & 128936 & 260 & 25022 & 23 & 0,1 & 4,2 & 0,1 & 2,1 & 16 \\
\hline $\mathrm{Ca}$ & 11,8 & 147,2 & 10,0 & 42,4 & 1 & 0,3 & 4,2 & 0,7 & 2,1 & 16 \\
\hline V & 1,8 & 5,8 & 1,8 & 1,4 & 2 & 0,1 & 4,2 & 0,2 & 2,1 & 16 \\
\hline $\mathrm{Cr}$ & 25 & 836 & 15 & 46 & 2 & 1,9 & 4,2 & 1,6 & 2,1 & 16 \\
\hline $\mathrm{Mn}$ & 56 & 3688 & 80 & 2591 & 8 & 0,2 & 4,2 & 1,0 & 2,1 & 16 \\
\hline $\mathrm{Fe}$ & 283 & 53059 & 188 & 8647 & 12 & 2,3 & 4,2 & 0,1 & 2,1 & 16 \\
\hline Co & 14 & 2 & 18 & 2 & 1 & 0,2 & 4,6 & 0,4 & 2,4 & 8 \\
\hline $\mathrm{Ni}$ & 22 & 336 & 30 & 290 & 3 & 1,4 & 4,2 & 1,5 & 2,2 & 14 \\
\hline $\mathrm{Cu}$ & 27 & 264 & 39 & 648 & 4 & 2,4 & 4,2 & 1,7 & 2,1 & 16 \\
\hline $\mathrm{Zn}$ & 14 & 310 & 10 & 40 & 3 & 0,6 & 4,2 & 0,9 & 2,1 & 16 \\
\hline Mo & $<3,0$ & $\mathrm{NC}$ & $<1$ & $\mathrm{NC}$ & 1 & $\mathrm{NC}$ & $\mathrm{NC}$ & $\mathrm{NC}$ & $\mathrm{NC}$ & 16 \\
\hline $\mathrm{Cd}$ & $<0,1$ & $\mathrm{NC}$ & $<2$ & $\mathrm{NC}$ & 2 & $\mathrm{NC}$ & $\mathrm{NC}$ & $\mathrm{NC}$ & $\mathrm{NC}$ & 12 \\
\hline $\mathrm{Ba}$ & $<0,2$ & $\mathrm{NC}$ & $<10$ & $\mathrm{NC}$ & 10 & $\mathrm{NC}$ & $\mathrm{NC}$ & $\mathrm{NC}$ & $\mathrm{NC}$ & 14 \\
\hline $\mathrm{Sn}$ & 39 & 698 & 78 & 214 & 1 & 10,03 & 4,96 & 2,4 & 2,8 & 5 \\
\hline $\mathrm{Pb}$ & 7,9 & 5,6 & 9,4 & 0,4 & 1 & 1,3 & 7,7 & 1,1 & 4,3 & 3 \\
\hline
\end{tabular}

$\mathrm{n}=$ número de observações; $\mathrm{NC}=$ não calculado 
Os resultados mostraram que o método de calibração multivariada por WDXRF $\left(\bar{X}_{\mathrm{CM}-\mathrm{WDXRF}}\right)$ apresenta precisão estatisticamente igual aos métodos de análise volumétrica $\left(\bar{X}_{\mathrm{AV}}\right)$ para a determinação de U e gravimétrica $\left(\bar{X}_{\mathrm{AG}}\right)$ para a determinação de Si, já que os valores de F são inferiores aos valores críticos. Os valores t também são inferiores aos valores críticos, demonstrando que as exatidões dos métodos também são iguais.

As mesmas observações podem ser feitas quando comparamos $\bar{X}_{\text {ICP-OES }}$ com $\bar{X}_{\mathrm{CM}}$ WDXRF, ou seja, a precisão e a exatidão entre os métodos para a determinação de impurezas em $\mathrm{U}_{3} \mathrm{Si}_{2}$ são estatisticamente iguais, tal que, para os elementos calculados, os valores de $\mathrm{F}$ e t são menores que os valores críticos. A única exceção observada refere-se ao Sn, quanto à precisão $\left(\mathrm{F}=10,03 ; \mathrm{F}_{\text {crítico }}=4,96\right)$.

Para os elementos aos quais não se aplicou os testes estatísticos (B, Mo, Cd e Ba), pelo fato dos valores serem menores que os limites de quantificação, a avaliação visual demonstra concordância.

Os limites de quantificação (LQ) calculados para o método calibração multivariadas por WDXRF são suficientes para a determinação dessas impurezas em $\mathrm{U}_{3} \mathrm{Si}_{2}$, e atende às especificações de um combustível nuclear de $\mathrm{U}_{3} \mathrm{Si}_{2}$ (TAB. 1). 


\section{CONCLUSÕES}

Os estudos e experiências realizados evidenciaram que:

- As condições de medida estabelecidas foram suficientes para permitir à técnica de fluorescência de raios $\mathrm{X}$ determinar elementos traço da ordem de grandeza exigida pela American Society for Testing and Materials (ASTM, 2009) para $\mathrm{U}_{3} \mathrm{O}_{8}$, e pelo Centro do Combustível Nuclear do IPEN (Laucht et al., 1998) para o $\mathrm{U}_{3} \mathrm{Si}_{2}$, materiais utilizados como combustível nuclear.

- O método de calibração multivariada aplicado para a determinação de impurezas em $\mathrm{U}_{3} \mathrm{O}_{8}$ apresenta precisão e exatidão estatisticamente iguais à calibração univariada, destacando-se pelo fato de permitir a determinação de boro, elemento muito complexo para ser determinado por fluorescência de raios $\mathrm{X}$ em virtude do baixo rendimento de fluorescência.

- A aplicação da quimiometria permitiu quantificar com precisão e exatidão estatisticamente iguais aos métodos de análises volumétrica, gravimétrica e ICPOES, maiores e menores constituintes e elementos traço presentes em $\mathrm{U}_{3} \mathrm{Si}_{2}$ enriquecido $20 \%$ em peso em ${ }^{235} \mathrm{U}$, com a vantagem de não se utilizar tratamentos químicos prévios na preparação de amostra, além de fornecer resultados significativamente muito mais rápidos.

- A metodologia proposta nesse trabalho permite atender às exigências das agências de controle de materiais nucleares em relação aos teores de $\mathrm{U}_{\text {total }} \mathrm{e}$ impurezas em combustíveis nucleares à base de $\mathrm{U}_{3} \mathrm{O}_{8}$ e $\mathrm{U}_{3} \mathrm{Si}_{2}$ enriquecido $20 \%$ em peso em ${ }^{235} \mathrm{U}$ em conformidade com a ISO/IEC 17025.

- O método desenvolvido apresenta como diferenciais a produção mínima de resíduos, reduzindo custo e tempo de análises significativamente. Mostra-se promissora para realizar a caracterização química em materiais em combustível nuclear. 
APÊNDICE A

Certificate of Analysis - Microgramas of Impurity Element per one gram of Uranium

\begin{tabular}{|c|c|c|c|c|c|c|c|}
\hline Element & $124-1$ & $124-2$ & $124-3$ & $124-4$ & $124-5$ & $124-6$ & $124-7^{\#}$ \\
\hline $\begin{array}{l}\text { Aluminum (Al) } \\
\text { (A) }\end{array}$ & $205 \pm 37$ & $105 \pm 14$ & $55,0 \pm 7,7$ & $25,0 \pm 3,4$ & $15,0 \pm 1,9$ & $10,0 \pm 1,4$ & 5 \\
\hline Beryllium (Be) & $25,0 \pm 7,3$ & $12,5 \pm 1,7$ & $5,00 \pm 0,75$ & $2,50 \pm 0,22$ & $1,30 \pm 0,08$ & $0,50 \pm 0,08$ & $<0,1$ \\
\hline Bismuth (Bi) & $50 \pm 14$ & $25,0 \pm 7,1$ & $10,0 \pm 2,1$ & $5,00 \pm 0,82$ & $2,50 \pm 0,33$ & $1,00 \pm 0,18$ & $<0,2$ \\
\hline Boron (B) & $5,1 \pm 1,0$ & $2,60 \pm 0,56$ & $1,10 \pm 0,28$ & $0,60 \pm 0,14$ & $0,35^{\#}$ & $0,2^{\#}$ & 0,1 \\
\hline Cadmium $(\mathrm{Cd})$ & $5,20 \pm 0,88$ & $2,70 \pm 0,35$ & $1,20 \pm 0,22$ & $0,70 \pm 0,15$ & $0,45 \pm 0,13$ & $0,3^{\#}$ & 0,2 \\
\hline Calcium $(\mathrm{Ca})$ & $200 \pm 36$ & $100 \pm 22$ & $51,0 \pm 9,3$ & $21,0 \pm 6,9$ & $11,0 \pm 3,8$ & $2,8^{\#}$ & 0,8 \\
\hline Chromium $(\mathrm{Cr})$ & $102 \pm 14$ & $52,0 \pm 6,5$ & $22,0 \pm 4,2$ & $12,0 \pm 2,3$ & $7,0 \pm 2,1$ & $4,3^{\#}$ & 2,3 \\
\hline Cobalt (Co) & $25,0 \pm 6,1$ & $12,5 \pm 2,5$ & $5,00 \pm 0,87$ & $2,60 \pm 0,42$ & $1,40 \pm 0,77$ & $0,60 \pm 0,09$ & 0,1 \\
\hline Copper $(\mathrm{Cu})$ & $50,0 \pm 9,4$ & $25,0 \pm 5,2$ & $10,4 \pm 2,1$ & $5,4 \pm 1,1$ & $2,9^{\#}$ & $1,40 \pm 0,44$ & 0,4 \\
\hline Iron $(\mathrm{Fe})$ & $210 \pm 24$ & $110 \pm 13$ & $60,0 \pm 9,9$ & $30^{\#}$ & $20^{\#}$ & $15^{\#}$ & 10 \\
\hline Lead $(\mathrm{Pb})$ & $51 \pm 15$ & $26,0 \pm 7,3$ & $10,8 \pm 3,1$ & $5,8 \pm 1,6$ & $3,3 \pm 1,0$ & $1,80 \pm 0,45$ & 0,8 \\
\hline Magnesium (Mg) & $101 \pm 13$ & $51 \pm 10$ & $21,0 \pm 4,5$ & $11,0 \pm 3,2$ & $6,0 \pm 1,6$ & $3,00 \pm 0,55$ & 1,00 \\
\hline Manganese (Mn) & $51,0 \pm 7,6$ & $26,0 \pm 2,4$ & $11,0 \pm 1,3$ & $5,70 \pm 0,83$ & $6,30 \pm 0,78$ & $1,70 \pm 0,49$ & 0,7 \\
\hline Molybdenum (Mo) & $100,0 \pm 5,5$ & $50,0 \pm 4,2$ & $20,0 \pm 3,9$ & $10,00 \pm 0,48$ & $5,0 \pm 1,4$ & $2,00 \pm 0,66$ & $<0,1$ \\
\hline Nickel (Ni) & $202 \pm 17$ & $102,0 \pm 7,2$ & $52,0 \pm 6,0$ & $22,0 \pm 3,1$ & $12,0 \pm 1,8$ & $7,0 \pm 1,0$ & 2 \\
\hline Silicon $(\mathrm{Si})$ & $202 \pm 58$ & $102 \pm 20$ & $52 \pm 11$ & $22,0 \pm 3,9$ & $12,0 \pm 2,5$ & $7,3 \pm 6,5$ & 2,3 \\
\hline Silver (Ag) & $5,0 \pm 3,6$ & $2,5 \pm 1,9$ & $1,00 \pm 0,79$ & $0,5 \#$ & $0,25^{\#}$ & $0,1^{\#}$ & $<0,1$ \\
\hline Sodium $(\mathrm{Na})$ & $400 \pm 127$ & $200 \pm 43$ & $100 \pm 33$ & $40 \pm 13$ & $20^{\#}$ & 10 & $<0,5$ \\
\hline $\operatorname{Tin}(\mathrm{Sn})$ & $51,0 \pm 6,9$ & $26,0 \pm 5,4$ & $10,6 \pm 1,6$ & $5,6 \pm 1,1$ & $3,10 \pm 0,58$ & $1,60 \pm 0,44$ & 0,6 \\
\hline Titanium (Ti) & $50 \pm 14$ & $25,0 \pm 5,6$ & $10,3 \pm 3,8$ & $5,3 \pm 1,6$ & $2,8 \pm 1,3$ & $1,30 \pm 0,28$ & 0,3 \\
\hline Tungsten (W) & $200 \pm 22$ & $100 \pm 12$ & $50,0 \pm 6,3$ & $20,0 \pm 9,8$ & $10^{\#}$ & $5,0 \pm 1,0$ & $<0,1$ \\
\hline vanadium $(\mathrm{V})$ & $50,0 \pm 7,2$ & $25,0 \pm 2,8$ & $10,0 \pm 1,1$ & $5,00 \pm 0,71$ & $2,50 \pm 0,35$ & $1,00 \pm 0,13$ & $<0,2$ \\
\hline Zinc $(\mathrm{Zn})$ & $202 \pm 57$ & $102 \pm 13$ & $52 \pm 11$ & $22,0 \pm 4,2$ & $12,0 \pm 3,1$ & $6,6^{\#}$ & 1,6 \\
\hline Zirconium $(\mathrm{Zr})$ & $200 \pm 61$ & $100 \pm 32$ & $50 \pm 18$ & $20,0 \pm 6,0$ & $10^{\#}$ & $5,0 \pm 1,7$ & $<0,5$ \\
\hline
\end{tabular}

"Values are not certified

1 P. M. Santoliquido, "Preparation and Provisional Certification of NBL Spectrographic Impurity Standards CRM Nos. 123(1-7) and CRM 124(1-7)", USDOE Report NBL-310, Sept. 1983.

2 S. Burgüer, K. J. Mathew, P. Mason, U. Narayanan. "Reference materials characterized for impurities in uranium matrices - an overview and re-evaluation of the NBL CRM 124 series", Journal of Radionalytical and Nuclear Chemistry, accepted.

$$
\text { July 08, } 2008 \quad \text { Argonne, Illinois www.nbl.doe.gov }
$$


APÊNDICE B

Certificate of Analysis - Microgramas of Impurity Element per gram of Uranium (as metal)

\begin{tabular}{|c|c|c|c|c|c|c|c|c|}
\hline Element & $123-1$ & $123-2$ & $123-3$ & $123-4$ & $123-5$ & $123-6$ & $123-7$ & Method \\
\hline Aluminum & $205,1 \pm 4,4$ & $98,4 \pm 1,7$ & $49,1 \pm 3,5$ & $21,6 \pm 2,6$ & $11,1 \pm 1,7$ & $5,6 \pm 0,8$ & $<2$ & $(2,3)$ \\
\hline Calcium & $218 \pm 13$ & $107 \pm 14$ & $52,2 \pm 4,4$ & $24,1 \pm 2,6$ & $12,6 \pm 1,4$ & $7,9 \pm 2,5$ & $4,1 \pm 2,5$ & $(3,4)$ \\
\hline Iron & $212,2 \pm 3,1$ & $109,7 \pm 2,4$ & $58,5 \pm 2,2$ & $27,2 \pm 1,1$ & $17,5 \pm 1,4$ & $12,2 \pm 1,1$ & $7,9 \pm 2,7$ & $(1,3)$ \\
\hline Nickel & $200,0 \pm 7,5$ & $100,1 \pm 4,3$ & $52,1 \pm 0,6$ & $21,3 \pm 0,9$ & $11,3 \pm 1,4$ & $6,3 \pm 0,5$ & $2,0 \pm 0,1$ & $(1,3))$ \\
\hline Silicon & $245 \pm 21$ & $120,2 \pm 7,2$ & $56,5 \pm 3,6$ & $24,2 \pm 1,3$ & $14,8 \pm 0,6$ & $10,9 \pm 0,6$ & $8,0 \pm 0,8$ & $(1))$ \\
\hline Sodium & $390,9 \pm 9,0$ & $174,0 \pm 4,1$ & $79,5 \pm 2,0$ & $42,4 \pm 1,8$ & $24,2 \pm 2,4$ & $14,5 \pm 1,1$ & $4,0 \pm 1,2$ & (3) \\
\hline Zinc & $222,0 \pm 5,4$ & $112 \pm 11$ & $52,7 \pm 5,4$ & $20,4 \pm 1,7$ & $11,7 \pm 0,7$ & $6,1 \pm 0,6$ & $0,3 \pm 0,1$ & $(3,4)$ \\
\hline Zirconium & $256 \pm 39$ & $134 \pm 15$ & $60 \pm 15$ & $20 \pm 8$ & $13 \pm 1$ & $<10$ & $<10$ & $(1,3)$ \\
\hline Chromium & $105,9 \pm 5,4$ & $54,9 \pm 2,3$ & $23,1 \pm 0,7$ & $12,9 \pm 0,4$ & $7,6 \pm 0,4$ & $4,3 \pm 0,5$ & $2,3 \pm 0,4$ & $(1,2)$ \\
\hline Magnesium & $102,3 \pm 3,0$ & $50,8 \pm 1,3$ & $20,3 \pm 0,4$ & $11,1 \pm 0,9$ & $5,5 \pm 0,2$ & $2,9 \pm 0,7$ & $1,8 \pm 0,3$ & $(2,3)$ \\
\hline Molybdenum & $97,7 \pm 6,9$ & $48,9 \pm 5,0$ & $20,6 \pm 0,4$ & $10,1 \pm 0,2$ & $5,0 \pm 0,2$ & $2,3 \pm 0,3$ & $<0,2$ & $(1,3)$ \\
\hline Copper & $52,8 \pm 4,8$ & $25,6 \pm 2,5$ & $10,8 \pm 2,5$ & $2,9 \pm 1,4$ & $2,6 \pm 0,2$ & $1,17 \pm 0,07$ & $0,20 \pm 0,05$ & $(2,3)$ \\
\hline Lead & $43,9 \pm 9,7$ & $22,8 \pm 3,2$ & $9,5 \pm 0,9$ & $4,9 \pm 0,7$ & $2,8 \pm 0,3$ & $1,3 \pm 0,7$ & $0,4 \pm 0,1$ & $(5,6)$ \\
\hline Manganese & $51,9 \pm 2,0$ & $27,4 \pm 2,4$ & $11,8 \pm 1,1$ & $5,6 \pm 0,3$ & $3,1 \pm 0,2$ & $1,2 \pm 0,2$ & $0,27 \pm 0,05$ & $(2,3)$ \\
\hline Tim & $48,0 \pm 3,9$ & $23,7 \pm 0,9$ & $9,5 \pm 0,7$ & $5,9 \pm 0,3$ & $2,8 \pm 0,5$ & $1,3 \pm 0,1$ & $0,2 \pm 0,1$ & (1) \\
\hline Vanadium & $50,5 \pm 2,1$ & $25,0 \pm 1,7$ & $9,4 \pm 1,3$ & $4,9 \pm 0,5$ & $2,7 \pm 0,3$ & $1,0 \pm 0,3$ & $0,2 \pm 0,1$ & $(1,3)$ \\
\hline Borom & $6,0 \pm 0,9$ & $2,3 \pm 0,3$ & $1,07 \pm 0,08$ & $0,51 \pm 0,04$ & $0,28 \pm 0,05$ & $0,11 \pm 0,01$ & $<0,07$ & (1) \\
\hline Cadmium & $5,3 \pm 0,2$ & $2,4 \pm 0,1$ & $1,10 \pm 0,04$ & $0,48 \pm 0,12$ & $0,28 \pm 0,04$ & $0,12 \pm 0,01$ & $<0,02$ & (2) \\
\hline
\end{tabular}

Method Code: $(1)=$ Spectrophotometry

(2) = Graphite Furnace Atomic Absorption (3) = Inductively Coupled Plasma Emissior

(4) $=$ Flame Atomic Absorption

(5) = Tungsten Filament Zeeman AA

(6) $=$ Anodic Stripping Voltammetry 


\section{REFERÊNCIAS BIBLIOGRÁFICAS}

American Society for Testing and Materials - ASTM, Standard Test Method for Mercury Sampling and Analysis in Natural Gas by Atomic Fluorescence Spectroscopy (Withdrawn 2012), 2003(D6350-98).

American Society for Testing and Materials - ASTM. Establishing and controlling spectrochemical analytical curves, v. 03.05., 2003. (E 305-89).

American Society for Testing and Materials - ASTM, Standard Specification for Nuclear-Grade Uranium Oxide $\left(\boldsymbol{U}_{3} \boldsymbol{O}_{8}\right)$, 2009(C753-04).

ARRUDA, M. A. Z. Trends in sample preparation, Nova Science Publishers, New York, USA, 2006.

BAIMA, C. Reator multipropósito vai garantir independência do Brasil. O GLOBO, Rio de Janeiro, 07 Fev. 2012, Cad. CIÊNCIA. Disponível em: <http://www .naval.com.br/blog/2012/02/07/reator-multiproposito-vai-garantir-independencia-nuclea rdo-brasil/\#axzz2EeAJy 8o G>. Acesso em: 10 Dez. 2012.

BARROS NETO, B. 25 anos de quimiometria no Brasil, Quim. Nova: v. 29, n.06, p.1401-1406, 2006.

BEEBE, K. R.; PELL, R. J.; SEASHOLTZ, M. B. Chemometrics: A Pratical Guide. John Wiley \& Sons, New York, 1998.

BERTIN, E. P. Principles and practice of X-ray spectrometric analysis. Plenum Press, New York, N. Y., cap.01. 1970.

BORTOLETO, G. G. Desenvolvimento de Métodos Analíticos Usando Espectrometria de Raios X e Quimiometria, 2007. Tese (Doutorado) - Instituto de Química, Departamento de Química Analítica. Universidade Estadual de Campinas, São Paulo.

BOUROCHE, J- M; SAPORTA, G. Análise de Dados. Zahar: Rio de Janeiro, p.117, 1982.

BOX, G. E. P.; Hunter, W. G.; Hunter, J. J. S. Statistics for experimenters, John Wiley and Sons: New York 1987.

BRERETON, R. G. Applied Chemometrics for Scientists. Chichester: John Wiley \& Sons Ltd, 2007. 
BRITO, N. M.; AMARANTE JR, O. P.; POLESE, P.; RIBEIRO, M. L. Validação de métodos analíticos: estratégias e discussão. Pesticidas: Revista de Ecotoxicologia e Meio Ambiente, v. 13, p.129-146, 2003.

CRISS, J. W.; BIRKS, L.S. Calculation Methods for Fluorescent X-Ray Spectromety empirical coeficients vs. fundamental paramenters. Anal. Chem., v.40, p. 1080-1086, 1968.

DE VRIES, J. L.; VREBOS, B. A. R. Handbook of X-Ray Spectrometry: Methods and Techniques; Van Grieken, R. E., Markowicz, A. A., Ed.; M. Dekker; New York, p.295, 1993.

DRAPER, N. R.; SMITH, H.; Apllied regression analysis,. John Wiley and Sons. New York, ed.2, 1981.

EURACHEM-Ccitac. The fitness for purpose of analytical methods - A Laboratory guide method validation and related topics, Guide: 1998.

FERREIRA, M.M.C.; ANTUNES, A.M.; MELGO, M. S.; VOLPE, P. L. O. Quimiometria I: calibração multivariada, um tutorial. Química Nova, 22(5): 724-731, 1999.

FERRUFINO, F. B.J. Determinação quantitativa da homogeneidade da distribuição de urânio em combustíveis nucleares tipo placa. 2011. Dissertação (Mestrado). Instituto de Pesquisas Energéticas e Nucleares, São Paulo.

FONTE NUCLEAR. w. n.3, jun. 2012. Disponível em: < http://www.aben.com.br/ publicacoes/fonte-nuclear/00000000035/combustvel-desenvolvido-no-ipen-poder-serutilizado-no-rmb/00000000108> Acesso em: 05 nov. 2012.

GOPALKRISHNNAN, M.; RADHAKRISHNNAN, K.; DHAMI, P. S.; KULKARNI, V. T.; JOSHI, M. V.; PATWARDHAN, A. B.; MATHUR, J. N. Determination of trace impurities in uranium, thorium and plutonium matrices by solvent extraction and inductively coupled plasma atomic emission spectrometry. Talanta, n.44 (2), p.169176, 1997.

HORIBA SIENTIFIC. Comparison between EDXRF and WDXRF. Disponível em: $<$ www.horiba.com/scientific/products/x-ray-fluorescence-analysis/tutorial/comparisonbetween-edxrf-and-wdxrf/>. Acesso em: 15 nov. 2012.

HOTELLING, H. Jornal Education of Psychology. v.24, p.417, 1933. 
Instituto Nacional de Metrologia, Normalização e Qualidade Industrial - INMETRO. Orientação sobre validação de métodos analíticos, 2010, V.03. (DOQ-CGRE-008) Disponível em: <http://www.inmetro.gov.br/Sidoq/Arquivos/ CGCRE/DOQ/DOQCGCRE-8_03.pdf> Acesso em: 12 jun. 2012.

International Atomic Energy Agency - IAEA, Advanced methods of process/quality control in nuclear reactor fuel manufacture, Proceedings of a Technical Committee meeting held in Lingen. Germany, p.18-22, oct. 1999. Disponível em: < http://wwwpub.iaea.org/MTCD/publications/PDF/te_1166_prn.pdf> Acessado em: 15 out. 2012.

International Atomic Energy Agency - IAEA, Programe B. Nuclear Fuel Cycle and Materials Technologies, 2001. Disponível em < http://www-pub.iaea.org/mtcd/ publications /pdf/te_1613_web.pdf> Acesso em: 14 nov. 2012.

International Atomic Energy Agency - IAEA, Management of high enriched uranium for peaceful purposes: Status and trends. 2005. Disponível em: <http://wwwpub.iaea.org/mtcd/publications/pdf/te_1452_web.pdf>. Acesso em: 15 out. 2012.

JENKIS, R., GOULD, R. W.; GEDCKE, D. Quantitative X-ray spectrometry, New York, Plenum, 1972.

JUAN, A.; JAUMOT, J.; GARGALLO, R. TAULER, R. Resolució multivariant en Química: a la cerca de la bela simplicitat de la mesura multivariate resolution in Chemistry: seeking the beautiful simplicity of the measurement, Revista de la Societat Catalana de Química, Barcelona: v.10(1), p.26-36, 2011.

KNIGHT, C.H.; CASSIDY, R.M.; RECOSKIE, B.M.; GREEN, L.W. Dynamic IonExchange Chromatography for Determination of Number of Fissions in Thorium Uranium-Dioxide Fuels, Anal. Chem. 56 (3) (1984) 474-478.

LACHANCE, G. R.; CLAISSE, F. Quantitative $x$-ray fluorescence analysis. New York, NY: John Wiley \& Sons, 1995.

LAUCHT, J.; MUELLER, H.; A New Standard For Uranium Metal Inteded For Research Reactor Fuel Fabrication, International Meeting $\left(21^{\text {st }}\right)$ - Reduced Enrichment for Research Test Reactors (RERTR): São Paulo, 1998.

LEME, A. B. P. Análise quimiométrica de méis, 2012. Dissertação (Mestrado), São Carlos: Universidade Federal de São Carlos - UFSCar.

MALHOTRA, R. K.; SATYANARAYANA, K. Estimation of trace impurities in reactorgrade uranium using ICP-AES, Talanta, vol.50 (3), p.601-608, 1999. 
MATOS, G. D. ; PEREIRA-FILHO, E. R. ; POPPI, R. J. ; ARRUDA, M. A. Z. . Análise exploratória em química analítica com emprego de quimiometria: PCA e PCA de imagens. Revista Analítica, São Paulo, v. 06, p. 38-50, 2003.

MATSUBARA, T. C. M. Estudo sobre a determinação de antimônio em amostras ambientais pelo método de análise por ativação com nêutrons. Validação da metodologia e determinação da incerteza da medição, 2011. Instituto de Pesquisas Energéticas E Nucleares - IPEN, São Paulo.

Müller, D. M. Spectrochemical analysis by X-ray fluorescence. Plenum, New York, 1972.

NAGATA, N.; BUENO, M. I. M. S. Métodos matemáticos para correção de interferências espectrais e efeitos interelementos na análise quantitativa por fluorescência de raios-X. Quim. Nova, v. 24, No. 4, p. 531-539, 2001.

NETO, M. M. J. Estatística multivariada. Revista de Filosofia e Ensino, 2004. Disponível em: $\langle$ http://www.criticanarede.com/cien_estatistica.html $>$ Acesso em: 10 nov. 2012.

OCEANKINGINDIA - Home of Quality Products. Disponível em: $\underline{\text { http://www. }}$ goldtester.co/xrf.html> Acesso em: 12 dez. 2012.

OLIVEIRA JUNIOR, O. P.; SAKIS, J.E.S. Determination of impurities in uranium oxide by inductively coupled plasma mass spectrometry (ICPMS) by the matrix matching method. Journal Radioanalytical and Nuclear Chemistry, n.254(3), p.519-526, 2002.

PARREIRA, T. F. Utilização de métodos quimiométricos em dados de natureza multivariada. Dissertação (Mestrado), Instituto de Química da Universidade de Campinas. Campinas, 2003.

PEARSON, K. Philosophical Magazine. ed.2, p. 559, 1901.

PIMENTEL, M. F.; NETO, B. B., Calibração: uma revisão para químicos analíticos. Química Nova, vol. 19, n 3, 1996. Disponível em < http://quimicanova .sbq.org.br/qn/qnol/ 1996/vol19n3/v19_n3_09.pdf > Acesso em 10, set. 2012.

RAMANAIAH, G. V. Determination of ytrium, scandium and other rare earth elements in uranium-rich geological materials by ICP-AES, Talanta, vol.46 (4), p.533-540, 1998.

REIS, E. Estatística multivariada aplicada. Lisboa, 1997. 
VOCABULARIO INTERNACIONAL EM METROLOGIA - VIM. Basic and General Concepts and Associated Terms - JCGM, 2008, $3^{\text {a }}$ ed, p.90. Disponível em: <http://www.bipm.org/en/publications/guides/>. Acesso em: 15 nov. 2012.

REIS, E.L.T.; SCAPIN, M. A.; COTRIM, M.B.E.; SALVADOR; V.L.; PIRES, M.A.F., Determination on Nuclear Fuel Element Components for the IEA-R1 Research Reactor by Analytical Methods based on ED-XRF and ICP-OES. International Nuclear Atlantic Conference-INAC, Rio de Janeiro,RJ, Brazil, September27 to October 2, 2009.

RIBEIRO, F. A. L. Aplicação de métodos de análise multivariada no estudo de hidrocarbonetos policíclicos aromáticos, 2001. Dissertação (Mestrado), Instituto de Química da Universidade de Campinas. Campinas.

ROUSSEAU, R., Detection limit and estimate of uncertainty of analytical XRF result. The Rigaku Journal, vol. 18, n. 2, 2001.

SALIBA SILVA, A.M.; DURAZZO, M.; CARVALHO, E.F.U.; RIELLA, H.G. Fabrication of $U_{3} S_{2}$ powder for fuels in IEA-RI nuclear research reactor. In: INTERNATIONAL LATIN-AMERICAN CONFERENCE ON POWDER TECHNOLOGY, Nov. 7-10, 2007, Anais eletrônicos. Buzios, RJ. 2007. Disponível em:< http://www.scientific.net/MSF.591-593.194>. Acesso em: 05 nov. 2012.

SANTOS, J.S.; TEIXEIRA, L.S.G.; SANTOS, W.N.L.; LEMOS, V.A.; GODOY, J.M.; FERREIRA, S.L.C., Uranium determination using atomic spectrometric techniques: An overview, Anal. Chim. Acta, n 674 (2), p.143-156, 2010.

SATYANARAYANA, K.; DURANI, S. Separation and inductively coupled plasma optical emission spectrometric (ICP-OES) determination of trace impurities in nuclear grade uranium oxide, J. Radioanal. Nucl. Chem. $\mathrm{N}^{\circ} 285$ (3), p.659-665, 2010. Disponível em < http://link.springer.com/article/10.1007/s10967-010-0591-8/fulltext .html $>$ acessado em 16, out. 2012

SCAPIN, M. A. Aplicação da difração e fluorescência de raios X (WDXRF): ensaios em argilominerais. 2003. Dissertação (Mestrado) - Instituto de Pesquisas Energéticas e Nucleares - IPEN-CNEN/SP, São Paulo.

SCAPIN, M. A. Estudo de Remoção de Elementos Inorgânicos e Degradação de Compostos Orgânicos por Radiação Gama em Óleos Lubrificantes Usados, 2008. Tese (Doutorado). Instituto de Pesquisas Energéticas e Nucleares, São Paulo.

SCAPIN, V. O.; SALVADOR, V. L. R.; COTRIM, M. E. B.; PIRES, M. A. F.; SCAPIN, M. A. Evaluation of analysis method standardless by WDXRF and EDXRF of aluminium powder used in MTR type fuel. In: International Nuclear Atlantic Conference; Meeting on Nuclear Applications, 10th; Meeting on Reactor Physics and Thermal 
Hydraulics, 17th; Meeting on Nuclear Industry, 2st, October 24-28, 2011, Belo Horizonte, MG. Proceedings... Sao Paulo: ABEN, 2011a. Disponível em: <http://www.ipen.br/biblioteca/2011/inac/17073>. Acesso em: 05 jul. 2012.

SCAPIN, M. A.; SALVADOR, V. L. R.; COTRIM, M. E. B.; PIRES, M. A. F.; SATO, I. M. Uncertainty measurement evaluation of WDXRF and EDXRF techniques for the Si and Utotal determination in $\boldsymbol{U}_{3} \boldsymbol{S i}_{2}$ nuclear fuel. Journal of radioanalytical and nuclear chemistry, 2011. V. 287, N.03, 807-811, 2011b. Disponível em < http://www .springerlink.com/content/ p413173186315087 /ffulltext.pdf>. Acessado em 05 jul. 2012.

SCHWAB, N. V.; DA-COL, J. A.; TERRA, J.; BUENO, M. I. M. S. Fast direct Determination of Titanium Dioxide in Toothpastes by X-ray Fluoresence and Multivariate Calibration, J. Braz. Chem. Soc., v.00, n. 00, p.1-19, 2012.

SENA, M. M.; POPPI, R. J.; AVALIAÇÃO DO USO DE MÉTODOS QUIMIOMÉTRICOS EM ANÁLISE DE SOLOS, Quim. Nova: v. 23, n.04, p. 547-556, 2000 .

SHIMAMOTO, G. G.; KAZITORIS, B.; LIMA, L. F. R.;ABREU, N. D.; SALVADOR, V. T.; BUENO, M. I. M. S. Quantificação de antimônio em garrafas de politereftalato de etileno (pet) brasileiras por fluorescência de raios-x e avaliação quimiométrica para verificar a presença de pet reciclado através do teor de ferro. Quim. Nova, v.34, n.08, p.1389-1393, 2011.

SILVA, C. P.; SALVADOR, V. L. R.; COTRIM, M. E. B., PIRES, M. A. F.; SCAPIN, M. A.; Study of resolution enhancement methods for impurities quantitative analysis in uranium compounds by xrf. International Nuclear Atlantic Conference - INAC, 2011. Belo Horizonte, MG, Brazil. Disponível em < http://pintassilgo2 .ipen.br/biblioteca /2011/inac/16932 >. Acessado em 10, jul. 2012.

SILVA, J. E. R. Aplicações de métodos não destrutivos para qualificação de combustíveis tipo dispersão de $\mathbf{U}_{3} \mathbf{O}_{8}-\mathbf{A l}$ e $\mathbf{U}_{3} \mathrm{Si}_{2} \mathbf{A l}$ no reator IEA-R1, 2011. Tese (Doutorado). Instituto de Pesquisas energéticas e Nucleares, São Paulo.

SKOOG, D. A.; HOLLER, F. J.; NIEMAN, T. A. Princípios de análise instrumental, 5 ed., São Paulo: SBQ, 2002.

SOUZA, A. L.; COTRIM, M. E. B.; PIRES, M. A. F. An overview of spectrometric techniques and sample preparation for the determination of impurities in uranium nuclear fuel grade, Microchem. J., doi: 10.1016/j.microc.2012.06.015, 2012.

SOUZA, J. A. B. Procedimentos de fabricação de elementos combustíveis a base de dispersões com alta concentração de urânio, Dissertação (Mestrado), Instituto de Pesquisas energéticas e Nucleares, São Paulo, 2011. 
SOUZA, S. V. C. Procedimentos para validação intralaboratorial de métodos de ensaio: delineamento e aplicabilidade em análises de alimentos. Dissertação (Mestrado), Universidade Federal de Minas Gerais - UFMG, Belo Horizonte, 2007.

SULCEK, Z.; POVONDRA, P. Methods of Decomposition in Analytical Chemistry, CRC Press, Boca Raton, Florida, 1989.

TERTIAN, R.; CLAISSE, F. Principles of Quantitative X-ray Fluorescence Analysis, Heyden and Son, Ltd., London, 1982.

THOMSON, M.; ELLISON, S. L. R.; FAJGELJ, A.; WILlETTS, P.; WOOD, R. Harmonized guidelines for internal single laboratory validation of methods of analysis. Pure Application Chemistry, v. 74, p 835 - 855, 2002.

VERMA, P; RAMAKUMAR, K.L. Determination of alkali and alkaline earth elements along with nitrogen in uranium based nuclear fuel materials by ion chromatography (IC), Anal. Chim. Acta, n 601, p.125-129, 2007.

WOLD, S.; ESBENSEN, K.; GELADI, P. Chemometrics Intelligent Laboratory Systems, v.02, p.37, 1987. 